\title{
Factors That Drive the Selection of Business Intelligence Tools in South African Financial Services Providers
}

Final Empirical Report presented to the

Department of Information Systems

University of Cape Town

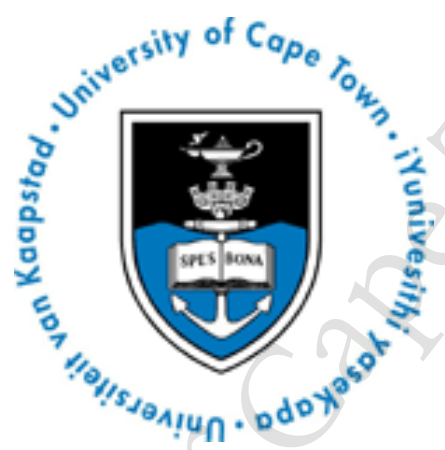

By

Bonginkosi Phila Gina

(GNXBON002)

Supervisor:

Prof. Adheesh Budree

In partial fulfillment of the requirements for the

Master's degree in information systems $31^{\text {st }}$ August 2020 
The copyright of this thesis vests in the author. No quotation from it or information derived from it is to be published without full acknowledgement of the source. The thesis is to be used for private study or noncommercial research purposes only.

Published by the University of Cape Town (UCT) in terms of the non-exclusive license granted to UCT by the author. 


\section{Declaration}

1. I know that plagiarism is wrong. Plagiarism is about using someone's work and pretend as one's work.

2. I have used Mendeley desktop for citation and referencing tool. Each contribution and quotation in this essay titled "Factors That Drive the Selection of Business Intelligence Tools in South African Financial Services Providers" from the work of other people has been attributed, cited, and referenced.

3. This empirical report is my work.

4. I have not allowed and will not allow anyone to copy my work with the intention of passing it off as his or her own.

5. I acknowledge that copying someone else's essay, or part of it, is wrong and declare that this is my own work.

Signature: $\quad$ Signed by candidate

Date: 31-08-2020

Full Name of Student: Bonginkosi Phila Gina 


\section{Contents}

1.CHAPTER ONE- INTRODUCTION AND OVERVIEW OF THE STUDY ............................................

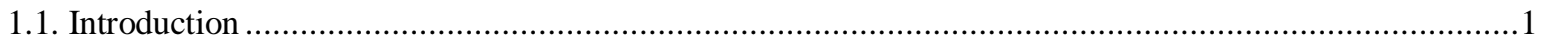

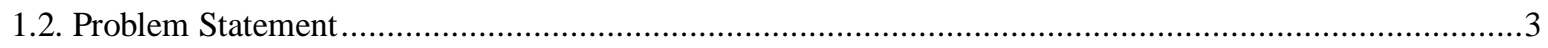

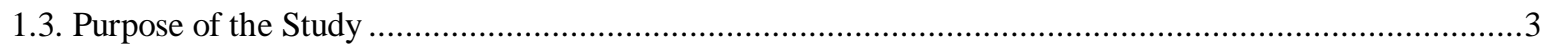

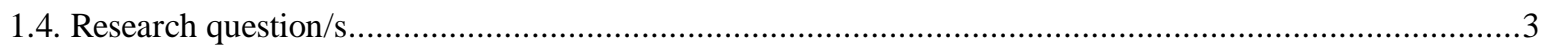

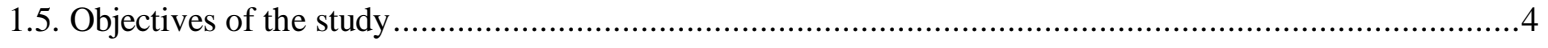

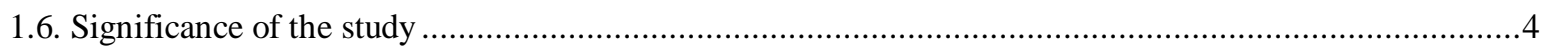

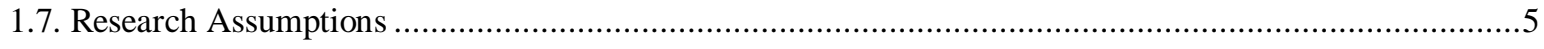

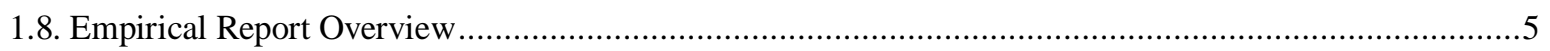

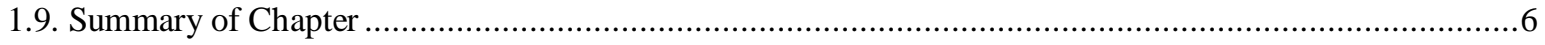

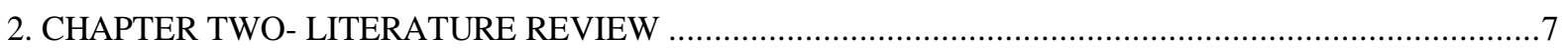

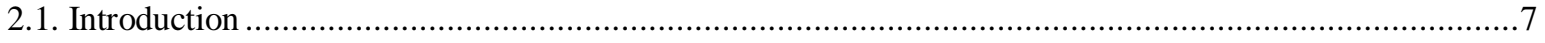

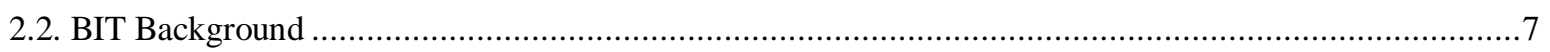

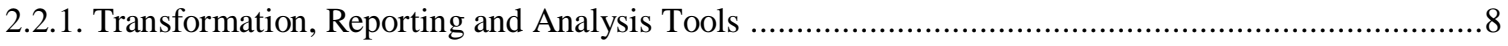

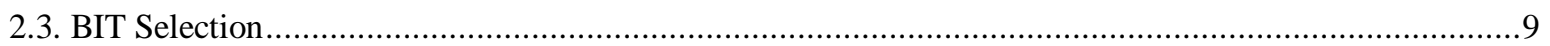

2.3.1. Software Application Acquisition ……………...................................................................

2.3.2. The Methodology for Selection of Software Packages...................................................................13

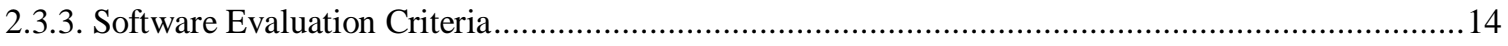

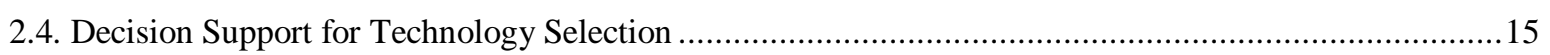

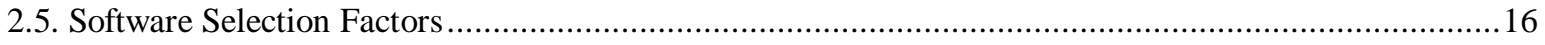

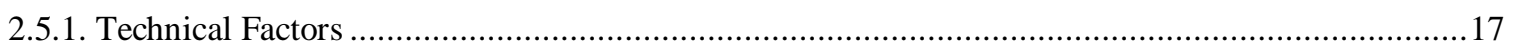

2.5.2. Non-Technical Factors .................................................................................................... 19

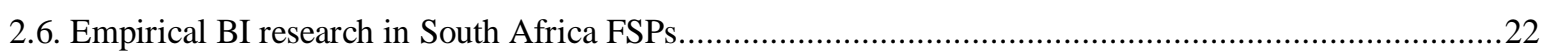

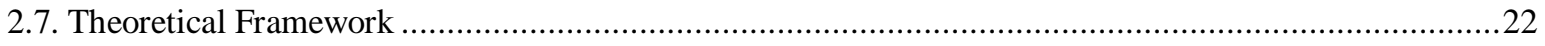

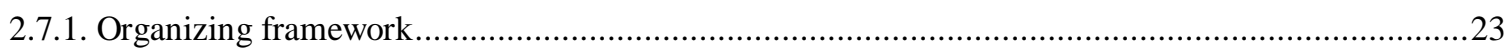

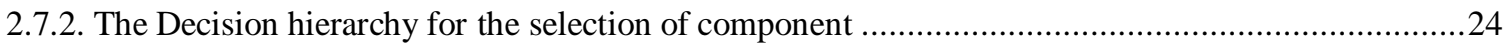

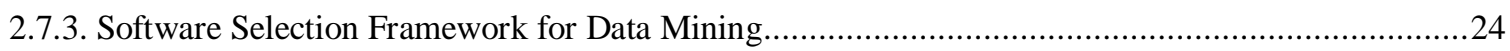

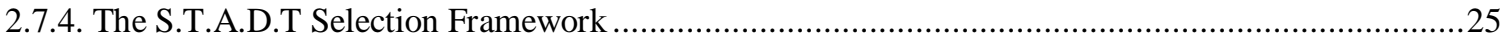

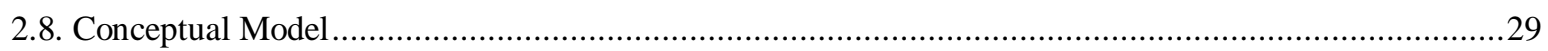

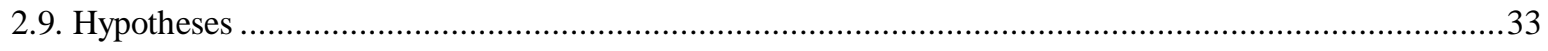

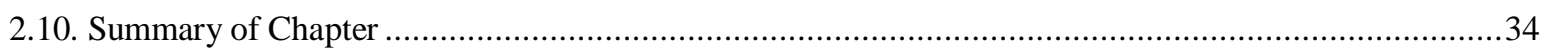

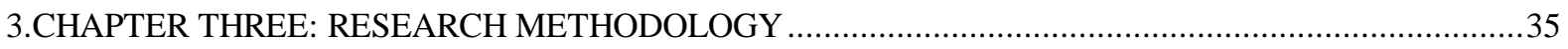

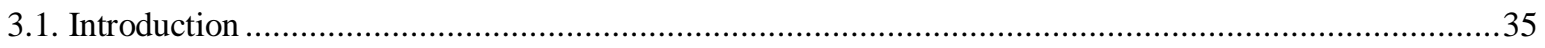

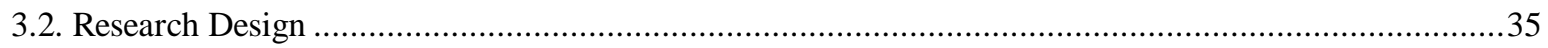

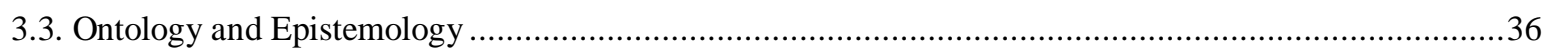

3.4. Research Purpose

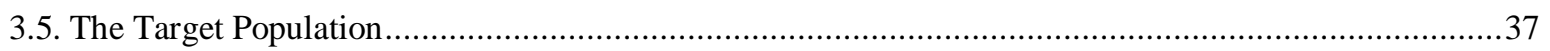

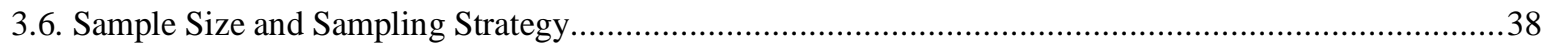

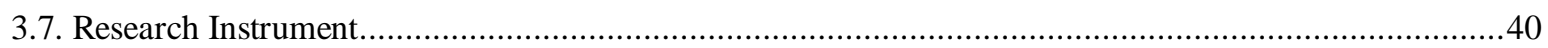

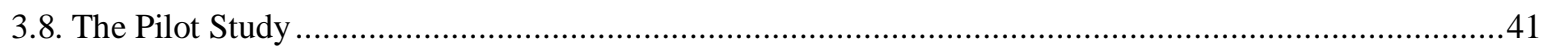

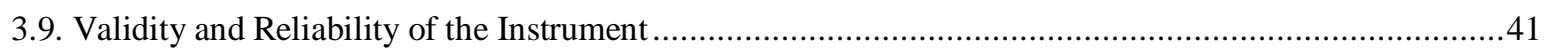




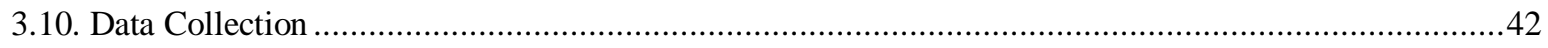

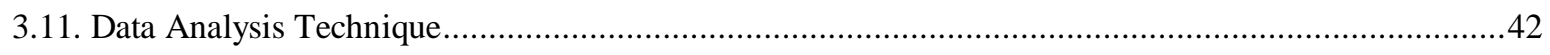

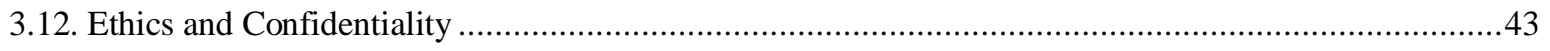

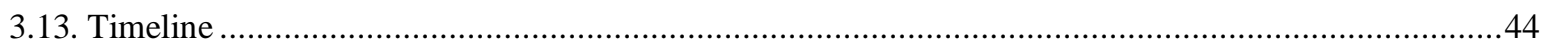

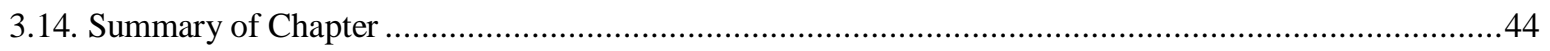

4.CHAPTER FOUR- DATA ANALYSIS PRESENTATION AND INTERPRETATION ...............................45

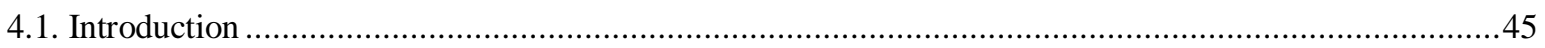

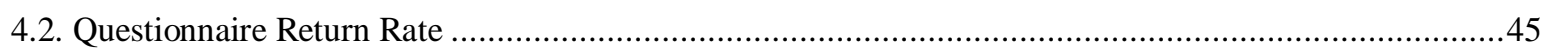

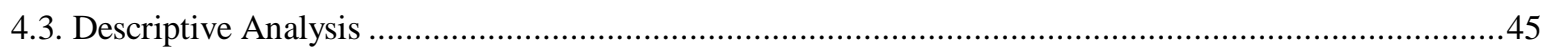

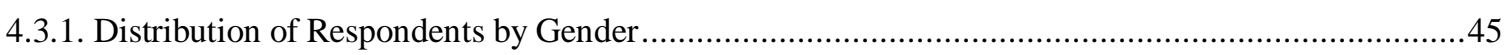

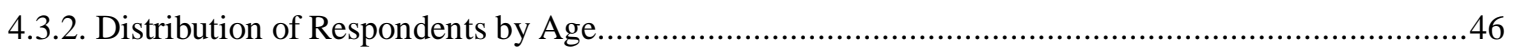

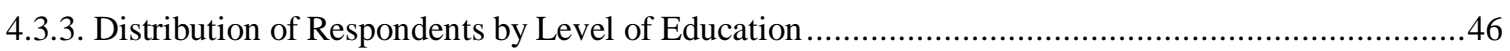

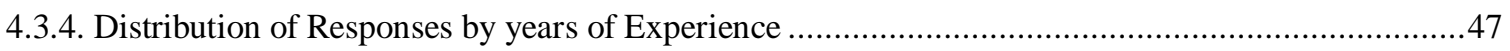

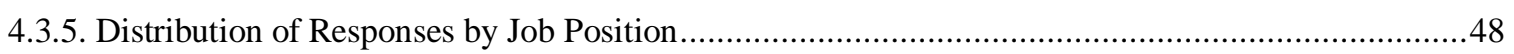

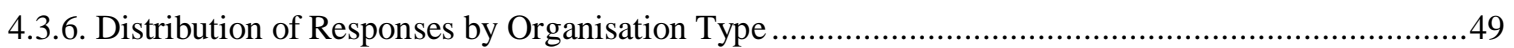

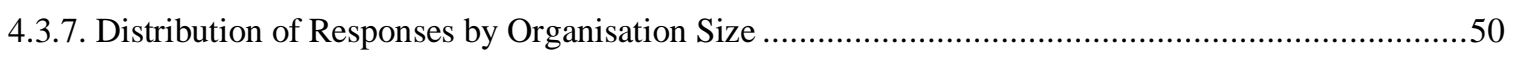

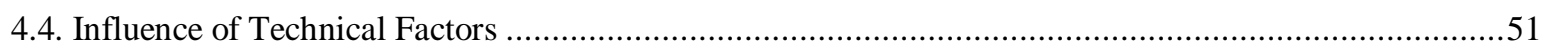

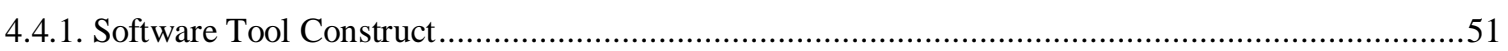

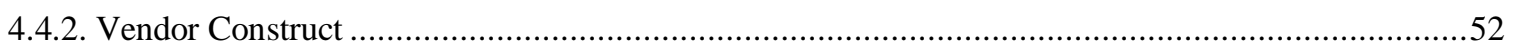

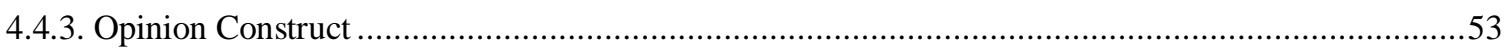

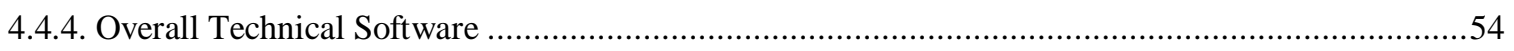

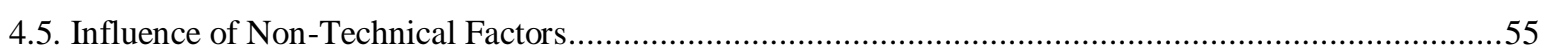

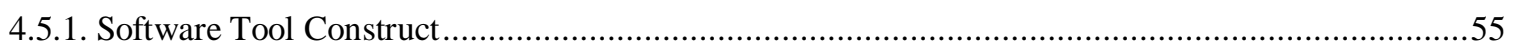

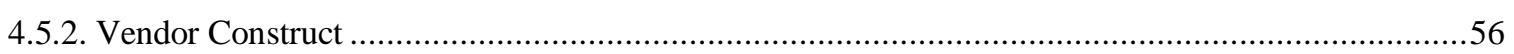

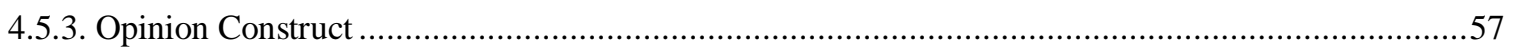

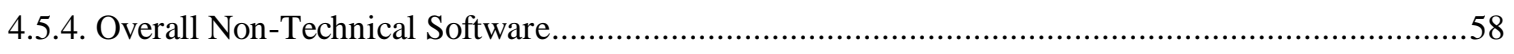

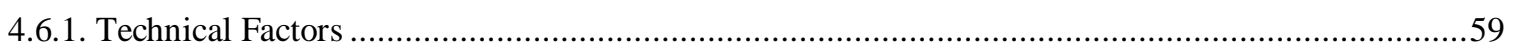

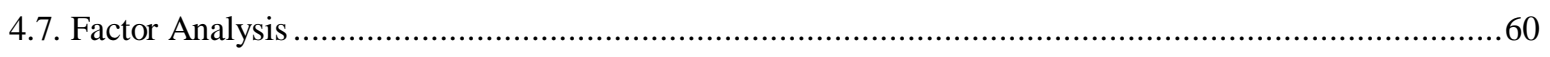

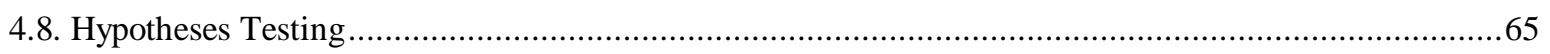

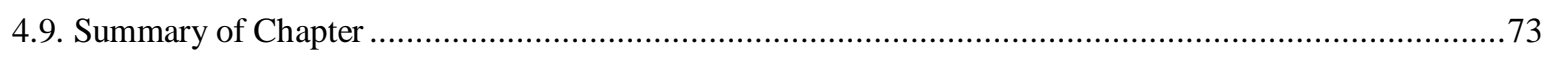

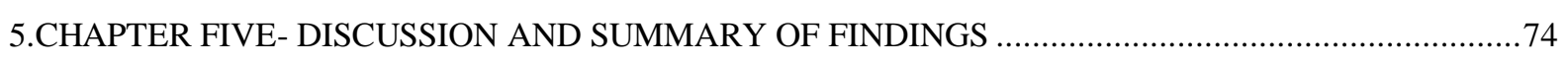

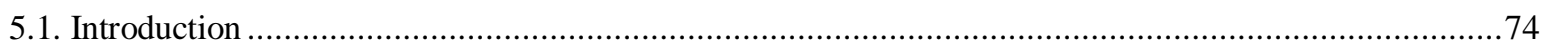

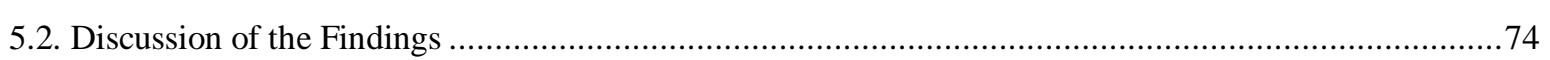

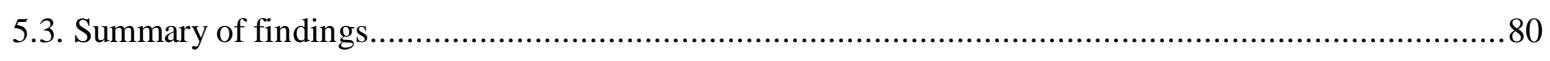

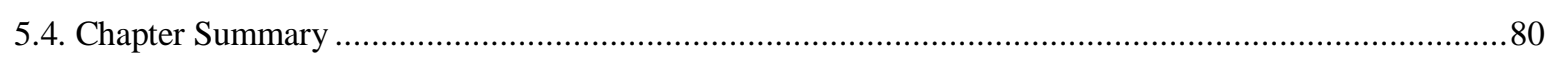

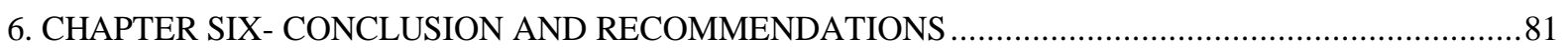

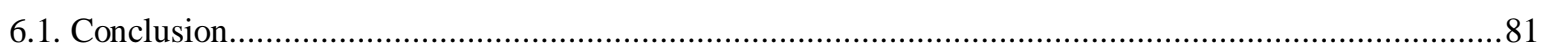

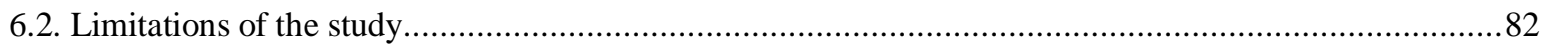

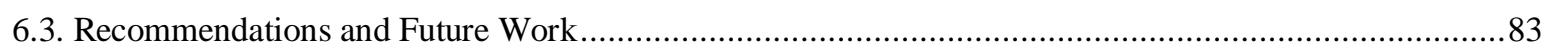

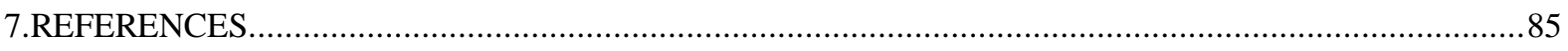

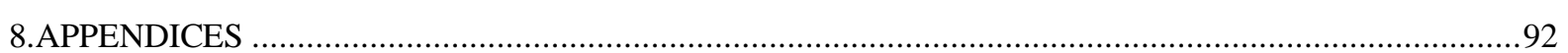

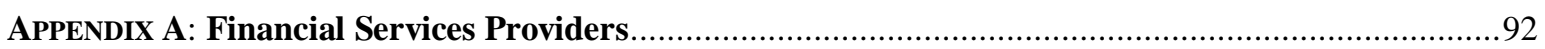


APPENDIX C: Survey of Factors Driving the Selection of Business Intelligence Tools.........................94

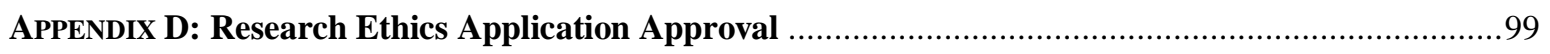

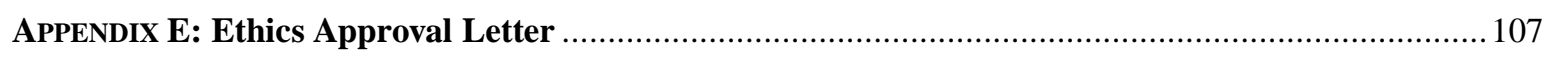

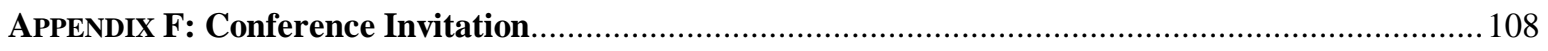

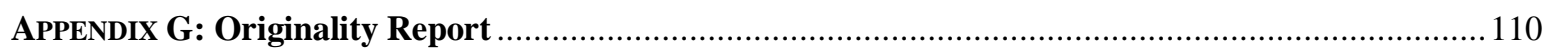




\section{List of Tables}

Table 2.1: The Technical Factors Affecting Selection of Packaged Software ............19

Table 2.2: The Non-Technical Factors Affecting Selection of Packaged Software ....21

Table 2.3: List of hypotheses against references .......................................................33

Table 3.1: Table for Decisive Sample Size from a Specified Population N ...............39

Table 4.1: Gender of Business Intelligence Professionals .......................................46

Table 4.2: Distribution of Business Intelligence Education Level ............................47

Table 4.3: Distribution of Business Intelligence Responses on Job Position..............49

Table 4.4: Respondents' opinions on Software Tools Technical Factors ....................52

Table 4.5: Respondents' opinions on Vendor Technical Factors ...............................53

Table 4.6: Respondents' opinions on Opinion Technical Factors .............................54

Table 4.7: Respondents' opinions on Overall Technical Factors ..............................55

Table 4.8: Respondents' opinions on Software Tools Non-Technical Factors ............56

Table 4.9: Respondents' opinions on Vendor Non-Technical Factors ......................57

Table 4.10: Respondents' opinions on Opinion Non-Technical Factors ....................58

Table 4.11: Respondents' opinions on Overall Non-Technical Factors .....................59

Table 4.12: Technical Factors Cronbach Alpha.....................................60

Table 4.13: Non-Technical Factors Cronbach Alpha...............................6 60

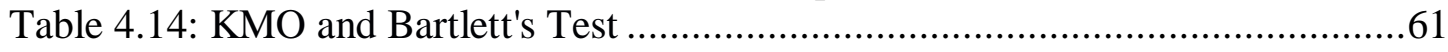

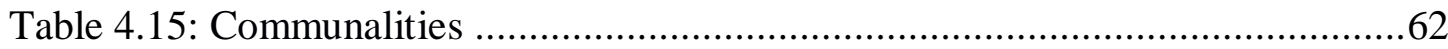

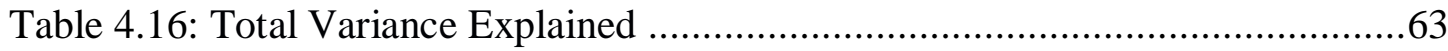

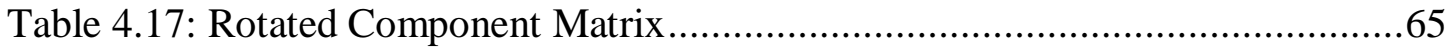

Table 4.18: Total results from the Bootstrap PLS Analysis ....................................70

Table 4.19: Hypotheses Summary Results.................................. 70 


\section{List of Figures}

Figure 2.1: Magic Quadrant for Business Intelligence Tools .................................11

Figure 2.2: Software Acquisition Process ....................................................... 12

Figure 2.3: Technology Software Evaluation Criteria. ............................................14

Figure 2.4: A model based DSS for technology selection problems ........................16

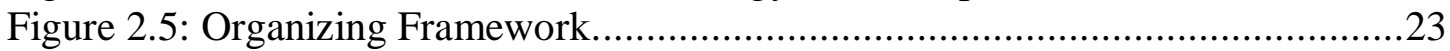

Figure 2.6: The Decision hierarchy for the component selection ............................24

Figure 2.7: Software Selection Framework for Data Mining ................................25

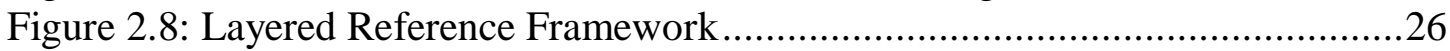

Figure 2.9: The S.T.A.D.T Selection Framework................................ 28

Figure 2.10: Conceptual Model for Business Intelligence Tools Selection ...............29

Figure 4.1: Age Groups of Business Intelligence Professionals...............................46

Figure 4.2: Distribution of Business Intelligence Responses on years of experience. 48

Figure 4.3: Distribution of Business Intelligence Responses on Organisation Type ..50

Figure 4.4: Distribution of Business Intelligence Responses on Organisation Size....51

Figure 4.5: Plot of eigenvalues against factor number.......................................63

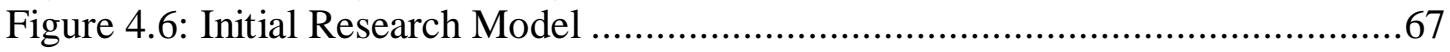

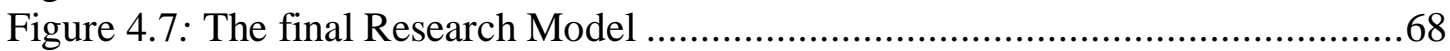

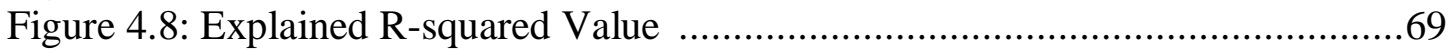

Figure 4.9: Diagram of model analysis with $\mathrm{T}$ ratio values ...................................69 


\section{Acknowledgements}

I would like to convey my words of gratitude to the following individuals for their effort in this study, without their assistance this study would not be possible:

$\checkmark$ My late father for his love for education and emphasizing its importance.

$\checkmark$ My mother for courageous words and support in difficult times.

$\checkmark$ My brothers, sisters, and friends for their assistance and understanding.

$\checkmark$ My supervisor, Prof. Adheesh Budree for his wonderful guidance, time, patience, and input.

$\checkmark \quad$ My employer for giving me time to pursue my studies. 


\begin{abstract}
Innovation and technology advancements in information systems (IS) result in multiple product offerings and business intelligence (BI) software tools in the market to implement business intelligence systems (BIS). As a result, a high proportion of organisations fail to employ appropriate and suitable software tools meeting organisational needs, resulting in a prime number of BI solution failures and abandoned projects are therefore recorded. Due to such project failures, benefits associated with $\mathrm{BI}$ are not realised hence organisations loose enormous investments on BI solutions and competitive advantage. The study aims at discovering and exploring critical factors influencing the selection of BI tools when embarking on the selection process. This is a quantitative research study and questionnaire surveyed data was collected from 92 participants working in South African financial services providers listed on the Johannesburg Stock Exchange (JSE) appearing in the top 100 based on market capitalization. The data was analysed quantitative by employing the use of SPSS and SmartPLS-3 software's to test the significance of influential factors using the proposed conceptual model that emerged from the literature. The findings showed that a combination of domain technical and non-technical factors is critical. Therefore, software tool technical factors (functionality, ease of use, compatibility, availability of an integrated hardware/software package, and availability of source code), vendor technical factors (availability of technical support, technical skills, quality of product, availability of user manual for important information, tutorial for learning and troubleshooting guide, and experience in using product developed by the same vendor), and opinion non-technical factors (end-users, subordinates, outside personnel acquaintances, and improvement in customer service) emerged as significant combination of influential factors to be considered. The study contributes to both academia and industry by providing influential determinants for software tool selection. It is hoped that the findings presented will contribute to a greater understanding of factors influencing the selection of BI tools to researchers and practitioners alike. Furthermore, organisations seeking to select and deliver appropriate BI tools will be better equipped to drive such endeavours.
\end{abstract}

Keywords-Business Intelligence (BI), Business Intelligence Tools (BITs), Business Intelligence Systems (BIS), Software Factors, Software Selection. 


\section{CHAPTER ONE- INTRODUCTION AND OVERVIEW OF THE STUDY}

\subsection{Introduction}

Given the development and upsurge use of business intelligence (BI) being observed, software tools implementing and delivering successful BI become a crucial factor driving the success of BI systems (Hanine et al., 2016). In previous studies conducted to highlight important questions concerning decision-makers and project designers, BI tools are classified as a top priority (Simitsis et al., 2009; Wyatt et al., 2009). BI has received prime focus from practitioners and information systems (IS) executives with many organisations investing a lot of resources in BI software services and BI cloud (Richards et al., 2019; Wieder \& Ossimitz, 2015). Many organisations are investing in BI solutions to constantly get value out of their growing data assets to gain competitive advantage and improved organisations operations (Lautenbach et al., 2017). As the type and number of BI solutions have grown there is an enormous risk of failure and inappropriate selection of tools (Mudzana \& Maharaj, 2015). Some of the failures observed in BI projects are a result of technological problems, particularly inappropriate selection of the correct software to employ (Eybers et al., 2019; Zaidan et al., 2015).

The BI era, began in the late 1950s has seen an abundance of tools for extraction, processing, analytics, reporting, and management of data (Magaireah et al., 2017; Wieder \& Ossimitz, 2015). According to Lautenbach et al. (2017), the term "Business Intelligence" was popularised during the 1990's and could be considered as a term that "encompasses a wide variety of processes and software used to collect, analyse, and disseminate data, all in the interest of better decision making and improved business operations". Furthermore, Wixom \& Watson (2010) acknowledge that BI "is an umbrella term that is commonly used to describe the technologies, applications, and processes for gathering, storing, accessing, and analysing data to help users make better decisions".

Most BI software tools are either commercial or open source, hence can be employed by anybody capable of adopting and arranging into appropriate solution architecture for the problem at hand and for reporting purpose to gain insights from organisational data (Borut et al., 2018; Mali \& Bojewar, 2015; Sharda et al., 2014). In the 2020s, data is an organisational asset and without "data" the concept of "business intelligence" is non-existent (Lake \& Crowther, 2013). Some organisations view and describe data as the new oil which assists companies to transform and become data-driven organisations (Lehmann et al., 2016). 
Unfortunately, there is not a single software solution to process such data but a variety of tools that each offer certain properties, characteristics, and functionalities (IcsiK et al., 2013; Lehmann et al., 2016). All organisation types and sizes face a difficult task to keep track of these, since the selection of such tools require time, money, skills, and knowledge to achieve and realise the benefits offered by BI solutions (Grandhi \& Wibowo, 2018; Malinin, 2016).

Many successful organisations from start up to established, have invested many resources on decision support systems (DSS) as the focal point and foundation for decision making (Trieu, 2017). The new era of BI has stimulated many organisations to dispose of traditional methodologies of reporting and decision making which depend on human intuition and uninformed decision making (Gillon et al., 2014). Such uninformed decisions have contributed to many BI project failures, and researchers emphasized that the main reason for failures is due to the lack of understanding of critical factors to consider when choosing a tool to employ (Magaireah et al., 2017). Some studies around the subject of BI tools selection has shown that the selection of appropriate and suitable BI tools is difficult, time-consuming, and a significant challenge for many organisations (Grandhi \& Wibowo, 2018; Hanine et al., 2017).

For organisations to reap the full benefits and capabilities that BI offers, they need to put in place a strong data platform (Bogdana et al., 2009). The first and initial step in achieving these benefits is the selection of business intelligence tools (BITs) that are the foundation of data preparatory prior to actual organisational reporting (Thamir \& Poulis, 2015). The process of BI tools selection is complex, and many organisations fail to select appropriate tools to meet organisational needs, objectives, and to answer complex questions embedded in data (Hanine et al., 2016; Yeoh \& Koronios, 2010).

This dissertation aimed at discovering and describing the critical factors to be considered when selecting BI tools to help curb the high failure rate and abandoned BI solutions being observed. Specifically, the study will focus on the South African financial services providers (SFPs). SFPs are referred to as organisations dealing with the management of funds and money (Curry, 2016). It is vital study the South African (RSA) setting since the uptake and adoption of BI tools is on the rise and many financial institutions are thriving to gain competitive advantage (Bach et al., 2016). Moreover, within RSA business context, an understanding of the practice, impact and BI tools selection is only partly addressed by existing research (Venter \& Tustin, 2009). 


\subsection{Problem Statement}

The selection of appropriate BI tools is the first and fundamental initial phase in achieving and meeting organisational strategic goals (Thamir \& Poulis, 2015). If organisations conclude with improper tools; the needs, objectives, and problems facing the organisations are compromised (Chhina, 2016). It is increasingly difficult and complex to identify the correct BI tool to employ due to the advancements in technology, several product offerings, and innovation observed in the BI space (Ma et al., 2013). Software selection is viewed and remains the major, crucial, and sensitive activity for many organisations that need to be given the attention it requires by researchers, organisations, and managers (Ansari et al., 2016).In the field of BI it is noteworthy that organisations struggle to select suitable BI tools to deliver successful BI systems given multiple and the abundance of product offerings in the market (Magaireah et al., 2017). This challenge results in an extremely high percentage of BI project failures and abandoned BI solutions recorded, in the region of $70 \%$ to $80 \%$ (Villamarín \& Diaz Pinzon, 2017). According to Pham et al. (2016), the success rate of BI projects implementation is in the region of $20 \%$ to $30 \%$, which is concerning. To try and address the problem at hand, critical factors driving the selection of BI tools that relate to technical and non-technical domain need to be discovered, identified, and explored.

\subsection{Purpose of the Study}

The purpose of this study was to explore and discover critical factors that influence the choice of BI technology to employ in South African financial services providers to combat the high failure rate and abandoned BI projects, due to improper selection of BI software tools.

\subsection{Research question/s}

The study sought to answer the following research question/s:

\section{Main Question}

- What are the critical factors to consider when selecting BI tools for South African financial services providers?

\section{Sub-Questions}

- What are the technical factors that influence the selection of BI tools for South African financial services providers? 
- What are the non-technical factors that influence the selection of BI tools for South African financial services providers?

\subsection{Objectives of the study}

The study was guided by the following objective/s:

\section{Main Objective}

- Identify critical factors to consider when selecting suitable BI tools for South African financial services providers.

\section{Sub-Objectives}

- Discover critical technical factors for BI tools selection in South African financial services providers.

- Discover critical non-technical factors for BI tools selection in South African financial services providers.

\subsection{Significance of the study}

The study aims to add to the body knowledge of the BI community/fraternity and to create a basis for future research for BI in South Africa and other developing countries. It is noteworthy that very little research has been done around software selection factors. Despite early calls for research in BI around the globe, the academic research community has embraced the topic and research to an extent but it is still fragmented and sparse (Ponelis, 2012; Wieder \& Ossimitz, 2015).

By discovering, examining, and exploring the critical factors affecting the choice of BI tools/ technology in South African financial service providers, this research may be of importance to organisations embarking on the process of technology selection who are concerned about the process and factors to consider. Factors affecting the choice of technology for BI tools selection may enable organisations to eradicate dependence on human intuition, often biased during technology selection and to minimize the rate of taking uninformed decisions when it comes to the selection of BI tools. The issue of BI systems failure and abandoned solutions is alarming and at an exponential trajectory of which improper selection of tools to employ is a big factor (Villamarín \& Diaz Pinzon, 2017). Therefore, to combat and minimize these failures, factors influencing the selection of BI tools will serve as a guide and checklist to use in the selection of suitable products that meet the needs of an organisation. Specifically, the study provides 
guidance for organisations and individuals in the selection level of software packages and provide more understanding of influential factors.

\subsection{Research Assumptions}

While undertaking this study, it was assumed that the respondents would give correct responses concerning the factors driving and influencing the selection of BI tools, and that the content of responses would be valid for all the questions. It was also assumed that respondents would give honest and truthful responses which were in line with and genuine indicators of BI factors. Lastly, it was assumed that respondents would give objective responses.

\subsection{Empirical Report Overview}

The research report consists of six sections, which provide and explore an overall review of the selection of BI tools. The second section is the literature review conducted around the subject of technology/BI selection, gathered from scholarly articles, journals databases, conference databases, and other relevant resources. This section focuses on prior research seeking to address the issue of software selection and factors influencing the selection of software tools which may be either technical or non-technical factors. The literature review will also discuss various constructs and variables of interest, which research has argued to be critical during the selection of software technology.

The literature review section further discusses different theoretical frameworks that attempted to answer questions relating to software selection and factors influencing the selection of software tools. Studied theoretical frameworks and theories resulted in a proposed conceptual model by borrowing important concepts and constructs. The proposed conceptual model was used to answer the research questions, and all the proposed hypotheses were tested using the proposed conceptual model.

The third section will discuss the research methodology employed to conduct the study. This section will discuss the research approach of the study, data collection method, research instruments, data analysis method and tools employed during the analysis phase of data, and pilot study. The target population and how the researcher arrived at the chosen sample size, ethics and confidentiality will also be discussed. 
The fourth section will focus on data analysis and findings discussion of collected data. This section will include the type of data analysis methods employed in the study as well as what the analysed data infer. All the proposed hypotheses will be tested for significance in this section.

The fifth section discusses results and findings. In this section findings and research impressions will be expanded. Lastly, section six is the conclusion of the study, in which the study will conclude the factors of the research done. Limitations and implications for research will be discussed, as well as contributions and future work of the current study in the body knowledge and community of BI fraternity will be stated.

\subsection{Summary of Chapter}

This chapter provided a brief description and overview of the study. The problem statement was stated and analysed broadly to equip the reader for what the study entails and to give an idea of what to expect in the next chapters. The objectives of the study were stated and the entire research questions that needs to be answered which are concerned in determining the factors influencing the selection of software tools in the BI field. Briefly, this section is detailing and setting the foundation of what will be discussed in the next chapters. The remainder of this research dissertation is structured as follows. First, the introduction and overview of the study (Chapter 1), Chapter 2 literature review, Chapter 3 research methodology, Chapter 4 data analysis, Chapter 5 discussion of results and findings, and Chapter 6 conclusion and recommendations. 


\section{CHAPTER TWO- LITERATURE REVIEW}

\subsection{Introduction}

This chapter presents literature reviewed to create the foundation from which the research problem was approached. The literature review is a compilation, classification, and evaluation of previous work studied and written by other researchers on a topic or studied phenomenon. It aims to show that the researcher has read and grasped previously published work concerning the studied topic in a specific field (Hart, 2018). This type of information is found in secondary sources of data on the chosen topic of interest, and it also stresses the evaluation of work concerning the defined problem. This section will focus on the software selection literature and factors influencing the selection of software tools in the BI and organisation reporting field. An in-depth and broad discussion of the variables of interests and constructs influencing the selection of BI tools will be explored.

\subsection{BIT Background}

BI has received focus and priority from practitioners, researchers and IS organisation management with many companies investing a lot of resources in software and BI cloud services (Richards et al., 2019; Wieder \& Ossimitz, 2015).Even though the use of BI has seen an exponential uptake in few decades, several researchers claimed that the term BI was since used by Luhn's work in 1958 by defining the concepts "Business" and "Intelligence" separately (Magaireah et al., 2017). Other researchers however, believe that BI is a new terminology invented by Dresner of Gartner Research Group in 1989 and since then several BI definitions are widely used (Magaireah et al., 2017). The most recent and relevant definitions found in literature were:

$\mathrm{BI}$ is defined as the process of using technology software tools to transform raw data into useful information to help organisations, executives, and individuals to make sound and data driven informed decisions (Trieu, 2017).

BIT is defined as a set of the application software used to extract, transform, and process data that is gathered from organisation data sources to conduct business reporting and improved organisational operations (Mudzana \& Maharaj, 2015). 


\subsubsection{Transformation, Reporting and Analysis Tools}

According to Chhina (2016), BI tools are categorized into three ways, firstly, data analysis and reporting which is responsible to read, process, and format the data into structured reports that are delivered to the end-users. Secondly, data mining tools that are used to process data using statistical techniques, discover patterns, and relationships in data to make predictions. Lastly, knowledge management tools which store organisational data, and this type of data is made available on request, the main source of this data is on human knowledge.

The heart and core of BI is based on the data warehouse (DW) which is powered by ETL ( Extract, Transform, and Load); ETL is regarded as the initial step and the starting point of any BI project Hanine et al. (2016), responsible for data extraction from different data source systems, transformation of raw data, and loading to an organisation DW for reporting and to gain insight (Hanine et al., 2016; Mali \& Bojewar, 2015). DW is understood to be the repository of integrated data obtained from multiple and different sources to support BI and subsequently decision making (Mali \& Bojewar, 2015).

ETL tools are ranked top as the main and important priority for an organisation and are said to be difficult and complex to select (Hanine et al., 2016). The chosen tools must achieve organisational goals and maximize the benefits of the organisation, therefore choosing appropriate tool limit risks associated with the BI project (Hanine et al., 2016). ETL tools are divided into two, there are commercial ETL tools which are licensed and only an allocated number of licensed individuals may use such tools and freeware ETL tools which are not licensed and any individual may use them, these tools are often called open source tools and are downloaded over the internet (Mali \& Bojewar, 2015). According to Hanine et al. (2016), there are many factors that involve and impact the selection of ETL tools, and these factors can be categorized into two groups either technical or non-technical.

Reporting and analysis tools are responsible for reading the data, which is already clean, transformed, formatted, and structured to produce visualization reports which organisations rely upon for reporting. Also, the same data is analysed by BI front-end tools to draw insights to help organisations plan for the future (Mali \& Bojewar, 2015). Reporting and analysis tools must conform and meet certain criteria e.g. produce reports which can be formatted, printed, parameterized by filtering and sorting, distributed automatically and frequent, and supports analysis of data sets (Mali \& Bojewar, 2015). These types of tools are developed and provided 
by software application vendors which market and sell the tools to the organisations intending to implement BI systems (Alireza \& Seyedeh, 2015; Chugh \& Grandhi, 2013). Some studies have highlighted the daunting task of selecting the vendor of BI tools as a challenge on its own (Alireza \& Seyedeh, 2015).

This study focused on and considered data transformation, reporting, and analysis tools since these are the heart and foundation responsible for achieving BI capabilities and offerings (Chhina, 2016).Additionally, these types of tools are said to be problematic and complex to select (Hanine et al., 2016).

\subsection{BIT Selection}

The issue of BI software tools selection has been in the research domain since the mid-1990s and its literature is dating back to more than two decades (Chau, 1995; Damsgaard \& Karlsbjerg, 2010; Mali \& Bojewar, 2015). The studies conducted in the 2000 years have shown that the appropriate selection of BI tools is deemed to be complex and a taxing process to embark on as an organisation (Shariat \& Hightower Jr, 2007). The nature of the software tool selection problem by the early 2000s was attributed to multiple product offerings in the market and the capability of vendors to produce more advanced products that complicated the selection procedure (Chugh \& Grandhi, 2013). Shariat \& Hightower Jr. (2007) claim that from a single Google search for "Business Intelligence Tools" results in thousands of responses and several vendor results.

The focus has changed, the nature of the problem is attributed to organisation's failure to select and choose appropriate BI software tools meeting organisational needs and objectives (Kara \& Cheikhrouhou, 2014; Villamarín \& Diaz Pinzon, 2017). The consequences of inappropriate selection of software tools are: organisational economic loss, improper strategic decisions, abandoned projects, and failure to implement sound BI systems (Hughes et al., 2017).

Other researchers posit that any software in the market cannot meet organisations expectations and needs fully since organisation strategies and goals differ significantly (Efe, 2016). To improve software selection success chances, organisation's management must choose appropriate software tools that suit closely its requirements. Many firms tend to choose software tools hastily without fully understanding the requirements to be considered, therefore 
the conclusion of this hurry is the failure of software selection that leads to project failures and weakened company performance (Efe, 2016).

According to Malinin (2016), organisations often need to select a prospective technology from several available options and make a business decision by investing in the prospective vendor while monitoring other competitors and that the wrong choice of technology selection can be disastrous. Bhargava et al. (2013) add that immature and wrong choice of tool to employ would result in a great loss of money and time. The staggering percentage of BI systems failure as a result of technological and managerial factors observed is in the region of $70 \%$ to $80 \%$ (Villamarín \& Diaz Pinzon, 2017). With the rate at which BI projects fail after years of attempts to significantly solve the problem, more and deeper analysis around the topic is required and necessary (Hughes et al., 2017).

According to Saedi \& Danielsson (2018), there are two universal viewpoints concerning the failure of BI project implementation, namely managerial and technological obstacles. To solve some of the technology related issues, it is imperative for organisations to employ software tools to meet organisational needs. The critical success factors (CSFs) studies have shown that the success or failure of the BI system implementation is also dependent on the choice of tool you employ as an organisation (Hussein et al., 2020; Saedi \& Danielsson, 2018). Therefore, it is necessary for organisations to put in place a strong and correct data platform (Shi \& $\mathrm{Lu}$, 2010). Figure 2.1 below depicts a subset list of BI tools providers and technology platforms in the market as per Gartner's 2019 mid-year magic quadrant which helps to ascertain how technology providers are executing stated visions and how they are performing against Gartner's market view (Canito et al., 2018). 


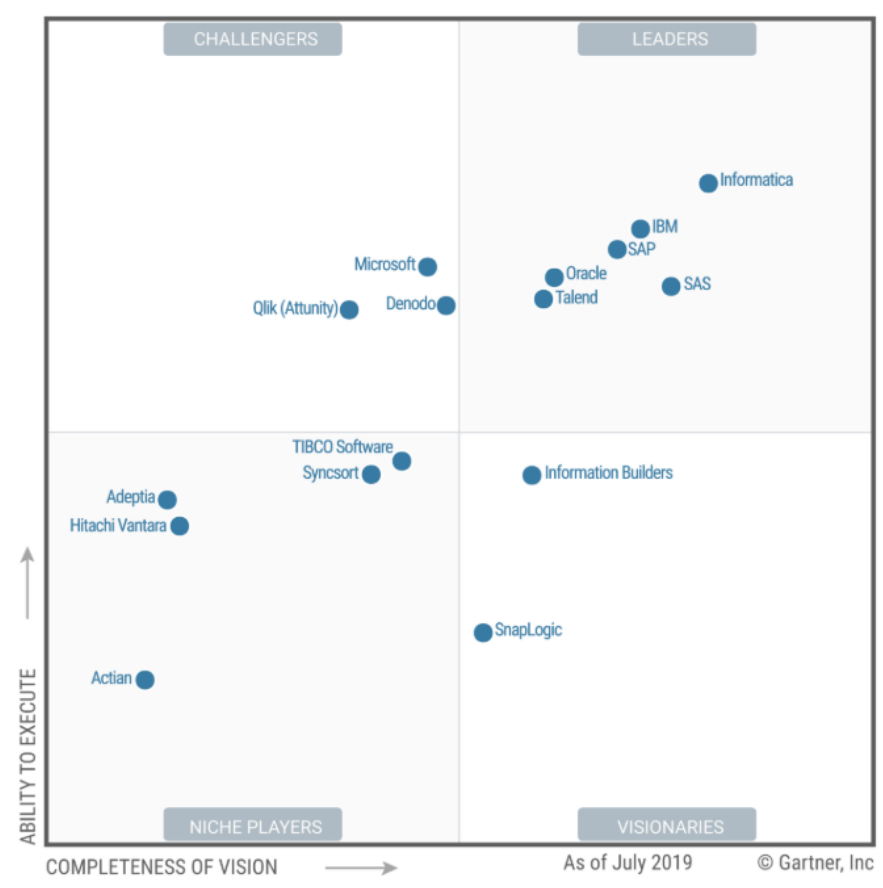

Figure 2.1: Magic Quadrant for Business Intelligence Tools Retrieved from https://www.gartner.com/doc/reprints?id=1-1OCI16P3\&ct=190801\&st=sb

As the kind and type of BI solutions have evolved there is an enormous risk of failure and inappropriate selection of tools (Rezaie et al., 2011). Based on the literature, an academic focus on IS tool selection has given birth to some academic research and studies (Wieder \& Ossimitz, 2015). The studies are classified into four different groups: evaluation and selection of software product, criteria for tool selection, selection methodology, and automated decision-making systems (Jadhav \& Sonar, 2011; Oztaysi, 2015).

Literature has proven that decision making in the field of software technology selection becomes more complex and difficult due to multiple tools and product offerings in the market (Chugh \& Grandhi, 2013; Thamir \& Poulis, 2015). Apart from the vast amount of product offerings to choose from, there are thousands of vendors offering BI solution services (Soloukdar \& Parpanchi, 2015). The problem of the choice of tool to use is regarded as an organisational strategic decision that impacts organisational performance (Hanine et al., 2016). If the selection of the software tool is not supported by a concrete plan, the acquisition of the tool to employ will become a distraction from the organisation's objectives (Villamarín \& Diaz Pinzon, 2017). As much as technology advancements and the introduction of new and upgraded versions of tools are welcomed, it creates problems in the minds of prospective buyers to take correct decisions (Bhargava et al., 2013). Employing and investing in suitable software leads to improved customer service and management (Mudzana \& Maharaj, 2015). 
Selecting proper and correct BI software tools is imperative and the process comprises four general known steps in any selection process (Palanisamy et al., 2010):

- Examine existing needs;

- Proof of concept by vendors;

- Consults fellow users of the software tool;

- Interview potential users.

Jadhav \& Sonar (2011) posit that the process of software selection is difficult, firstly, due to challenge in finding application of software to meet organisational needs. Secondly, incongruities between numerous software and hardware systems. Thirdly, lack of essential technical experience and technical knowledge from final decision-makers. Lastly, innovation and technology advancements observed. It is common that organisation head of information technology (IT) or BI is vested with all the powers to select the software technology to be employed by playing an important role to collate all necessary information, engaging with potential vendors, conducting software analysis, and making the final decision (Damsgaard \& Karlsbjerg, 2010). Most notable is that the process of software selection is usually allocated little time by organisations and under enormous pressure which negatively affects decisionmakers; e.g. lack of time and experience to plan the selection procedure (Oztaysi, 2015).

\subsubsection{Software Application Acquisition}

Software acquisition in many different software development environments has been observed to be a challenge. There is a plethora of research addressing software acquisition in the project management (PM), accounting, Big data, decision support systems (DSS), simulation, enterprise resource planning (ERP) systems, and data mining (Bhargava et al., 2013; Fischer et al., 2017; Zaidan et al., 2015). In information systems literature, a generic process-oriented software acquisition has been predominantly adopted and the process is depicted in Figure 2.2 below.

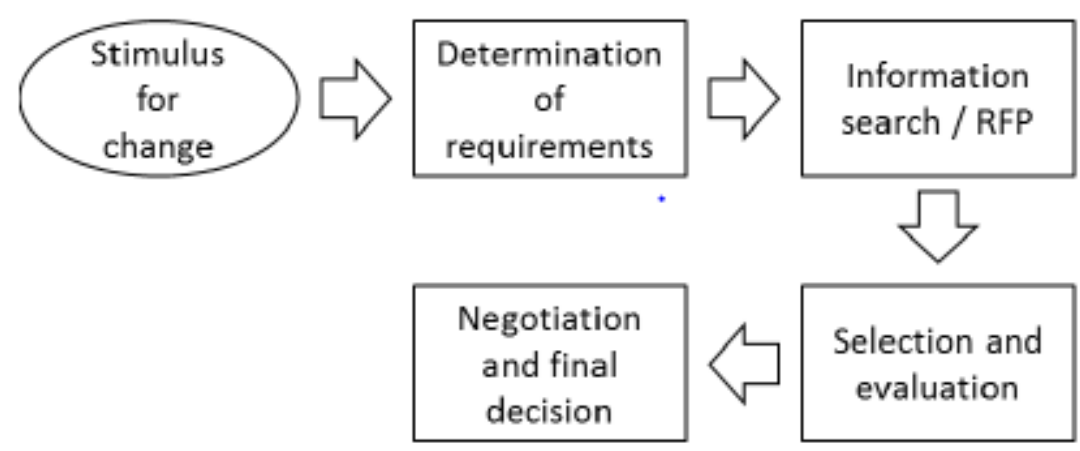

Figure 2.2: Software Acquisition Process (Harnisch, 2014). 
The software acquisition process starts with a stimulus for change desired by an organisation (Chugh \& Grandhi, 2013). After the project approval, the process of requirements gathering and determination kicks in (Kara \& Cheikhrouhou, 2014). Mostly these requirements are used for the identification of vendors capable of fulfilling requirements or inclusion in the request for proposals (Villamarín \& Diaz Pinzon, 2017). The next stage is the evaluation of vendors and possible solutions (Hughes et al.2017). This is followed by shortlisting of potential candidates (Chugh \& Grandhi, 2013). Lastly, contractual negotiations with a couple of shortlisted vendors take place until a decision is made (Palanisamy et al., 2010).

The order of activities for the software acquisition process is iterative and not linear. The selection and evaluation phase has been discussed extensively by many researchers and still lacks a generic method for selection and evaluation. Based on the literature gathered around the subject of software selection criteria, seven salient clusters have emerged: functionality, software vendor, software quality, software and hardware, cost and benefits, opinions, and output (Jadhav \& Sonar, 2011). According to Tsai et al. (2012), the factors influencing the selection and evaluation of any software, including their importance are crucial and need to be understood.

\subsubsection{The Methodology for Selection of Software Packages}

The methodology for the selection of software tools encompasses procedures and steps which decision-makers follow during the software selection process (Efe, 2016). The methodology is used and projected as an adaptable guideline based on the organisation's requirements and needs. According to Efe (2016) and Jadhav \& Sonar (2011) the methodology consists of six sequential steps to be followed: requirements definition, preliminary investigation of the availability of software packages, shortlisting packages, establishing criteria for evaluation, evaluating software packages, and selecting software package.

There is quite an observed amount of BI research focusing on the methodology to follow when evaluating BI tools as to help to solve the problem of selection, namely: analytical hierarchy process (AHP-TOPSIS), fuzzy AHP, and fuzzy TOPSIS (Hanine et al., 2016; Soloukdar \& Parpanchi, 2015). The application of these methodologies has been used and applied in different fields and are observed to be good for subjective and objective factors in selecting the suitable tool from multiple alternatives available (Jadhav \& Sonar, 2011). These methodologies have proven to be not enough since there is much research that has emerged seeking to find 
alternative methodologies hence the birth of Delphi-fuzzy AHP-PROMETHEE as to bridge the gap on the previously stated methodologies (Hanine et al., 2017).

Some studies maintain that operational managers continue to experience difficulties to select and choose software that suits business requirements given the methodologies researchers propose and posits that there is a need for decision makers to clarify their needs and what the software packages must offer, therefore the critical factors influencing software tool selection is vital (Grandhi \& Wibowo, 2018; Kara \& Cheikhrouhou, 2014).

\subsubsection{Software Evaluation Criteria}

The literature concerning evaluation and selection of software provides the criteria to help organisations to evaluate software packages e.g. DSS, CRM, data mining, and ERP (Bhargava et al., 2013; Zaidan et al., 2015). The observed kinds of literatures lack the generic list of criteria to be employed and followed for evaluating any software package. The meaning of each evaluation criterion can be interpreted in either way by the evaluator (Jadhav \& Sonar, 2011). Some of the observed literature only focuses on the functionality and quality attributes of the technology software and disregards the crucial criteria/element associated with opinions, vendor, cost, and benefits characteristics of the software tool. Figure 2.3 below depicts the evaluation criterion which includes several factors to consider for a technology software tool selection (Jadhav \& Sonar, 2011).

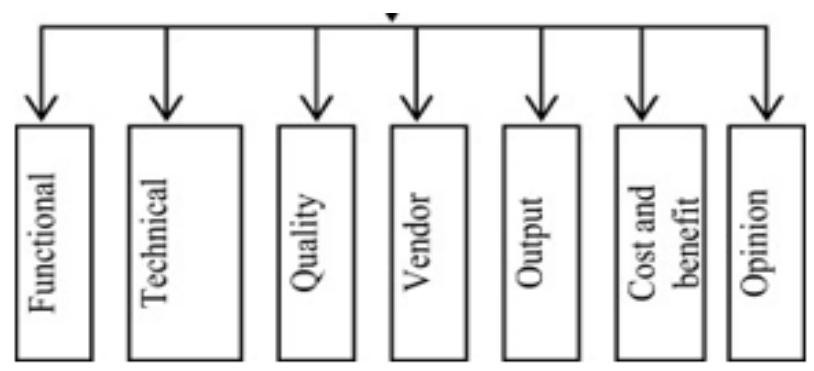

Figure 2.3: Technology Software Evaluation Criteria (Jadhav \& Sonar, 2011).

The components depicted in Figure 2.3 above are defined as follows: Functional criteria denote practical and usefulness capabilities of the technology software and the functional capabilities for a software package are said to vary e.g. ERP, CRM, BI, and Data mining (Thamir \& Poulis, 2015). The technical criteria component denotes technical requirements concerning software and hardware characteristics (Bhargava et al., 2013). Quality criteria are responsible for 
assessing the eminence of software. The ISO/IEC 9126 stipulates the quality model and features to be considered for the evaluation of software tools (Chau, 1995). Vendor criteria are concerned with the valuation of vendor ability and capabilities regarding the software tool they offer. Output component measures the ability of the software tool to support other systems outputs e.g. tool support for output to other packages (Chen et al., 2012). Cost and benefits component measures the affordability and aids of the software tool while opinion component measure perceptions, advice, and views surrounding the software tool by different stakeholders (Jadhav \& Sonar, 2011).

Kara and Cheikhrouhou (2014) maintain that difficulties observed in the selection of software tools that suits business requirements need to be clarified hence the factors influencing softwa re tool selection should be studied, explored, and discovered to help decision makers to make informed decisions. The latter study is supported by Mali \& Bojewar (2015) who state that de cision on the tool selection depends on the factor's organisation consider during the selection process.

Organisations need to understand and define the requirements of the BI system prior and factors that influence the selection of tools to minimize buying technology in a vacuum (Villamarín \& Diaz Pinzon, 2017). There are many factors that involve and impact the selection of software tools; therefore, they need to be discovered and clarified. According to Villamarín \& Diaz Pinzon (2017), information and technology in the BI space consist of several factors and characteristics that must be considered when choosing a technology to employ.

\subsection{Decision Support for Technology Selection}

Technology selection is the process of assessing the potential value of technologies and their return on investment to gain competitiveness and profitability (Farshidi et al., 2018). The challenge of technology selection is evaluating and selecting suitable technology for the organisation (Farshidi et al., 2018). The complexity of the selection process is due to multiple factors to be considered, such as suitability and cost. Researchers have introduced a variety of methods, techniques, and decision support tools to solve the problem of technology selection. Technology selection decisions are usually made $a d$ hoc and therefore lack reliable and sound methodologies (Farshidi et al., 2018). The solutions found in the literature that address the issue of technology selection is valid for a specified period; as technology advancements are 
observed new methodologies are needed. Therefore, generic, and stable selection methodologies are necessary where its characteristics must be clarified.

Farshidi et al. (2018) propose a model-based decision support system for technology selection problems depicted in Figure 2.4 below such that a list of technologies to choose from (Alternatives $=[a 1, a 2, \ldots a \mid$ Alternatives $\mid])$ are a subset of certain critical factors $($ Factors $=[f 1$, $f 2, \ldots f \mid$ Factors $\mid])$ which are prominent technical and non-technical domain. These factors need to be known and understood since the critical factors driving the selection of technology are vital.

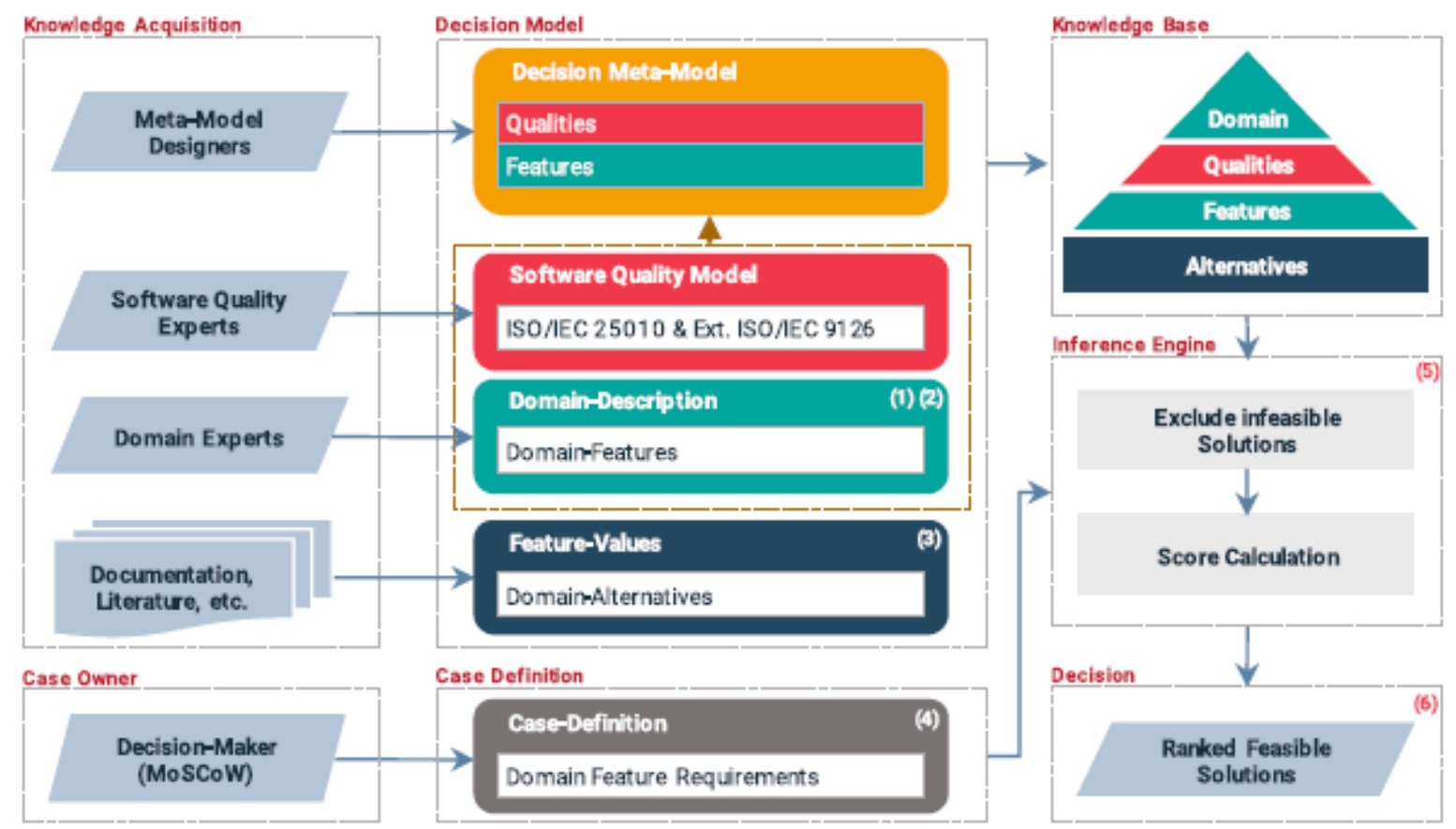

Figure 2.4: A model based DSS for technology selection problems (Farshidi et al., 2018)

\subsection{Software Selection Factors}

Many studies have highlighted the difficulties faced by many organisations in selecting software tools. As much as literature provides and suggests many factors and characteristics for software selection, very few studies have looked at the factors influencing the selection of BI tools extensively. A plethora of literature by Bhargava et al. (2013); Kara \& Cheikhrouhou (2014) and Mali \& Bojewar (2015) has revealed that the selection of software tools depends on technical factors and non-technical factors and based on these items the factors are grouped into a software tool, vendor, and opinion constructs. Both these type of factors are interrelated 
and need to be considered equally hence there is none which weigh more than the other (Bhargava et al., 2013). For this study and its objectives, the researcher will focus on technical and non-technical factors as guided by literature. It must be stated from the onset that software tools factors influencing the selection are important and that during the evaluation of software purchase descriptive variables related to a software tool, vendor, and opinions are considered and given attention and focus (Jadhav \& Sonar, 2011; Mali, 2015).

\subsubsection{Technical Factors}

Technical factors are the type of factors that focus on the practical ability and capability of the software tool to deliver desired results without experiencing technical issues and problems (Thamir \& Poulis, 2015). According to Farrokhi \& Pokoradi (2013) software tool must conform to a certain number of characteristics to be considered suitable and capable to deliver it intended competences and subsequently deliver value and objectives intended, namely: reliability, functionality, efficiency, usability, and maintainability. In a study conducted by Chau (1995) to determining the factors that small, medium, and micro-enterprises (SMMEs) consider during the selection of packaged software, found that the organisations owners tend to weigh technical factors more heavily, take more factors into consideration, and consider those factors in a more serious manner than managers. Below is a list of critical and prominent technical factors found useful in literature that plays a vital role during the selection of software tools and are broadly discussed and explained.

\subsubsection{Reliability}

This refers to the capability of the software package to run and execute consistently without any errors and crashing (Jadhav \& Sonar, 2011). In most cases, reliable software should be capable of supporting backup operations and recovery features when required (Bhargava et al., 2013). According to ISO/IEC 9126 and Farrokhi et al. (2013) any software must conform to this characteristic to be deemed useful and able to deliver it intended capabilities.

\subsubsection{Functionality}

Software functionality encompasses multiple criteria that are taken into consideration when dealing with the functionality capabilities (software and hardware) of the software which includes adaptability and customization according to the organisations' requirements (Bhargava et al., 2013). It is imperative for the software to integrate and work well with existing organisational tools and applications (Jadhav \& Sonar, 2009). Functionality is one of the salient 
factors that is deemed significant to be considered, it plays a vital role during the selection of any software (Jadhav \& Sonar, 2011).

\subsubsection{Efficiency}

The capability of the software package to produce correct results within a reasonable amount of time relative to the volume and size of data ingested (Bhargava et al., 2013; Jadhav \& Sonar, 2009). ISO/IEC 9126 stipulates that effectiveness of the software tool must be the driving factor during the selection process. Any software tool sufficing to competency needs must be adopted (Chau, 1995).

\subsubsection{Usability}

This factor is concerned with software package ease of use e.g., user-friendly interface, easy to learn, and operate as a user. It is critical for the software tools to accommodate all user groups from beginners to experienced users. The capability of the software to report errors, messaging, and presentation of data effectively is critical and need to be considered during the selection process (Bhargava et al., 2013).

\subsubsection{Maintainability}

This refers to the maintenance of software and effortlessly migrating from one version to the other. It is imperative to simultaneously support users during the maintenance period to save time (Bhargava et al., 2013).

\subsubsection{Technical Support Availability}

Refers to support provided by the vendor. From time to time clients encounter software tool technical problems which might relate to crashing and other unforeseen errors, therefore support from the vendor is necessary (Jadhav \& Sonar, 2009).

\subsubsection{User manual and Tutorials}

This factor refers to the availability of all material for the purpose of upskilling e.g. user manual information, tutorials for training, and error troubleshooting guides (Bhargava et al., 2013).

\subsubsection{Vendor and sales representatives}

This refers to the opinion of the vendor and sales personnel regarding the software tool. The opinions may vary from being very poor to very good (Jadhav \& Sonar, 2009). 


\subsubsection{In-house experts}

Each organisation has experts and individuals regarded as highly skilled and knowledgeable therefore the opinion of such individuals is critical to be captured regarding the software tool to employ (Jadhav \& Sonar, 2009).

\subsubsection{External Consultants}

This factor is about the opinion of external consultants and personnel regarding the software tool (Jadhav \& Sonar, 2009). Consultants' opinions and views need to be considered when selecting the software tool.

Table 2.1 below depicts the list of some technical factors gathered from literature with the variable of interest (construct) which previous research deems crucial for consideration during the selection of software tools.

Table 2.1: The Technical Factors Affecting Selection of Software (Chau, 1995; Jadhav \& Sonar, 2009; Villamarín \& Diaz Pinzon, 2017).

\begin{tabular}{|l|l|}
\hline \multicolumn{1}{|c|}{ Technical Construct } & \multicolumn{1}{|c|}{ Technical Factors } \\
\hline Software Tool & $>$ Availability of an integrated hardware/software package \\
& $>$ Compatibility with existing hardware/software \\
& $>$ Ease of use/user-friendly \\
& $>$ Functionality \\
& $>$ Availability of source code \\
\hline Vendor & $>$ Availability of technical support \\
& $>$ Availability of user manual for important information, \\
& tutorial for learning and troubleshooting guide \\
& $>$ Technical skills \\
& $>$ Experience in using product developed by same vendor \\
& $>$ Quality of product \\
\hline Opinion & $>$ Potential vendors/sales representatives \\
& $>$ In house "Experts" \\
& $>$ External Consultants \\
& $>$ Computer/IS trade magazine, software product leaflets \\
\hline
\end{tabular}

2.5.2. Non-Technical Factors

Non-Technical factors are the type of factors that do not involve the technical ability of the technology software and focus on the non-practical aspect of the software tool (Yeoh \& Koronios, 2010). Literature has shown that these types of factors play a vital role in the acquisition of the software and in most cases are overlooked during the software tool selection process. According to Eybers \& Giannakopoulos (2015) non-technological factors play a 
dominant role in BI initiatives which in most cases are disregarded especially during the taxing period of acquiring the technology to employ. Below is a list of critical and prominent nontechnical factors found useful in literature that plays a vital role during the selection of software tools and are broadly discussed and explained.

\subsubsection{Cost}

Cost refers to the price and benefits of software package characteristics which includes multiple measurable attributes namely: licensing, hardware and software, installation, maintenance, training, upgrading, and direct and indirect costs (Büyüközkan et al., 2018). Literature has shown that software price is one of the factors organisations need to consider Chau (1995)

\subsubsection{Popularity}

This refers to how common the software package is widely used in the market and by fellow competitors to leverage benefits the tool possesses. This factor goes a long way since the more software tool is popular and widely used, it implies that the skill set of such tools is also available in the market (Bhargava et al., 2013). This factor is very important for consideration since it address the issue of skillset availability for the procured software tool.

\subsubsection{Lifespan}

Lifespan refers to the software tool longevity, durability, and how long the software will be in the market. It is common that some software comes to the market with a storm and after some couple of years are obsolete and no longer offered and supported by the vendor (Bhargava et al., 2013). Therefore, for organisations to avoid adopting obsolete software tools, factors relating to durability need to be scrutinised.

\subsubsection{Version currently in the market}

Software tool vendors often upgrade software's by including certain features either functional or non-functional. This factor measures whether the vendor is offering a version with features supporting the latest technologies e.g. ability to extract different types of data and connection to cloud services (Jadhav \& Sonar, 2009). Since technology is advancing fast, it is important for organisation to consider this factor to avoid purchasing technology that will not meet organisational needs due to technological limitations. 


\subsubsection{Subordinates}

Refers to all opinions and views of subordinates regarding the software tool (Jadhav \& Sonar, 2009). This factor forms part of wide consultations and its important since it captures the views individuals who depend on the software tool to avoid purchasing the technology in a vacuum.

\subsubsection{End Users}

Refers to individuals who interact with the software daily, these individuals are likely to be software developers. What they think of the tool to be employed is important and a critical factor to be considered (Jadhav \& Sonar, 2011).

\subsubsection{Outside personnel acquaintances}

This refers to the opinion of outside personnel regarding the software tool to be employed. This is currently regarded as seeking a secondary and objective opinion (Bhargava et al., 2013).

\subsubsection{Improvements in customer services}

This refers to how the vendor value and treat the clients. No client will want to do business with a vendor or company that is lacking business ethics and ethos (Jadhav \& Sonar, 2011).

Table 2.2 below depicts the list of non-technical factors and the variables of interest as per literature that is important to consider when selecting the software technology to employ.

Table 2.2: The Non-Technical Factors Affecting Selection of Software (Chau, 1995; Jadhav \& Sonar, 2009; Villamarín \& Diaz Pinzon, 2017).

\begin{tabular}{|l|l|}
\hline Non-Technical Construct & Non-Technical Factors \\
\hline Software Tool & $>$ Price \\
& $>$ Popularity \\
& $>$ Lifespan \\
& $>$ Version currently in the market \\
\hline Vendor & $>$ Reputation \\
& $>$ Business Skills \\
& $>$ References \\
& $>$ Past business experience with vendor \\
& $>$ Ethics and Integrity \\
& $>$ Professionalism \\
\hline Opinion & $>$ Subordinates \\
& $>$ End-users \\
& $>$ Outside acquaintances \\
& $>$ Improvement in customer service \\
\hline
\end{tabular}




\subsection{Empirical BI research in South Africa FSPs}

Some studies have been recorded in the field of BI in financial services organisations, these studies provide insights into the extent of South African BI use and its success (Dawson \& Van Belle, 2013). In their study, Dawson \& Van Belle (2013) put forward studies that looked at the $\mathrm{BI}$ research relating to the CSFs, $\mathrm{BI}$ adoption, $\mathrm{BI}$ benefits, and $\mathrm{BI}$ usage. What is noteworthy from these studies is that the BI field is still growing, and many financial organisations are embracing it, furthermore, there is still a lot of room for research that is needed to gear up organisations employing BI (Mudzana \& Kotze, 2015).

The early empirical study conducted by O'Brien and Kok (2006) for financial organisations, stipulates that large organisations still do not fully understand BI and its practices. In another recent study by Pellissier \& Kruger (2011) focusing on the insurance industry looking at the strategic use of BI, the results showed that FSPs lack BI awareness and use. Ponelis (2012) conducted a study focusing on SMMEs in the Gauteng province (RSA), the findings were that SMMEs struggle to meet BI CSFs.

These latter findings stress a point that more research is still needed in the field of BI pertaining to FSPs, hence the current study is necessary to be conducted to add to the body knowledge and existing research. Furthermore, based on the studies the researcher encountered, there are very few studies found that are looking at the factors influencing the selection of BI tools in the RSA context and developing countries for that matter. As it has been observed in the literature that the selection of BI tools is a challenge global, this is the case for developing countries due to issues that pertain to BI adoption, financial resources, and many unknowns in this field (Mudzana \& Kotze, 2015).

\subsection{Theoretical Framework}

The theoretical framework is defined as the group of related ideas which provide guidance to the research project or studied phenomenon and is responsible for introducing and describing the theory that explains the existence of research problem under study (Lederman \& Lederman, 2015). Multiple theoretical frameworks that speak to the selection of software technology were studied and gathered from the literature namely; the Organizing framework, Decision hierarchy for the component selection, Software Selection Framework for Big Data, The S.T.A.D.T 
Selection Framework (Bhargava et al., 2013; Jadhav \& Sonar, 2011; Lehmann et al., 2016; Liberatore \& Pollack-Johnson, 2003).

\subsubsection{Organizing framework}

The organizing framework used in the study seeking to identify critical factors influencing the selection of project management (PM) software and the framework, proved to be suitable for the then studied phenomenon (Liberatore \& Pollack-Johnson, 2003). The framework is depicted in Figure 2.5 below, based on the framework both environmental and intermediate factors showed to be influential in the outcome of PM software selection.

\section{Intermediate Factors}

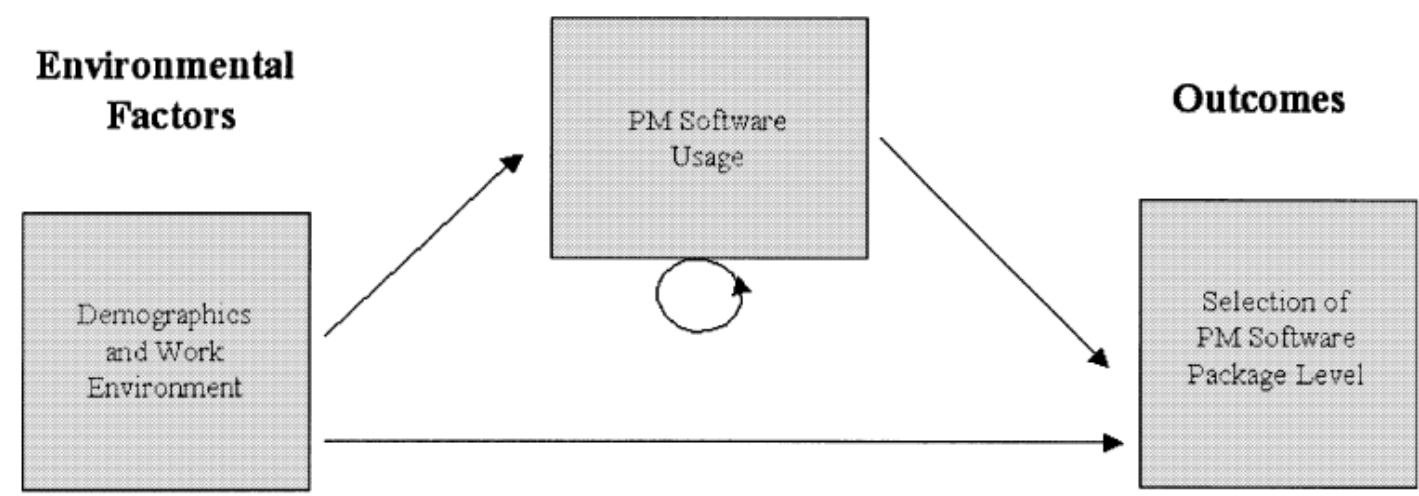

Figure 2.5. Organizing Framework (Liberatore \& Pollack-Johnson, 2003).

The components in Figure 2.5 are described by the researchers as follows:

- Environmental factors, Demographics, and work environment which includes factors like organisation size, years of experience in PM as a team member/leader, Percentage of work effort in PM, number of activities in the project.

- Intermediate factors, PM Software Usage focuses on software use category (planning only or planning and control), the initial year of using PM software, and several projects worked on using PM software.

- Outcomes, Selection of PM software package level considers the level (high-low end) based on respondents who frequently used the tool before the study. 


\subsubsection{The Decision hierarchy for the selection of component}

The decision hierarchy for the selection of components is depicted in Figure 2.6 below which was used and proposed by Jadhav \& Sonar (2011) in a study addressing the issue of software evaluation and selection of packages. According to Jadhav \& Sonar (2011) the decision hierarchy consists of three levels prior to reaching the outcome/goal (software to select) which are: alternative of software available to choose from, sub-criteria to use for shortlisting, and criteria. The highest level represents the goal which is the selection of the software to use and is said to be the best and suitable component to select, the second level represents the criteria mainly focused on technical aspect or factors which the software to be chosen must suffice as per the ISO/IEC 9126 which focus on the functionality, reliability, efficiency, and maintainability of the software. The third level represents the criteria which are the breakdown of the second level criteria therefore it provides the detail of each ISO/IEC 9126 factor provided by the criteria level. The last level represents the components to be evaluated or selected.

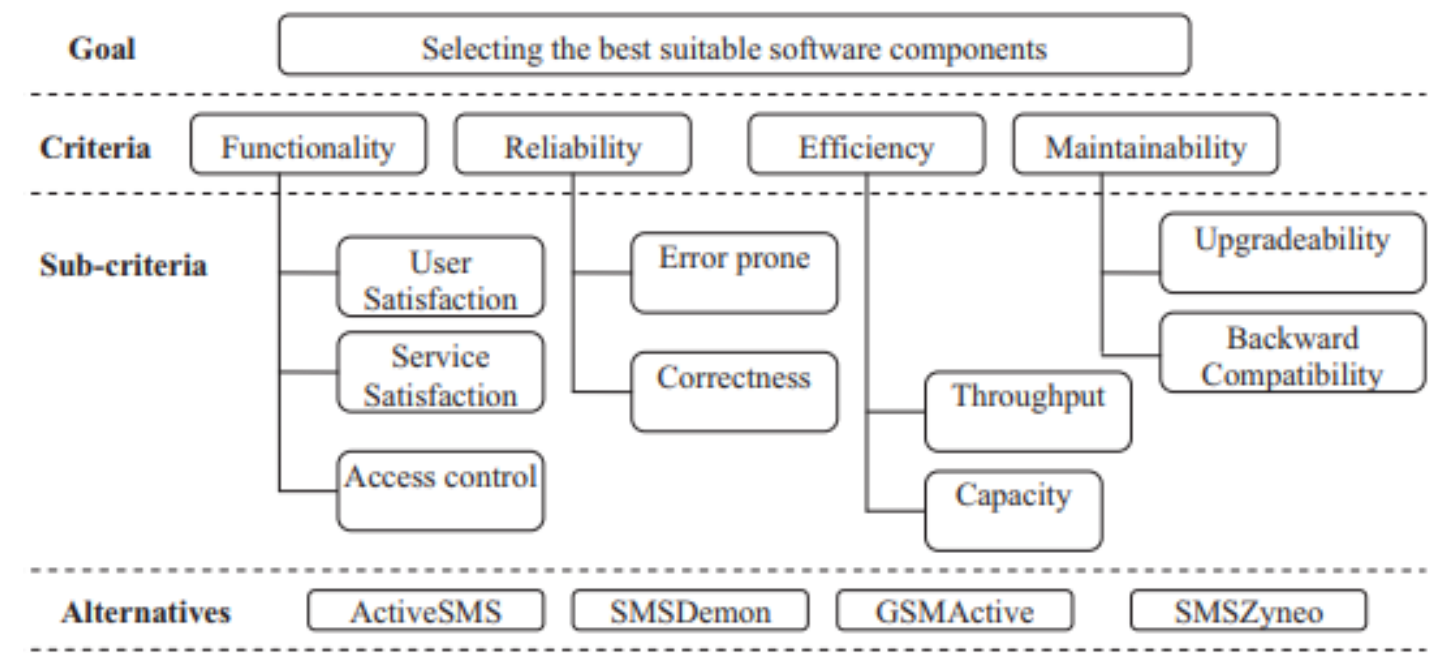

Figure 2.6: The Decision hierarchy for the component selection (Jadhav \& Sonar, 2011).

\subsubsection{Software Selection Framework for Data Mining}

The software selection framework for data mining was used by Bhargava et al. (2013) which addressed the issue of data mining software selection described as a complex and a taxing process. The framework is depicted in Figure 2.7 below, according to Bhargava et al. (2013) any software package selection depends on various factors and they posit that all the factors are interrelated namely software performance, functionality, auxiliary task, and hardware and software requirements of the software package. Vendor responsibilities and quality/ability of software packages are proposed to handle data discrepancies. The factors on the framework 
must be considered for software selection and these factors relate to both technical and nontechnical aspects of the software or tool.

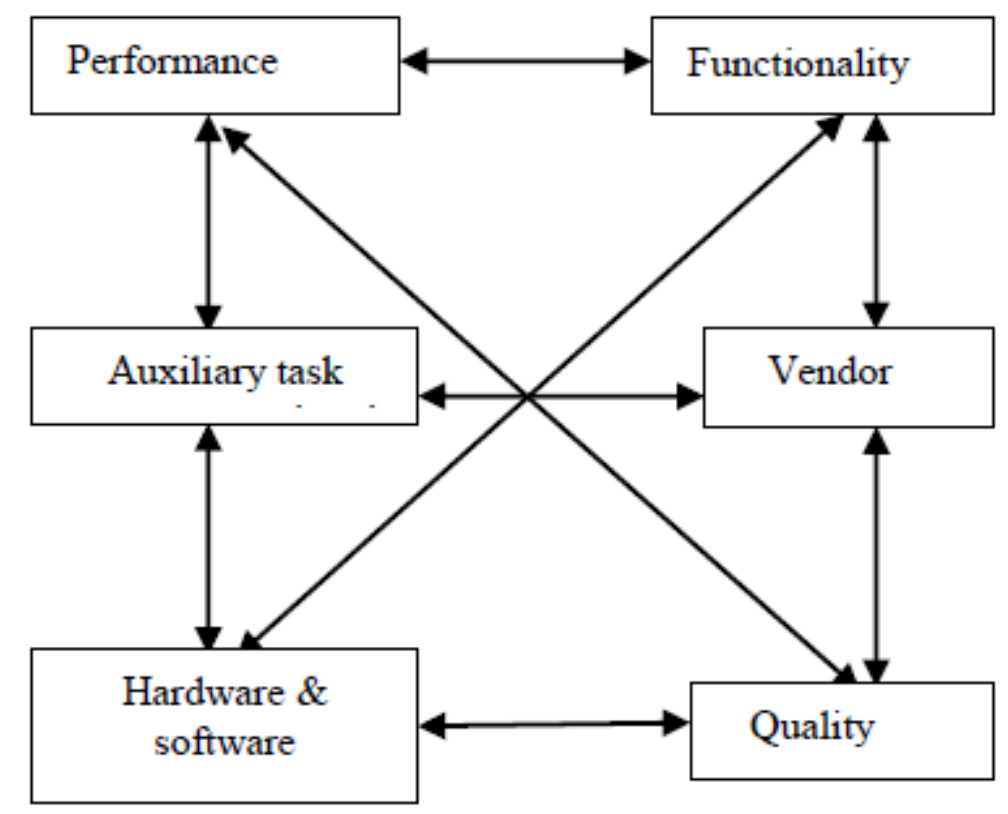

Figure 2.7: Software Selection Framework for Data Mining (Bhargava et al., 2013).

\subsubsection{The S.T.A.D.T Selection Framework}

The S.T.A.D.T. Selection Framework (SSF) was proposed by Lehmann et al. (2016) which aims at guiding technology selection in the era of Big Data. Its main objective is to find all valid solutions for big data use cases. SSF is said to be based on a layered reference framework that seeks to map technologies into different service layers to guide the selection of suitable technology. It also seeks to inherit big data technologies at different service layers e.g., acquisition, storage, analytics, and storage. Figure 2.8 and Figure 2.9 below depict both the layered reference framework and SSF framework. 


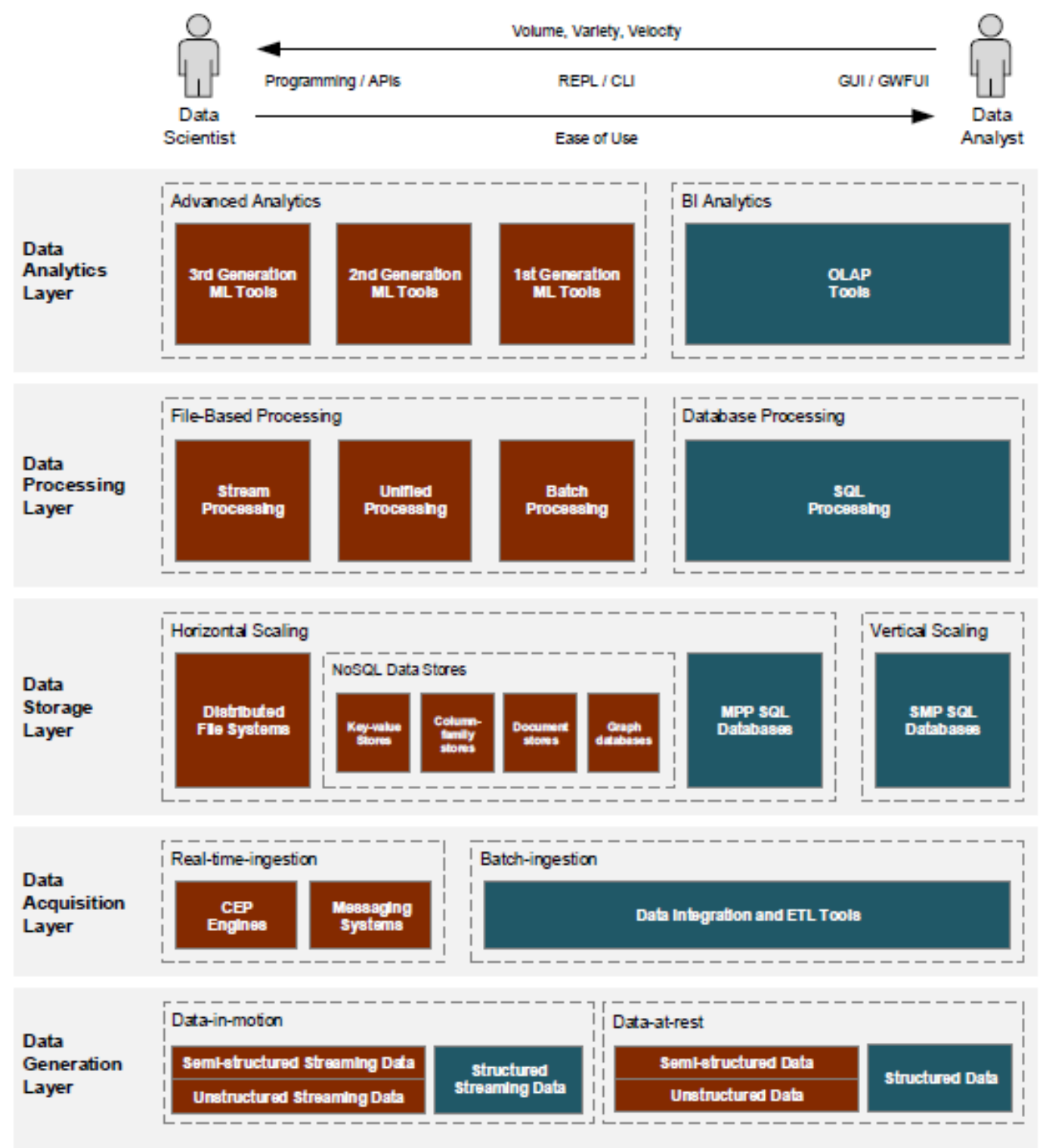

Figure 2.8: Layered Reference Framework (Lehmann et al., 2016).

- Data Generation Layer

The data generation layer is concerned with different data sources types (Lehmann et al., 2016). The main distinguishing dimensions are velocity (data-in-motion vs data-at-rest) and variety (structured, semi-structured, unstructured data). Data-in-motion summarizes data which is known as streaming data and constantly generated at low and high velocities. Examples of such data include very high frequency financial and transactional data. Data-at-rest is all types of historic generated data and needs to be stored prior to data analysis. Based on the layered reference framework the distinction between data in motion and data at rest drive and influence the technology selection. The velocity of data has an impact on the selection of suitable software because of how data is generated and analysed latency. 
- Data Acquisition Layer

This layer deals with technologies responsible for the ingestion of data from different sources and formats (Lehmann et al., 2016). The distinguishing dimension is velocity, whether it is real-time or batch ingestion. Batch ingestion is formally known to use Extract-Transform-Load (ETL) or Extract-Load-Transform (ELT) process which many tools offer in a single stack. For real-time data, prior to any storage of data it is processed. The main reason data is processed before storage is the data volume of real-time data.

- Data Storage Layer

This layer deals with technologies capable of persistent data storage and the velocity of data. The variety is the distinguishing factor.

- Data Processing Layer

This layer is responsible for all data operations responsible for reading, write, and delete data execution. The main differentiator is the velocity and variety, the variety determines whether a database or file system is required for processing.

- Data Analytics Layer

This layer comprises technologies for the value generating process, such technologies deal with finding uncovered hidden patterns and correlations to improve decision making. There are two distinguishing dimensions of data analytics: type of data analytics and the generation of machine learning. 


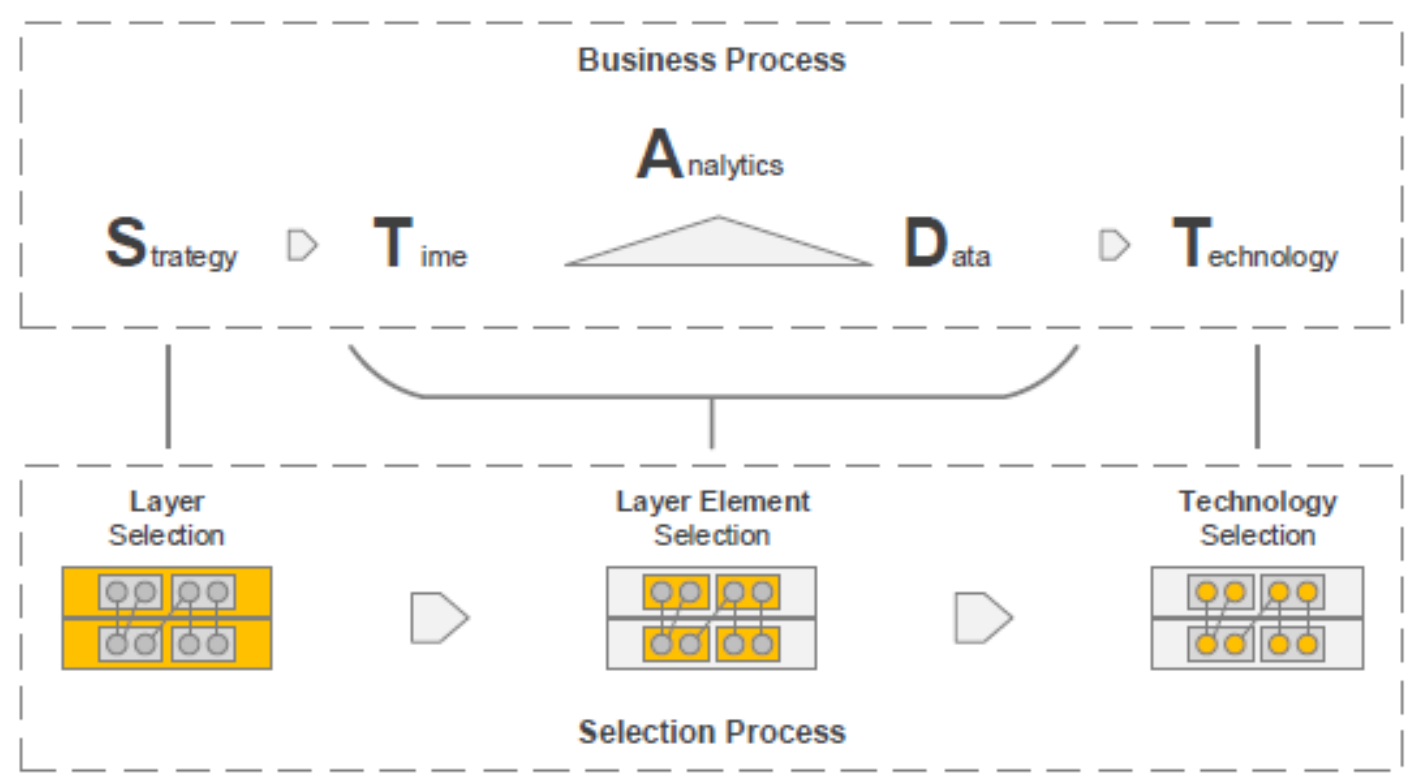

Figure 2.9: The S.T.A.D.T Selection Framework (Lehmann et al., 2016)

The SSF is a building block of layered reference framework presented in the section above. It consists of two parts: business process and selection process. The overview of the framework is depicted in Figure 2.9 above. The business process is based on SMART model which is used as a guide on how to transform and evolve towards a big data-driven smart organisation. SSF aims at the selection of technology and not at business transformation, therefore it renames the MARR process steps to strategy, time, analytics, data, and technology (Lehmann et al., 2016).

The business process of SSF can be used as a roadmap for organisations embarking on technology selection for their use case. The process starts with organisational overall strategy meaning organisation goals and objectives. Depending on the strategy indicators and measures of data input, appropriate analytics, and required response times are derived. These timelines are used to select suitable storage systems, analytics tools, and processing engines. Finally, suitable technology is selected based on the input use case (Lehmann et al., 2016). It is noteworthy that all the steps in the business process have implications on the technology selection for an organisation. 


\subsection{Conceptual Model}

A conceptual framework is an understanding of how the research problem will be explored, the specific direction the research will undergo, and the relationship between the different variables in the study (Grant \& Osanloo, 2014). Based on the literature and theoretical framework for software selection in packaged software, project management, and data mining (Bhargava et al., 2013; Jadhav \& Sonar, 2011; Liberatore \& Pollack-Johnson, 2003), the conceptual model has emerged and is depicted in Figure 2.10 below that will help to guide the deeper analysis of the study. To develop the below conceptual model, the researcher employed important concepts from thoroughly studied literature and theoretical frameworks that closely relate to the studied phenomenon. The significant constructs that emerged were software tool, vendor, and opinion that are classified into technical and non- technical domain. Furthermore, there is no BI study found in the literature proving to use these constructs.

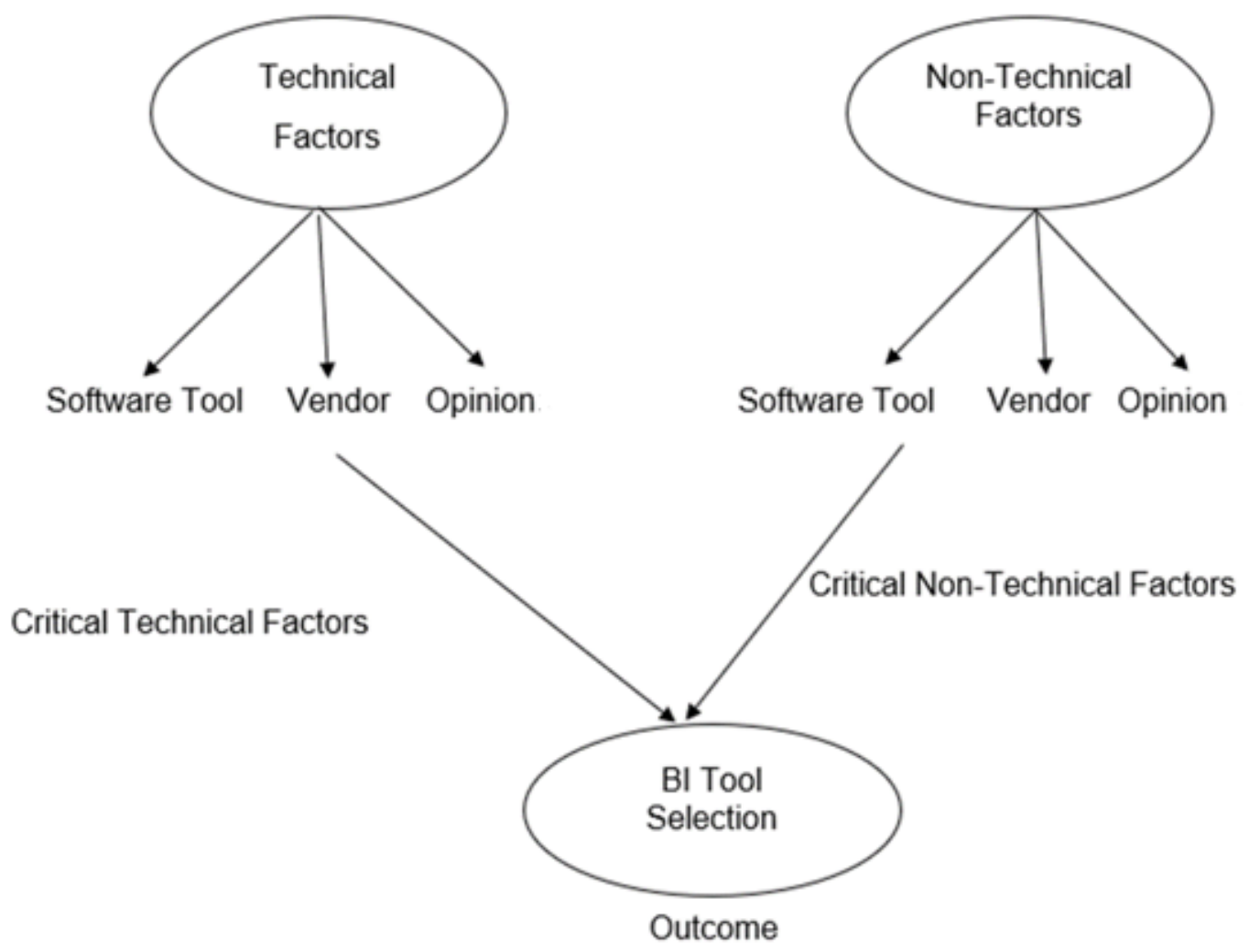

Figure 2.10: Conceptual Model for Business Intelligence Tools Selection

The conceptual model guided the researcher towards the development of the research objectives which allowed the researcher to explore the different aspects of BI tools selection. 
Furthermore, concepts from the model were selected to assist in the development of the data collection instrument i.e., the questionnaire.

\subsubsection{Variables of Interest and Constructs}

The two types of variables that emerged from studied literature are dependent and independent variables. The independent variable is defined as a variable with a strong and contingency effect on the studied phenomenon (Flannelly et al., 2014). The technical and non-technical factors emerged as independent variables to be measured utilizing the software tool, vendor, and opinion constructs. The technical and non-technical factors variables together with their associated constructs assist us in identifying the critical factors that are said to have a strong contingency effect in the BI tool's selection process and outcome. The dependent variable is referred to as the variable being analysed, studied, and of interest (Flannelly et al., 2014). In this instance, the BI tools selection is thus a dependent variable. However, in selecting BI tools, considerations of the critical factors are of paramount importance.

\subsubsection{Software Tool Construct}

The software tool construct refers to a set of technologies, practices, and applications used for the extraction, transformation, analysis, and presentation of organisational information to achieve sound planning, reporting, and insights (Chen et al., 2012). The software tool construct consists of technical and non-technical factors. The technical factors for the software tool are listed in Table 2.1 above (not limited to the list) on page 19, these factors are argued by researchers in different studies to be the determinants for the selection of software tools (Chau, 1995; Jadhav \& Sonar, 2009; Villamarín \& Diaz Pinzon, 2017). According to Bhargava et al. (2013) any software tool selection depends on several factors that need extensive consideration, these factors are said to be technical and non-technical. The most prominent software tool technical factors that appeared in most articles are functionality, ease of use, reliability, maintenance, and efficiency of the software tool. Some literature highlights the significance of paying attention to the technical aspects of the software which speaks to the underlying code set and availability of source code (Chau, 1995). Farrokhi \& Pokoradi (2013) in their study deem functionality, reliability, usability, and maintainability as the key attributes leading to the optimal performance of the software without experiencing any technical issues. Therefore, the researcher hypothesises the following: 
H1: "Software tool technical factors influence the selection of BI tools"

H0: "Software tool technical factors do not influence the selection of BI tools"

On the other hand, the most extensively discussed non-technical factors for the software tool is the cost and price, many studies stress that the adoption of BI tools are costly, expensive, and exorbitant nevertheless their return on investment is valuable (Alireza \& Seyedeh, 2015). Furthermore, Farrokhi \& Pokoradi (2013) in their study found that price, and popularity are critical non-technical factors not to be overlooked. The issue of software cost tends to attract different views, in a study conducted by Chau (1995), the SMMEs owners did not rate software price as significant whereas, the mangers highly rated the software price. Büyüközkan et al. (2018) posit that software tool non-technical factors consists of multiple measurable attributes that need to be considered, namely: licensing, hardware and software, installation, maintenance, training, upgrading, and direct and indirect cost. Other software tool nontechnical factors that emerged from literature are software lifespan, and version of the software currently in the market (Bhargava et al., 2013; Jadhav \& Sonar, 2011). Therefore, the researcher hypothesises the following:

H4: "Software tool non-technical factors influence the selection of BI tools"
H0: "software tool non-technical factors do not influence the selection of BI tools"

\subsubsection{Vendor Construct}

The vendor construct component refers to the custodian, external companies, and consultants responsible for providing BI services (Stříteský, 2017). The market is flooded with multiple vendors offering and providing BI platforms and products designed to solve organisational problems (Ferland \& Flachbarth, 2018). BI vendors play an important role in the selection of software since are viewed as experts and specialists of BI products (Chhina, 2016). The literature suggests that organisations generally lack in-house experts and rely on the vendor for technical support (Alireza \& Seyedeh, 2015). In a study conducted by Chau (1995), the findings showed organisation owners and managers rated vendor support as of the highest importance. Furthermore, Chau (1995) stress importance of gaining information regarding the vendor and experience of using the product developed by the same vendor. Therefore, the vendor is required to possess a high level of technical and non-technical expertise. The 
technical factors for the vendor include technical support, technical skills, and user training \& experience (Bhargava et al., 2013). The non-technical factors characteristics are measured by business skills, reputation, references, and past business experience with the vendor (Chau, 1995; Jadhav \& Sonar, 2009; Villamarín \& Diaz Pinzon, 2017). The list of vendor technical and non-technical factors is in Table 2.1 and Table 2.2 above on pages 19 and 21, respectively. Therefore, the researcher hypothesises the following:

H2: "Vendor technical factors influence the selection of BI tools"

H0: "Vendor technical factors do not influence the selection of BI tools"

H5: "Vendor non-technical factors influence the selection of BI tools"

H0: "Vendor non-technical factors do not influence the selection of BI tools"

\subsubsection{Opinion Construct}

The opinion refers to the perceptions and views from BI fraternity and management regarding the BI tool to employ (Chau, 1995). What the professionals and decision-makers think of the tool or hear from peers may influence the choice of tool to employ (Jadhav \& Sonar, 2011). Opinion has emerged in the literature as one of the crucial constructs to be considered during the selection process. According to Chau (1995), opinion technical factors that relate to in-house experts, external consultants, and potential vendors need to be given equal importance. Even though technical information that can be found in software products leaflets and magazines is rated high in some studies, to an extent prove to be least important (Chau, 1995). According to Chau (1995), other than seeking opinions/views from technical experts and organisational consultants, seeking perceptions from end-users, subordinates, and outside personal acquaintances is paramount. The full list of opinion technical and non-technical factors is on Table 2.1 and Table 2.2 on page 19 and 21, respectively. Therefore, the researcher hypothesises the following:

H3: "Opinion technical factors influence the selection of BI tools"

H0: "Opinion technical factors do not influence the selection of BI tools"

H6: "Opinion non-technical factors influence the selection of BI tools"

H0: "Opinion non-technical factors do not influence the selection of BI tools" 


\subsection{Hypotheses}

After exploring the literature that focused on the selection of software in different software selection environments and the conceptual model in Figure 2.9 on page 29 above, the summary of hypotheses posed are shown in Table 2.3 below with the list of references it was derived from. These hypotheses emerged in previous studies and theories that regard software tool, vendor, and opinion constructs as vital, the constructs are classified into technical and nontechnical domain factors.

Table 2.3: List of hypotheses against references

\begin{tabular}{|c|l|}
\hline Hypotheses & \multicolumn{1}{|c|}{ List of References } \\
\hline H1 & $\begin{array}{l}\text { (Bhargava et al., 2013; Chau, 1995; Chen et al., } \\
\text { 2012; Jadhav \& Sonar, 2009; Farrokhi \& Pokoradi, } \\
\text { 2013; Villamarín \& Diaz Pinzon, 2017) }\end{array}$ \\
\hline H2 & $\begin{array}{l}\text { (Bhargava et al., 2013; Chau, 1995; Chhina, 2016; } \\
\text { Ferland \& Flachbarth, 2018; Stř́teský, 2017) }\end{array}$ \\
\hline H3 & $\begin{array}{l}\text { (Bhargava et al., 2013; Chau, 1995; Jadhav \& } \\
\text { Sonar, 2009, 2011) }\end{array}$ \\
\hline H4 & $\begin{array}{l}\text { Alireza \& Seyedeh, 2015; Bhargava et al., 2013; } \\
\text { Büyüközkan et al., 2018;Chau, 1995; Farrokhi \& } \\
\text { Pokoradi, 2013; Jadhav \& Sonar, 2011) }\end{array}$ \\
\hline H5 & $\begin{array}{l}\text { (Bhargava et al., 2013; Chau, 1995; Jadhav \& } \\
\text { Sonar, 2009) }\end{array}$ \\
\hline H6 & $\begin{array}{l}\text { Bhargava et al., 2013; Chau, 1995; Jadhav \& } \\
\text { Sonar, 2009, 2011) }\end{array}$ \\
\hline
\end{tabular}

H1: "Software tool technical factors influence the selection of BI tools"

H0: "Software tool technical factors do not influence the selection of BI tools"

H2: "Vendor technical factors influence the selection of BI tools"

H0: "Vendor technical factors do not influence the selection of BI tools"

H3: "Opinion technical factors influence the selection of BI tools"

H0: "Opinion technical factors do not influence the selection of BI tools" 
H4: "Software tool non-technical factors influence the selection of BI tools"

H0: "software tool non-technical factors do not influence the selection of BI tools"

H5: "Vendor non-technical factors influence the selection of BI tools"

H0: "Vendor non-technical factors do not influence the selection of BI tools"

H6: "Opinion non-technical factors influence the selection of BI tools"

H0: "Opinion non-technical factors do not influence the selection of BI tools"

\subsection{Summary of Chapter}

It is evident from the studied literature that factors influencing the selection of BI tools must be discovered, understood, and considered by the organisations to select appropriate tools for successful BI solutions. Technical and non- technical factors relating to the software tool construct need to be discovered to help organisations to employ correct tools and reap the benefits BI offers. Vendor emerged as an important construct in the process of software selection hence both technical and non-technical factors relating to the vendor need to be discovered and lastly, opinion plays a vital role during the process of software selection and literature showed that it must not be overlooked. The number of literature studies discovered, highlights the key point that organisations need to understand and know the factors influencing the choice of tool to use, therefore it is vital to study the factors influencing BI tools selection. Based on the studied literature, the list of hypotheses was derived, and these hypotheses were tested to answer the study questions concerning the factors influencing the selection of BI tools. 


\section{CHAPTER THREE: RESEARCH METHODOLOGY}

\subsection{Introduction}

Research methodology is defined as a systematic way of solving a research problem and the study of methods concerned with how knowledge is gained (Saunders et al., 2016). Many researchers define research methodology as the science of studying how research is going to be conducted (Bhattacherjee, 2012). It entails and details procedures by which the researcher goes about explaining, describing, and predicting the phenomenon of their work. The main objective of the research methodology is to plan the research and how to go about conducting it; therefore, this section will be explaining and giving the template of how this research was conducted to achieve the following objectives:

- To discover and get new facts about the study;

- To test and verify crucial facts;

- To find solutions to the problem.

The process which was followed to conduct the study is explained under the following subsections: research design, ontology and epistemology, the target population, sample size and sampling strategy, research instrument, pilot study, validity and reliability of the instrument, data collection, data analysis technique, ethics and confidentiality, and the study timeline.

\subsection{Research Design}

The research design is defined as the structure of the research and a blueprint for data collection and analysis (Saunders et al., 2016). Another definition of research design widely used is the arrangements of data collection and analysis that aims to combine relevance in the research objective. This is a quantitative research design; the results will be generalized for the entire population. Quantitative research is based on mathematical measurements of amount or quantity, it relies on measuring variables using a numerical system (Walliman, 2017). This study adopted a descriptive survey research approach which is concerned with obtaining precise and pertinent information regarding the state of a phenomenon, and moreover, to draw valid conclusions from the facts gathered and discovered (Amuhaya, 2013). This study aimed at discovering critical factors that influence and drive the selection of BI tools in financial services providers (FSPs) in the South African (RSA) setting. 


\subsection{Ontology and Epistemology}

Prior to clarifying the type of ontology used in the study, it is vital to define the term ontology. Ontology is defined as "the study of being" concerned with "what kind of world we are investigating, with the nature of existence, with the structure of reality as such" (Ahmed, 2008). According to Edirisingha (2012), ontological assumptions are those that respond to the following questions: what is there that can be known? Or what is the nature of reality? Ontologies are created to serve multiple goals and purposes, including support for more effective retrieval of data and for different sorts of reasoning.

Positivist ontology was employed in the present study. Positivist ontology believes that the world is external and that there is a single objective truth and reality to any research phenomenon (Edirisingha, 2012). Positivist ontology has been employed since the focus is on observable data as per Walliman (2017), and the knowledge required can be gathered from individuals who have personal experience of the studied phenomenon and the source of knowledge resides with the respondents. It is assumed that knowledge already exists and appropriate instruments are required to extract and interpret it (Hanson, 2012).

Another crucial factor is that respondents' views and opinions regarding the factors influencing the choice of a software tool to employ can be quantified and generalized. It was assumed that sampled individuals' thoughts and views regarding the studied phenomenon are real and not simply social constructs. In undertaking the study, the researcher remained detached from the participants by creating a distance (no face-to-face or in person communication with respondents), which is crucial for remaining neutral and not having an influence on respondents' views about the studied phenomenon. Lastly, since this is a quantitative study, positivist philosophy is mandatory (Walliman, 2017).

On the other hand, epistemology is concerned with deciding what knowledge is regarded as being valid and appropriate within our reality (Edirisingha, 2012). Questions that arise are: What are its sources? What is its structure, and what are its limits? How can we use our reason and other resources to acquire knowledge? Therefore, objectivist epistemology was employed which assumes that knowledge exists independently of the individual mind and that objectivist research is useful in providing reliability, consistency of results, and external validity. The 
objectivist position is said to emphasize the logical construction of theories based on empirical facts (Feast \& Melles, 2010).

Since this study is grounded in positivist ontology, objective reality is assumed and can be acquired when appropriate methods are applied in a correct manner. The researcher intended to be independent of the study and not have any influence on the respondent's views. This ensured that issues of bias were minimised since the role the researcher played was data collection and interpretation of the results (Hanson, 2012). This is in conformity with objectivist position requirements.

\subsection{Research Purpose}

The purpose of the study was to discover and explore the critical factors influencing the selection of BI tools in South African FSPs. Given the nature of the research problem and questions to be answered, the study adopted an exploratory approach which involves investigating and exploring the factors that influence the selection of BI tools/software (Moody et al., 2010).

\subsection{The Target Population}

The population is defined as a group of items, individuals, or objects from which target samples are drawn for measurement (Saunders et al., 2016). It represents the entire group of elements that have something in common. Bhattacharjee (2012) defines a population as a set of individuals, objects, or cases with one or more observable characteristics. The study focused on all BI professionals working in RSA FSPs listed on the Johannesburg Stock Exchange (JSE) regardless of the job title, position, and level of experience in the field. Financial services are referred to as organisations that deal with the management of funds or money e.g. banks, investment companies, insurance companies, and stock brokerages (Curry, 2016).

BI systems' adoption for listed companies and financial services institutions has been observed to be very high due to mandatory and timely reporting required for listed organisations (Bach et al., 2016). Apart from timeous reporting, complex business processes, and fight to gain competitive advantage dictates for such systems to be employed (Moreno Saavedra \& Bach, 2017). To determine the target population, the researcher followed the following process: the number of JSE listed companies is 388 of which financial services organisations constitute 
$34 \%$ plus (+-132 organisations in number) as per the JSE website and 2018 year end results (JSE, 2019). According to Negash \& Gray (2008) there is a minimum of five (5) roles for a fully flashed and core BI team. Therefore, 660 workforces serve as the population for the study that is gathered through the product of $5 \mathrm{BI}$ roles and 132 financial services companies listed on the JSE from a total of 388. It is important to study the RSA setting since many success stories in the field of BI are drawn from developed European countries as per Mudzana \& Maharaj (2015) and since RSA is a developing country, the study results can be generalized for all developing countries (Avgerou, 2008; Hartley \& Seymour, 2011).

\subsection{Sample Size and Sampling Strategy}

A sample is defined as a smaller group gathered from the accessible population (Bhattacherjee, 2012); it is a representative group for the whole population that is enabled to gather knowledge from the population (Saunders et al., 2016). According to Saunders \& Lewis (2016), sampling is referred to as the procedure to gather things to study, people, and places. It is the procedure to be followed when selecting several individuals and objects from the entire population such that the selected group is the representative of the characteristics found on the entire population. For this study, the data was collected using snowball sampling methods to reach a representative and even wider sample to generalize the results. Snowball sampling is defined as where research participants recruit and nominate other participants that meet the research criteria (Valerio et al., 2016). Snowball sampling proved to be effective since the researcher relied on individuals known to him to further distribute the surveys to acquaintances within respondents reach and meeting research criteria (Bhattacherjee, 2012). It was imperative to adopt snowball sampling since the BI profession is still new and a growing field in RSA as to reach subjects which might have been difficult to gather (Dawson \& Van Belle, 2013).

To determine the final sample to be used in the study, the researcher focused only on the financial services organisations listed on the JSE top 100 based on the market capitalization (cap). Market cap is the value of the listed organisation which is calculated by multiplying the share price by the number shares e.g. the product of 10 share price and 1000 shares gives 10000 market cap. Financially healthy and viable organisations were targeted since it is common for them to adopt and implement BI solutions (Bach et al., 2016). A total number of 23 financial services organisations are listed in the top 100 and its list is attached in APPENDIX A: Financial

\section{Services Providers.}


Two methods were used to determine the sample size of the study, the first is the table by Krejcie \& Morgan (1970), which is used given the population. According to the table, a population of 10 requires a sample size of 10,100 require 80 while 130 require a sample size of 97 respondents; the table is depicted in Table 3.1 below on page 39. The second method used to identify the sample size was an online calculator used by Browner et al. (2007) that is responsible for determining the final sample size for accurate results and variables (total sample). This calculation had to be provided with input to give the final sample size at a $95 \%$ confidence level. Based on these methods a statistical representative sample is achieved hence reliable results are gathered (Browner et al., 2007; Krejcie \& Morgan, 1970).

Therefore, to arrive at the sample size the following procedure was followed: BI teams consist of five (5) roles within an organisation and JSE listed FSP organisations in the top 100 is 23 hence the product of BI roles and FSP organisations amount to 115 sample which was sufficient for the study. Based on Krejcie \& Morgan (1970) table, a sample of 115 give 89 subjects and for the online calculator it gives the same number (89). Both these strategies amount to relatively the same and most regularly accepted sample for a population of generalization studies. Additionally, for the RSA setting being studied these sample objects are sufficient given that RSA is a developing country and very few financial companies are in the market even though JSE is regarded as one of the top stock exchanges around the globe (Hartley \& Seymour, 2011; Pellissier \& Kruger, 2011).

Table 3.1: Table for Decisive Sample Size from a Specified Population N.

\begin{tabular}{|c|c|}
\hline$N$ & $S$ \\
\hline 10 & 10 \\
\hline 50 & 44 \\
\hline 100 & 80 \\
\hline 130 & 97 \\
\hline 150 & 108 \\
\hline 190 & 127 \\
\hline 200 & 132 \\
\hline 250 & 152 \\
\hline 1000000 & 384 \\
\hline
\end{tabular}

Note. $-N$-population. $S$-sample (Krejcie \& Morgan, 1970). 


\subsection{Research Instrument}

The study employed a questionnaire as a research instrument that entailed written items to which the respondents were asked to respond to individually in writing objectively. The questionnaire was driven by the objectives of the study and written in a form of statements. The questions were adapted from Amuhaya (2013), were prepared well and capable of being modified post the pretesting and pilot study where necessary. To ensure that the questionnaire collected the purported data for the studied phenomenon, it was informed by the developed conceptual model and literature that focused and explained each construct e.g. All the factors that explained software tool technical factors construct had a matching section and a question in the questionnaire. To ensure that the research instrument was reliable and valid, the instrument pretesting was conducted to ten (10) subjects of the target population to evaluate the reliability and validity of the questionnaire prior to the final distribution for data collection (Collins, 2003). The pre-test showed that the instrument was well structured, reliable, and valid. The individuals who participated in the pretesting process were not included in the final data collection.

The research tool was set to be open ended and closed. For this research study, the selfcompletion survey was used as the method for data collection since questionnaires can be used to identify variables domain and relationships between variables of interest (Amuhaya, 2013). Accordingly, this method is useful for descriptive and exploratory studies which are in line with the studied phenomenon (Ghauri et al., 2020). The use of Qualtrics survey software was utilized which is an online licensed software that is used to prepare the questions for real-time surveys (Qualtrics, 2014).

The survey questionnaire is divided into three sections. The first section of the questionnaire asks questions about respondents' demographic information e.g., gender, age, level of education, work experience, organisation type, and organisation size. It is important to capture demographic information to determine whether the respondent is a representative sample of the target population for the results of generalization purposes (Ghauri et al., 2020). The second section of the survey asks questions about technical factors of BI tools. The questions were displayed in a five -point Likert scale ranging from 1- strongly disagree to 5- strongly agree and open-ended questions as to gather more views and critical technical factors for the selection of software tool. Lastly, the third section of the survey asked questions about non-technical 
factors of BI tools, the questions were displayed in a five-point Likert scale ranging from 1strongly disagree to 5- strongly agree plus open-ended questions to gather more views on nontechnical factors deemed critical for the selection of software tools. The questionnaire comprised of 21 questions. The questionnaire survey is documented in APPENDIX C: Survey of Factors Driving the Selection of Business Intelligence Tools

\subsection{The Pilot Study}

A pilot study was conducted prior to the main study by surveying BI professionals working for JSE listed FSPs organisations appearing in the top 100 based on the market cap within the researcher's reach to test the data collection instrument (questionnaire). The survey took approximately 15-20 minutes to complete. The main reason to conduct the pilot study was to test discrepancies and misunderstood questions with the intention to fix the research instrument in accordance with the pilot study. The researcher sampled 15 respondents randomly and 11 respondents managed to return the survey, which was a $73 \%$ return rate and this return rate was deemed adequate for the pilot study (Amuhaya, 2013). The data collected from the pilot study was analysed and the findings were that respondents understood the questions in terms of terminology and language used. The instrument was deemed reliable and consistent to proceed with actual data collection since no changes were made to the data collection instrument (Saunders et al., 2016). Participants in the pilot study were not included in the main study.

\subsection{Validity and Reliability of the Instrument}

The validity of an instrument refers to the extent to which the chosen instrument measures what is purported to be measured (Saunders et al., 2016). To ensure the correctness of the results the validity construct testing was conducted by using the technology software called statistical package for social sciences (SPSS). The items that fail and not suffice to measure the variables intended to measure are either adjusted or discarded completely when necessary. The pilot study usually plays an important role in ensuring that the questions on the instrument either need to be modified or discarded completely prior to the actual data collection process. The questions were designed in conformity of the validity measures (Hancock, 2011).

Reliability is about measuring the degree to which a chosen instrument yields correct and consistent results after repeated and several study trials (Saunders et al., 2016). To test for the reliability of the research instrument, a pilot study was conducted in FSPs organisations within 
researcher's reach that are listed in the top 100 of the JSE list. To determine the reliability of the instruments, an internal consistency technique was used. To ensure error-free and reliability in the study, the Cronbach's Alpha was calculated and if the result is greater than 0.7 this implies there's consistency in the study, otherwise it will mean there is no consistency (Joseph F Hair et al., 2006). Therefore, for the study at hand, all the constructs proved to be reliable since the Cronbach's Alpha value was greater than 0.7, the results are shown in Table 4.12 and Table 4.13 on page 60 below.

\subsection{Data Collection}

Questionnaire and surveys were used for data collection and the research instruments (questionnaires/ surveys) were physically delivered to the respondents which were within researchers reach and the survey did not require any identifiable information from the respondents to ensure anonymity and confidentiality. For the Individuals who were not reached due to geographical distribution, the surveys were emailed and the researcher was cautious of the low return rate of emailed surveys (Ghauri et al., 2020). To reach even a wide and representative audience the researcher made use of online surveys and social media platforms like LinkedIn (platform geared for professionals) to locate potential respondents meeting the sampling criteria since it helps to increase voluntary participation in the study, and the ability to ensure confidentiality in the research (Kilinç \& Firat, 2017). The formulated data collection instrument was understandable to extract information from all respondents. The data collection commenced immediately after the pilot study was conducted and the research instrument deemed adequate and suitable. The data collection lasted for a period of three (3) months.

\subsection{Data Analysis Technique}

Data analysis is concerned with the interpretation of collected data from respondents into useful and sound information (Bhattacherjee, 2012). Data collected was analysed quantitatively. Quantitative data analysis is described as the means of using data which is in the form of numbers to investigate their properties. The quantitative data analysis considers inferences made from respondents' opinions and views (Amuhaya, 2013). The SPSS and SmartPLS3 free version were used for data analysis. The data was initially entered into a spreadsheet to easily ingest with the software tool and to make it easy for the analysis to take place. The computed data was analysed using descriptive statistics. Multiple statistics were conducted that included 
frequencies, means, and percentages. The main test conducted was the regression test to identify the factors that influence the selection of BI tools as to answer the research questions. The interpretation of results was done within the frame of reference of the research questions and problem statement.

\subsection{Ethics and Confidentiality}

Consideration of ethics both in research and business is of growing importance, therefore the researcher needs to understand the ethical research and how it can affect the study (Walliman, 2017). This is important in this research since it involves interaction with organisations employees as respondents. The ethical considerations in this study will be upheld as follows:

- Respondents given informed consent.

Respondents were given the opportunity to choose whether to participate in the study or not (nobody was forced to take part in the study), this is in line with the good practice of ethical research where respondents are asked to participate in the study voluntarily (Walliman, 2017). It was ensured that the respondents understand the research procedure and any risks associated with the study if any exists (Bhattacherjee, 2012). Respondents were informed of their rights before they participated in the study, especially the important one that the respondent can withdraw from the study at any given point. To achieve these, the researcher attached a cover letter explaining and detailing all the considerations, and respondents were asked to go through them prior to responding. The letter is attached in APPENDIX B: Letter of Introduction to

\section{Respondents.}

- No harm to the respondents

Respondents have a right to be told about any risks associated with the study before they participate, in this study, there is no harm and respondents had an opportunity to discontinue at any point (Walliman, 2017). The research application form in APPENDIX D: Research Ethics Application Approval which was submitted to the UCT ethics committee to get authorization to commence with data collection, the form details the reasons why the researcher needed to conduct the study and all the necessary attachments which include the questionnaire were supplied during the process. The APPENDIx E: Ethics Approval Letter is the ethics 
clearance form from UCT which serves as an official letter from the ethics department granting the researcher permission to collect data.

\subsection{Timeline}

This research used a Cross-sectional time frame because the data collection and research happened only once for a limited period.

\subsection{Summary of Chapter}

The research design for the study at hand detailed and outlined the skeleton on how the researcher intended to solve the research problem by answering the proposed questions under the above-discussed subtopics. This section described that the study at hand is the quantitative research design which employed snowball sampling as a sampling method, questionnaires as a data collection method, pilot testing was conducted to assess reliability and validity of data to ensure study success. Moreover, data analysis instruments and methods used were also highlighted. 


\section{CHAPTER FOUR- DATA ANALYSIS PRESENTATION AND INTERPRETATION}

\subsection{Introduction}

This section presents the findings of the analysed study data together with the interpretation. The themes which discussed the research questions are presented and analysed together. The section begins by presenting the demographic information (Section A of the survey instrument) of the respondents followed by presentations of both research sections of technical factors (Section B of the survey instrument) and non-technical factors (Section C of the survey instrument), and lastly the interpretation of findings based on research questions.

\subsection{Questionnaire Return Rate}

The completion rate is defined as the proportion of the sample that participated voluntarily in the study and as intended in all research procedures (Walliman, 2017). For the research at hand, a highly significant representative sample size was sampled and sufficed normally acceptable responses as per quantitative research studies (Krejcie \& Morgan, 1970). In totality, 103 respondents managed to return the survey of which 92 (sample size) respondents observed were finally used in the study after carefully eliminating outliers and individuals' responses who returned incomplete surveys (Saunders et al., 2016).

\subsection{Descriptive Analysis}

The demographic information of respondents, all BI professionals working in South African financial services listed on the JSE top 100 based on the market cap was based on seven (7) items viz: Gender, Age, Education level, Years of experience, Position, Organisation type, and Organisation size. The demographic information is presented in this section.

\subsubsection{Distribution of Respondents by Gender}

BI professionals were asked to indicate their gender, the data is presented in Table 4.1 below. Data on the gender indicated that $65(70.7 \%)$ were male while $27(29.3 \%)$ were female and this implies a greater proportion of males participated in the study than females. The gender distribution, however, is deemed satisfactory given that the IT profession in RSA and worldwide is mostly dominated by males (Pretorius et al., 2015). 
Table 4.1: Gender of Business Intelligence Professionals

\begin{tabular}{lll|l|l|}
\multicolumn{1}{c}{} & & Frequency & Percent & Valid Percent \\
\hline \multirow{2}{*}{ Valid } & Female & 27 & 29.3 & 29.3 \\
\cline { 2 - 5 } & Male & 65 & 70.7 & 70.7 \\
\cline { 2 - 5 } & Total & 92 & 100.0 & 100.0 \\
\hline
\end{tabular}

\subsubsection{Distribution of Respondents by Age}

The age group between 25-34 years participated mostly in the study with a recorded $56.52 \%$ participation rate followed by 35-44 years with a recorded rate of 29.35\%,45-54 years $9.78 \%, 18-24$ years $3.26 \%$, and lastly $1.09 \%$ for individuals above 55 years. Figure 4.1 below shows the distribution of respondent's age.

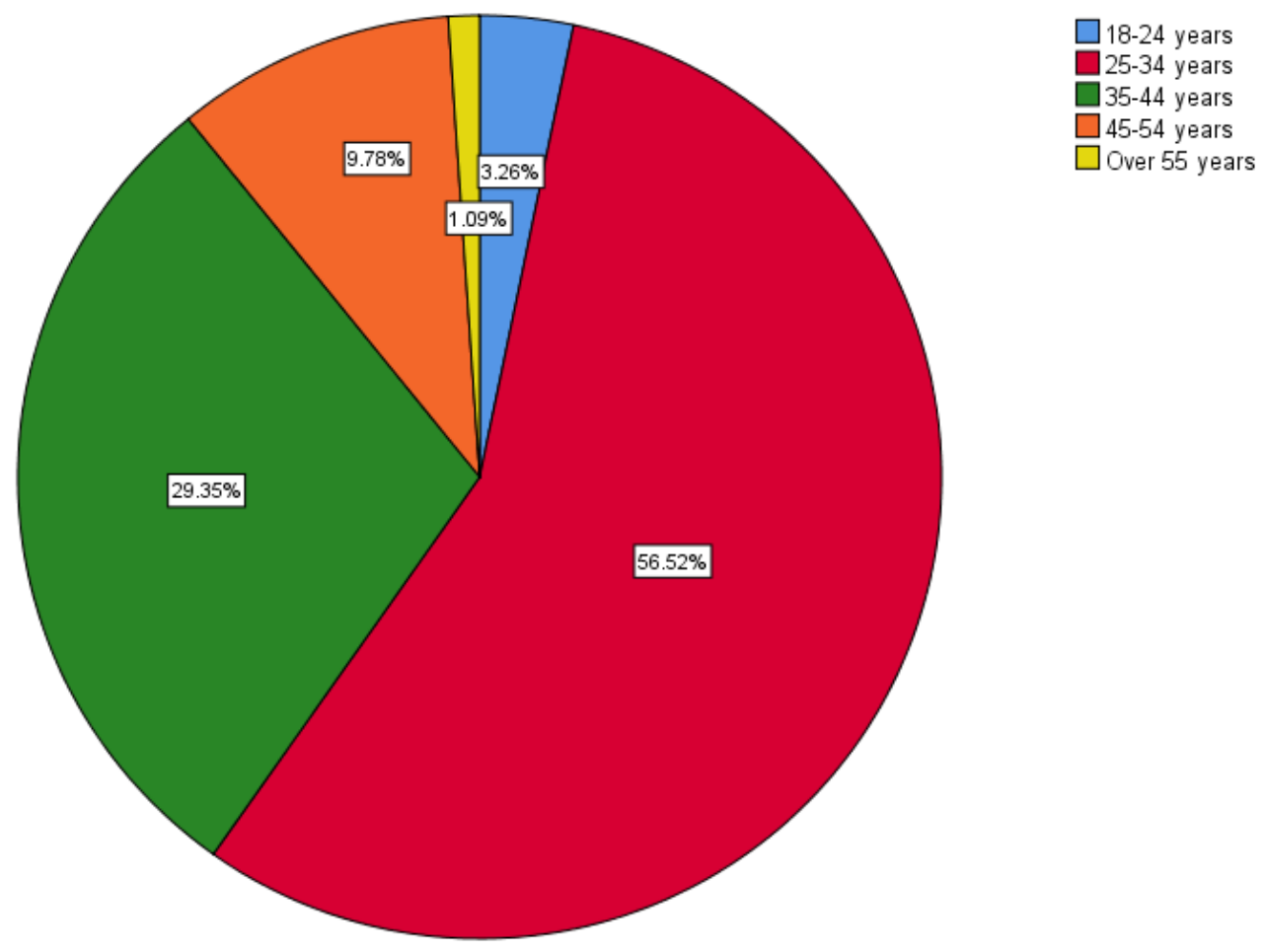

Figure 4.1: Age Groups of Business Intelligence Professionals

\subsubsection{Distribution of Respondents by Level of Education}

The BI professionals were asked to indicate their academic level and the data is presented in

Table 4.2 below. The findings indicated that most BI professionals hold an Honours degree comprising of 32 respondents (34.8\%) followed by bachelor's degrees 30 (32.6\%), Diploma 21 (22.8\%), Master's Degree 7 (7.6\%), and $\mathrm{PhD}$ recorded the lowest value of $2(2.2 \%)$ 
respondents. These findings show that BI professionals are highly qualified, and this infers that they are adequately informed to answer the questions presented in the survey (Amuhaya, 2013).

Table 4.2: Distribution of Business Intelligence Education Level

\begin{tabular}{lll|l|} 
& & Frequency & Percent \\
\hline Valid & Honours Degree & 32 & 34.8 \\
\cline { 2 - 4 } & Bachelor's Degree & 30 & 32.6 \\
\cline { 2 - 4 } Diploma & 21 & 22.8 \\
\cline { 2 - 4 } & Master's Degree & 7 & 7.6 \\
\cline { 2 - 3 } PhD & 2 & 2.2 \\
\cline { 2 - 3 } Total & 92 & 100.0 \\
\hline
\end{tabular}

\subsubsection{Distribution of Responses by years of Experience}

BI professionals were asked to indicate the years of experience in their respective positions. The data findings are shown in Figure 4.2. The indication is that BI professionals experience is $32.61 \%$ for $6-10$ years category which is the highest represented group, followed by 1-5 years category with $29.35 \%, 23.91 \%$ for a group over 16 years of experience, and lastly $14.13 \%$ for 11-15 years group. The findings imply that all groups of BI professionals from junior to senior participated in the study and their views were captured hence information provided is reliable and accurate. 


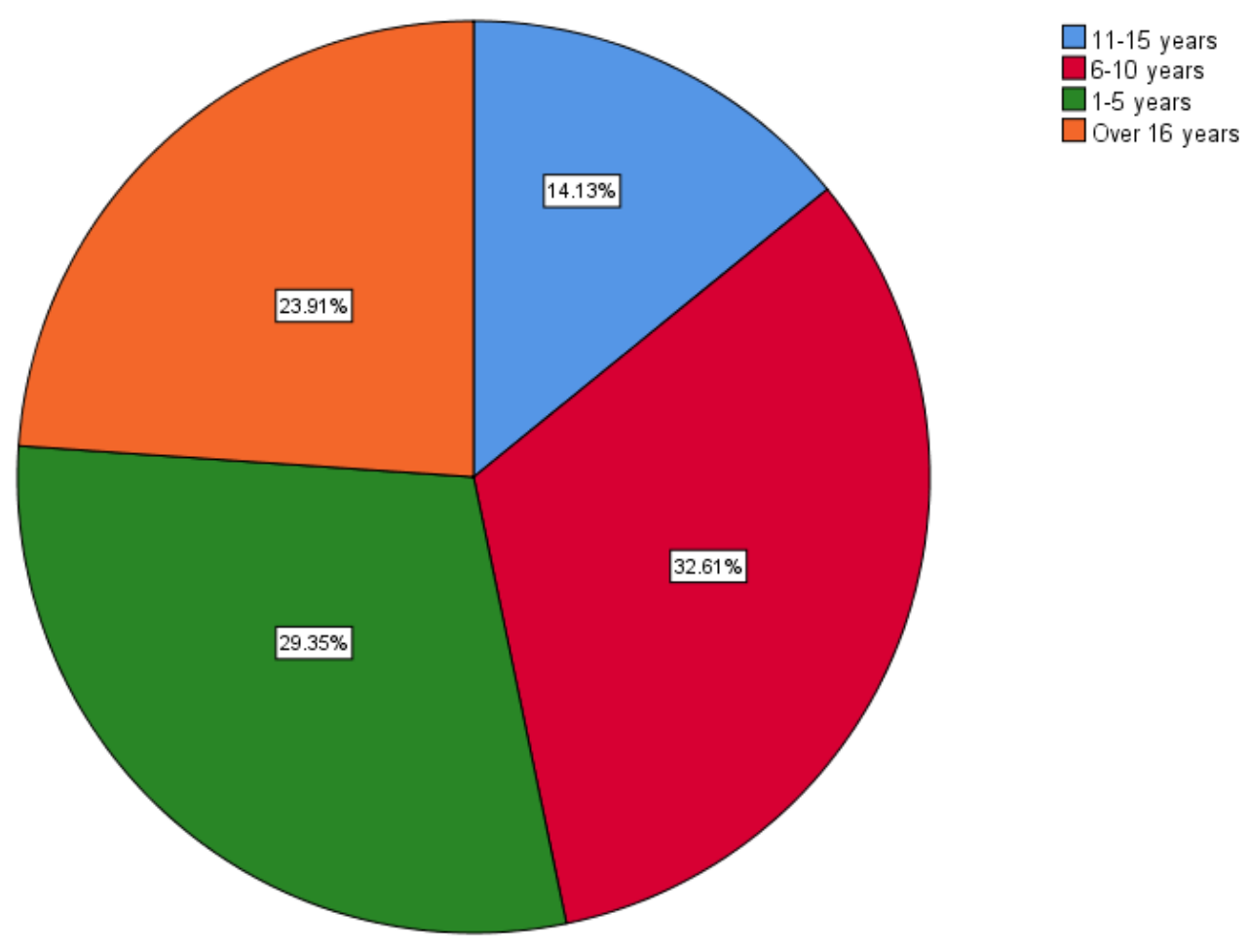

Figure 4.2: Distribution of Business Intelligence Responses on years of experience.

\subsubsection{Distribution of Responses by Job Position}

BI professionals were asked to indicate the position they are currently holding in their respective organisations. The data findings are shown in Table 4.3 below. The indication is that BI professionals who responded are mostly BI developers with $26.1 \%$ followed by BI Analyst with $17.4 \%$ representation. A combined $30.5 \%$ of organisations managerial hierarchy is represented in the study based on different managerial positions they hold. Most notable is that multiple skillset views have been captured on the survey which are in the BI space. 
Table 4.3: Distribution of Business Intelligence Responses on Job Position.

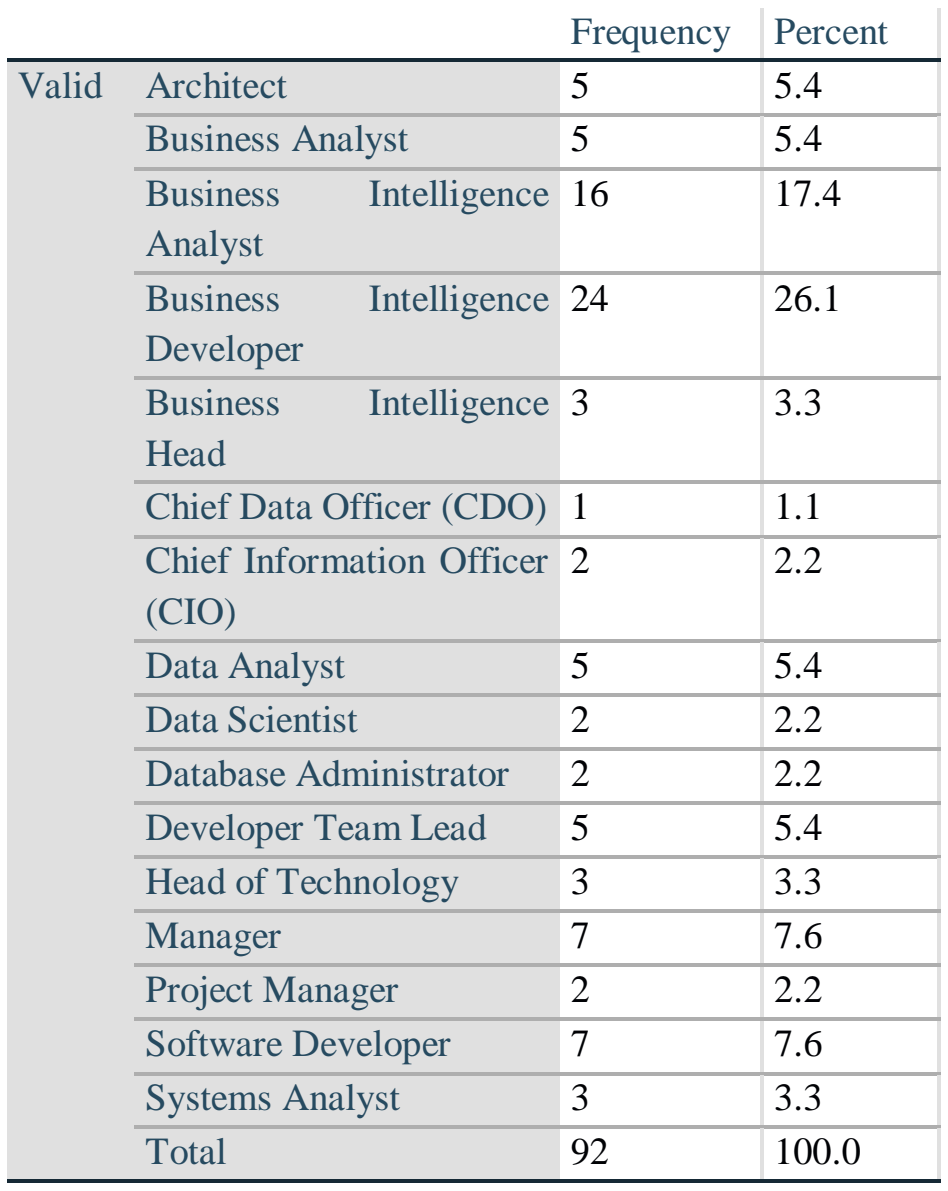

\subsubsection{Distribution of Responses by Organisation Type}

BI professionals were asked to indicate their respective organisation types. The data findings are shown in Figure 4.3. The indication is that BI professionals who responded mostly are employed by insurance and Banks's organisations with $35.87 \%$ and $29.35 \%$ representation, respectively. 


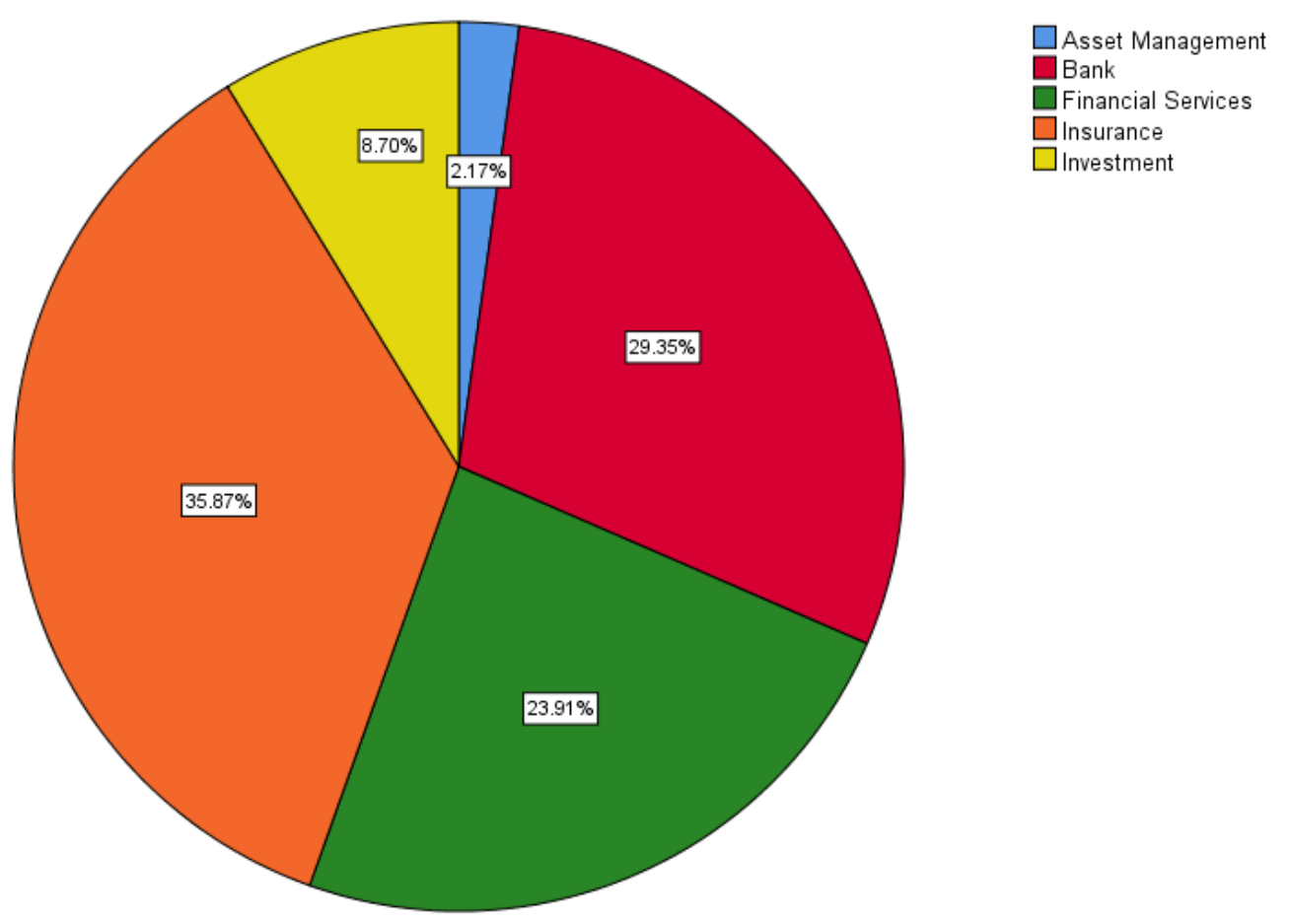

Figure 4.3: Distribution of Business Intelligence Responses on Organisation Type

\subsubsection{Distribution of Responses by Organisation Size}

BI professionals were asked to indicate the size of their respective organisations. The data findings are shown in Figure 4.4. The indication is that most BI professionals are employed by big organisations with a workforce of 1,000-9'999 employees which constitute $42.39 \% ; 10,000-99,999$ constitute $29.35 \% ; 100,000$ or more constitute $8.70 \%$; while a group of employees working for organisations with a workforce of less than 999 constitute $19.56 \%$. The findings imply that these organisations are old and have been in the market for a long period, and one can conclude that they are registered on the JSE. 


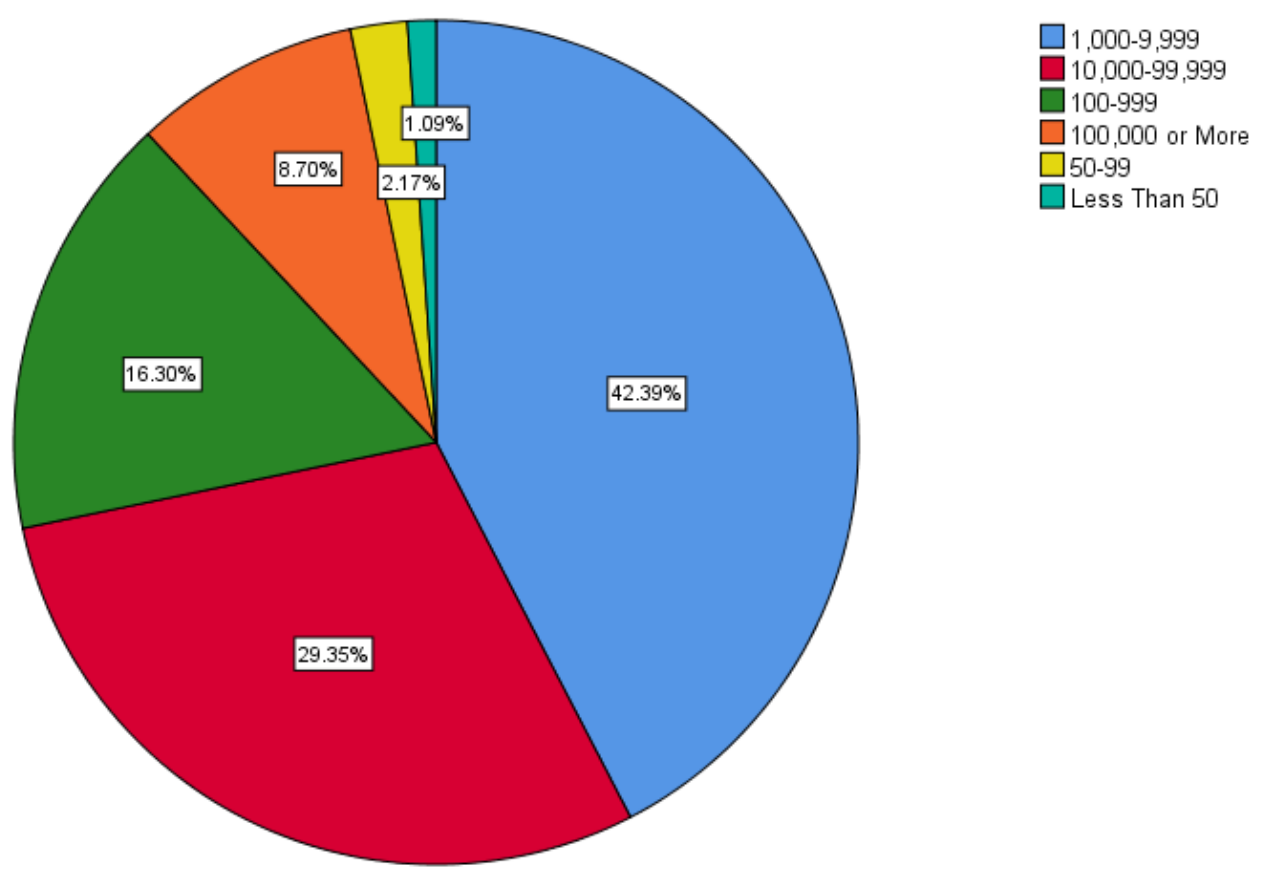

Figure 4.4: Distribution of Business Intelligence Responses on Organisation Size

\subsection{Influence of Technical Factors}

\subsubsection{Software Tool Construct}

The BI professionals were instructed to respond to the statements based on a five-point Likert scale and indicate the extent to which some of the technical factors concerning software tools are critical based on these keys: 5-Very Great Extent, 4-Great Extent, 3-No Opinion, 2-Little Extent, 1-Very Little Extent. A mean (M) score of 0-1.5 means that the respondents indicated very little extent, between 1.50 to 2.50 means they indicated Little Extent, 2.50 to 3.50 means the respondents had no opinion, 3.50-4.50 means they indicated Great Extent, and a mean above 4.50 means they indicated Very Great Extent. Based on the findings in Table 4.4 below, the respondents indicated that the following factor was almost critical to a Very great extent: (Functionality $\mathrm{M}=4.48 ; \mathrm{SD}=0.58$ ). The $\mathrm{BI}$ professionals indicated that the following factors are critical to a great extent: ease of use/user-friendly, compatibility with existing hardware/software, availability of an integrated hardware/software package, and lastly, availability of source code. 
Table 4.4: Respondents' opinions on the Extent of Software Tools Technical Factors.

\begin{tabular}{|c|c|c|c|c|c|c|}
\hline & & $\begin{array}{l}\text { Availability of } \\
\text { an Integrated } \\
\text { hardware/soft } \\
\text { ware package }\end{array}$ & $\begin{array}{l}\text { Compatibility } \\
\text { with existing } \\
\text { hardware/soft } \\
\text { ware }\end{array}$ & $\begin{array}{c}\text { Ease of } \\
\text { use/User- } \\
\text { friendly }\end{array}$ & Functionality & $\begin{array}{c}\text { Availability of } \\
\text { source code }\end{array}$ \\
\hline \multirow[t]{2}{*}{$\mathrm{N}$} & Valid & 92 & 92 & 92 & 92 & 92 \\
\hline & Missing & 0 & 0 & 0 & 0 & 0 \\
\hline \multicolumn{2}{|c|}{ Mean } & 4.20 & 4.24 & 4.37 & 4.48 & 3.77 \\
\hline \multicolumn{2}{|c|}{ Std. Deviation } & .650 & .542 & .658 & .583 & .840 \\
\hline \multicolumn{2}{|c|}{ Minimum } & 2 & 3 & 2 & 3 & 1 \\
\hline \multicolumn{2}{|c|}{ Maximum } & 5 & 5 & 5 & 5 & 5 \\
\hline
\end{tabular}

\subsubsection{Vendor Construct}

Participants were instructed to respond to the statements based on a five-point Likert scale and indicate the extent to which some of the technical factors concerning the vendor are critical based on these keys: 5-Very Great Extent, 4-Great Extent, 3-No Opinion, 2-Little Extent, 1Very Little Extent. A mean (M) score of 0-1.5 means that the respondents indicated very little extent, between 1.50 to 2.50 means they indicated Little Extent, 2.50 to 3.50 means the respondents had no opinion, 3.50-4.50 means they indicated Great Extent, and a mean above 4.50 means they indicated Very Great Extent. Based on the findings in Table 4.5 below, the respondents indicated that the following factors were critical at a great extent: quality of product $\mathrm{M}=4.38 ; \mathrm{SD}=0.739$, availability of technical support, technical skills, availability of user manual for important information, tutorial for learning and troubleshooting guide, and experience in using product developed by the same vendor. 
Table 4.5: Respondents' opinions on the Extent of Vendor Technical Factors.

\begin{tabular}{|c|c|c|c|c|c|c|}
\hline & & $\begin{array}{c}\text { Availability of } \\
\text { technical } \\
\text { support }\end{array}$ & $\begin{array}{l}\text { Availability of } \\
\text { User manual } \\
\text { for important } \\
\text { information, } \\
\text { tutorial for } \\
\text { learning and } \\
\text { troubleshootin } \\
\text { g guide }\end{array}$ & $\begin{array}{c}\text { Technical } \\
\text { skills }\end{array}$ & $\begin{array}{l}\text { Experience in } \\
\text { using product } \\
\text { developed by } \\
\text { same vendor }\end{array}$ & $\begin{array}{c}\text { Quality of } \\
\text { product }\end{array}$ \\
\hline \multirow[t]{2}{*}{$\mathrm{N}$} & Valid & 92 & 92 & 92 & 92 & 92 \\
\hline & Missing & 0 & 0 & 0 & 0 & 0 \\
\hline \multicolumn{2}{|c|}{ Mean } & 4.18 & 3.83 & 3.99 & 3.50 & 4.38 \\
\hline \multicolumn{2}{|c|}{ Std. Deviation } & 1.005 & .968 & .871 & 1.104 & .739 \\
\hline \multicolumn{2}{|c|}{ Minimum } & 1 & 1 & 2 & 1 & 2 \\
\hline \multicolumn{2}{|c|}{ Maximum } & 5 & 5 & 5 & 5 & 5 \\
\hline
\end{tabular}

\subsubsection{Opinion Construct}

Participants were instructed to respond to the statements based on a five-point Likert scale and indicate the extent to which some of the technical factors concerning the Opinion are critical based on these keys: 5-Very Great Extent, 4-Great Extent, 3-No Opinion, 2-Little Extent, 1Very Little Extent. A mean (M) score of 0-1.5 means that the respondents indicated very little extent, between 1.50 to 2.50 means they indicated Little Extent, 2.50 to 3.50 means the respondents had no opinion, 3.50-4.50 means they indicated Great Extent, and a mean above 4.50 means they indicated Very Great Extent. Based on the findings in Table 4.6 below, the respondents indicated that the following factor was critical to a great extent: (In house "Experts" $\mathrm{M}=3.72 ; \mathrm{SD}=1.103)$. The BI professionals had no opinion on the following factors: external consultants, potential vendors/sales representatives and computer/IS trade magazine, software product leaflets. 
Table 4.6: Respondents' opinions on the Extent of Opinion Technical Factors

\begin{tabular}{|c|c|c|c|c|c|}
\hline & & $\begin{array}{c}\text { Potential } \\
\text { vendors/sales } \\
\text { representatives }\end{array}$ & $\begin{array}{l}\text { In house } \\
\text { "Experts" }\end{array}$ & $\begin{array}{c}\text { External } \\
\text { Consultants } \\
\end{array}$ & $\begin{array}{c}\text { Computer/IS } \\
\text { trade } \\
\text { magazine, } \\
\text { software } \\
\text { product } \\
\text { leaflets } \\
\end{array}$ \\
\hline \multirow[t]{2}{*}{$\mathrm{N}$} & Valid & 92 & 92 & 92 & 92 \\
\hline & Missing & 0 & 0 & 0 & 0 \\
\hline \multicolumn{2}{|c|}{ Mean } & 3.15 & 3.72 & 3.43 & 2.77 \\
\hline \multicolumn{2}{|c|}{ Std. Deviation } & 1.048 & 1.103 & 1.082 & .853 \\
\hline \multicolumn{2}{|c|}{ Minimum } & 1 & 1 & 1 & 1 \\
\hline \multicolumn{2}{|c|}{ Maximum } & 5 & 5 & 5 & 5 \\
\hline
\end{tabular}

\subsubsection{Overall Technical Software}

Participants were instructed to respond to the statements on a five-point Likert scale and indicate the extent they agree with the statements using the keys: 5-Strongly agree, 4-Agree, 3-No Opinion, 2-Disagree, 1-Strongly disagree. A mean (M) score of 0-1.5 means that the respondents strongly disagreed, between 1.50 to 2.50 means they disagreed, 2.50 to 3.50 means the respondents had no opinion, 3.50-4.50 means they agreed, and a mean above 4.50 means the respondents strongly agreed. The findings on Table 4.7 below revealed that the BI professionals agreed with the following statements: The Identified technical factors for selection of BI tools influence the success of BI systems implementation and agree to the following statements: Software tools technical factors drive BI tool selection, Vendor technical factors drive BI tool selection and had no opinion that Opinion technical factors drive BI tool selection. 
Table 4.7: Respondents' opinions on the Extent Overall Technical Factors

\begin{tabular}{|c|c|c|c|c|c|}
\hline & & $\begin{array}{l}\text { Software tools } \\
\text { technical } \\
\text { factors drive } \\
\text { business } \\
\text { intelligence } \\
\text { tool selection }\end{array}$ & $\begin{array}{c}\text { Vendor } \\
\text { technical } \\
\text { factors drive } \\
\text { business } \\
\text { intelligence } \\
\text { tool selection }\end{array}$ & $\begin{array}{c}\text { Opinions } \\
\text { technical } \\
\text { factors drive } \\
\text { business } \\
\text { intelligence } \\
\text { tool selection }\end{array}$ & $\begin{array}{l}\text { The Identified } \\
\text { technical } \\
\text { factors for } \\
\text { selection of BI } \\
\text { tools influence } \\
\text { the success of } \\
\text { BI systems } \\
\text { implementatio } \\
n\end{array}$ \\
\hline \multirow[t]{2}{*}{$\mathrm{N}$} & Valid & 92 & 92 & 92 & 92 \\
\hline & Missing & 0 & 0 & 0 & 0 \\
\hline \multicolumn{2}{|c|}{ Mean } & 3.96 & 3.60 & 3.42 & 3.80 \\
\hline \multicolumn{2}{|c|}{ Std. Deviation } & 1.015 & 1.028 & 1.019 & 1.072 \\
\hline \multicolumn{2}{|c|}{ Minimum } & 1 & 1 & 1 & 1 \\
\hline \multicolumn{2}{|c|}{ Maximum } & 5 & 5 & 5 & 5 \\
\hline
\end{tabular}

\subsection{Influence of Non-Technical Factors}

\subsubsection{Software Tool Construct}

Participants were instructed to respond to the statements based on a five-point Likert scale and indicate the extent to which some of the non-technical factors concerning the software tool are critical based on these keys: 5-Very Great Extent, 4-Great Extent, 3-No Opinion, 2-Little Extent, 1-Very Little Extent. A mean (M) score of 0-1.5 means that the respondents indicated a very little extent, between 1.50 to 2.50 means they indicated Little Extent, 2.50 to 3.50 means the respondents had no opinion, 3.50-4.50 means they indicated Great Extent, and a mean above 4.50 means they indicated Very Great Extent. Based on the findings in Table 4.8 below, the respondents indicated that the following factors were critical to a great extent: Price $(\mathrm{M}=4.49 ; \mathrm{SD}=0.687)$, lifespan, popularity, and version currently in the market. Most notable is that the price was rated high by respondents. 
Table 4.8: Respondents' opinions on the Extent of Software Tools Non-Technical Factors

\begin{tabular}{|c|c|c|c|c|c|}
\hline & & Price & Popularity & Lifespan & $\begin{array}{l}\text { Version } \\
\text { currently in } \\
\text { the market }\end{array}$ \\
\hline \multirow[t]{2}{*}{$\mathrm{N}$} & Valid & 92 & 92 & 92 & 92 \\
\hline & Missing & 0 & 0 & 0 & 0 \\
\hline \multicolumn{2}{|c|}{ Mean } & 4.49 & 3.97 & 4.12 & 3.80 \\
\hline \multicolumn{2}{|c|}{ Std. Deviation } & .687 & .818 & .724 & .842 \\
\hline \multicolumn{2}{|c|}{ Minimum } & 2 & 1 & 2 & 2 \\
\hline \multicolumn{2}{|c|}{ Maximum } & 5 & 5 & 5 & 5 \\
\hline
\end{tabular}

\subsubsection{Vendor Construct}

The BI professionals were instructed to respond to the statements based on a five-point Likert scale and indicate the extent to which some of the non-technical factors concerning the vendor are critical based on these keys: 5-Very Great Extent, 4-Great Extent, 3-No Opinion, 2-Little Extent, 1-Very Little Extent. A mean (M) score of 0-1.5 means that the respondents indicated very little extent, between 1.50 to 2.50 means they indicated Little Extent, 2.50 to 3.50 means the respondents had no opinion, 3.50-4.50 means they indicated Great Extent, and a mean above 4.50 means they indicated Very Great Extent. Based on the findings in Table 4.9 below, the respondents indicated that the following factors were critical to a great extent: with reputation rated high by many $\mathrm{BI}$ professionals $(\mathrm{M}=4.25 ; \mathrm{SD}=0.779)$, ethics and integrity, professionalism, past business experience with the vendor, business skills, and references. 
Table 4.9: Respondents' opinions on the Extent of Vendor Non-Technical Factors

\begin{tabular}{|c|c|c|c|c|c|c|c|}
\hline & & Reputation & $\begin{array}{l}\text { Business } \\
\text { Skills }\end{array}$ & References & $\begin{array}{l}\text { Past business } \\
\text { experience } \\
\text { with vendor }\end{array}$ & $\begin{array}{l}\text { Ethics and } \\
\text { Integrity }\end{array}$ & $\begin{array}{c}\text { Professionali } \\
\text { sm }\end{array}$ \\
\hline \multirow[t]{2}{*}{$\mathrm{N}$} & Valid & 92 & 92 & 92 & 92 & 92 & 92 \\
\hline & Missing & 0 & 0 & 0 & 0 & 0 & 0 \\
\hline \multicolumn{2}{|c|}{ Mean } & 4.41 & 4.11 & 4.11 & 4.14 & 4.25 & 4.17 \\
\hline \multicolumn{2}{|c|}{ Std. Deviation } & .649 & .763 & .805 & .921 & .779 & .735 \\
\hline \multicolumn{2}{|c|}{ Minimum } & 2 & 2 & 2 & 1 & 2 & 2 \\
\hline \multicolumn{2}{|c|}{ Maximum } & 5 & 5 & 5 & 5 & 5 & 5 \\
\hline
\end{tabular}

\subsubsection{Opinion Construct}

The BI professionals were instructed to respond to the statements based on a five-point Likert scale and indicate the extent to which some of the technical factors concerning the Opinion are critical based on these keys: 5-Very Great Extent, 4-Great Extent, 3-No Opinion, 2-Little Extent, 1-Very Little Extent. A mean (M) score of 0-1.5 means that the respondents indicated very little extent, between 1.50 to 2.50 means they indicated Little Extent, 2.50 to 3.50 means the respondents had no opinion, 3.50-4.50 means they indicated Great Extent, and a mean above 4.50 means they indicated Very Great Extent. Based on the findings in Table 4.10 below, the respondents indicated that the following factors were critical to a great extent with improvement in customer service rated high by many $\mathrm{BI}$ professionals $(\mathrm{M}=3.95 ; \mathrm{SD}=0.906)$, and end-users $(\mathrm{M}=3.75 ; \mathrm{SD}=1.034)$. The $\mathrm{BI}$ professionals did not have any view on the following factors: subordinates and outside personnel acquaintances. 
Table 4.10: Respondents' opinions on the Extent of Opinions Non-Technical Factors

\begin{tabular}{|c|c|c|c|c|c|}
\hline & & Subordinates & End-users & $\begin{array}{c}\text { Outside } \\
\text { personnel } \\
\text { acquaintances }\end{array}$ & $\begin{array}{l}\text { Improvement } \\
\text { in customer } \\
\text { service }\end{array}$ \\
\hline \multirow[t]{2}{*}{$\mathrm{N}$} & Valid & 92 & 92 & 92 & 92 \\
\hline & Missing & 0 & 0 & 0 & 0 \\
\hline \multicolumn{2}{|c|}{ Mean } & 3.17 & 3.75 & 2.95 & 3.95 \\
\hline \multicolumn{2}{|c|}{ Std. Deviation } & .859 & 1.034 & .999 & .906 \\
\hline \multicolumn{2}{|c|}{ Minimum } & 1 & 1 & 1 & 1 \\
\hline \multicolumn{2}{|c|}{ Maximum } & 5 & 5 & 5 & 5 \\
\hline
\end{tabular}

\subsubsection{Overall Non-Technical Software}

Participants were instructed to respond to the statements on a five-point Likert scale and indicate the extent they agree with the statements using the key: 5-Strongly agree, 4-Agree, 3No Opinion, 2-Disagree, 1-Strongly disagree. A mean (M) score of 0-1.5 means that the respondents strongly disagreed, between 1.50 to 2.50 means they disagreed, 2.50 to 3.50 means the respondents had no opinion, 3.50-4.50 means they agreed, and a mean above 4.50 means the respondents strongly agreed. The findings in Table 4.11 below revealed that the BI professionals agreed with the following statements, The Identified non-technical factors for selection of BI tools influence the success of BI systems implementation and software tools non-technical factors drive BI tool selection. Nevertheless, BI professionals had no view on whether vendor non-technical factors drive BI tool selection and opinion non-technical factors drive BI tool selection. 
Table 4.11: Respondents' opinions on Overall Non-Technical Factors

\begin{tabular}{|c|c|c|c|c|c|}
\hline & & $\begin{array}{l}\text { Software tools } \\
\text { non-technical } \\
\text { factors drive } \\
\text { business } \\
\text { intelligence } \\
\text { tool selection }\end{array}$ & $\begin{array}{l}\text { Vendor non- } \\
\text { technical } \\
\text { factors drive } \\
\text { business } \\
\text { intelligence } \\
\text { tool selection }\end{array}$ & $\begin{array}{l}\text { Opinions non- } \\
\text { technical } \\
\text { factors drive } \\
\text { business } \\
\text { intelligence } \\
\text { tool selection }\end{array}$ & $\begin{array}{c}\text { The Identified } \\
\text { non-technical } \\
\text { factors for } \\
\text { selection of BI } \\
\text { tools influence } \\
\text { the success of } \\
\text { BI systems } \\
\text { implementatio } \\
n\end{array}$ \\
\hline \multirow[t]{2}{*}{$\mathrm{N}$} & Valid & 92 & 92 & 92 & 92 \\
\hline & Missing & 0 & 0 & 0 & 0 \\
\hline \multicolumn{2}{|c|}{ lean } & 3.70 & 3.48 & 3.34 & 3.66 \\
\hline \multicolumn{2}{|c|}{ Std. Deviation } & 1.035 & 1.043 & .855 & .917 \\
\hline \multicolumn{2}{|c|}{ Minimum } & 1 & 1 & 1 & 1 \\
\hline \multicolumn{2}{|c|}{ Maximum } & 5 & 5 & 5 & 5 \\
\hline
\end{tabular}

\subsection{Reliability}

Reliability refers to the consistency of the measure of the research study and tool used for data collection, there are three types of measures viz. test-retest reliability, internal consistency, and inter-rater reliability. The internal consistency for reliability tests was employed which is the consistency of the respondent's responses across the items on a measure. Cronbach alpha testing will be used to test the reliability and any results yielding the alpha value $>.70$ concludes that the items are consistent (Saunders et al., 2016).

\subsubsection{Technical Factors}

The Cronbach alpha values for technical factors constructs are as following: software tool is .728 , vendor (.717), opinion (.716), and overall factors (.803) which is greater than 0.7 thresholds, therefore, the technical factors for software tool construct are consistent given sample size (N) of 92 . Table 4.12 below depicts the constructs and matching Cronbach alpha values given the specified sample size. 
Table 4.12. Technical Factors Cronbach Alpha

\begin{tabular}{|l|c|c|c|c|c|c|}
\hline Construct/s & $\begin{array}{c}\text { Valid } \\
\text { Cases(N) }\end{array}$ & $\begin{array}{l}\text { Excluded } \\
\text { Cases(N) }\end{array}$ & $\begin{array}{c}\text { Total } \\
\text { Cases(N) }\end{array}$ & $\begin{array}{l}\text { Percentage } \\
(\%)\end{array}$ & $\begin{array}{l}\text { Cronbach's } \\
\text { Alpha }\end{array}$ & $\begin{array}{c}\text { N of } \\
\text { Items }\end{array}$ \\
\hline $\begin{array}{l}\text { Software Tool } \\
\text { Construct }\end{array}$ & 92 & 0 & 92 & 100.0 & .728 & 5 \\
\hline $\begin{array}{l}\text { Vendor } \\
\text { Construct }\end{array}$ & 92 & 0 & 92 & 100.0 & .717 & 5 \\
\hline $\begin{array}{l}\text { Opinion } \\
\text { Construct }\end{array}$ & 92 & 0 & 92 & 100.0 & .716 & 4 \\
\hline $\begin{array}{l}\text { Overall } \\
\text { Technical } \\
\text { Factors }\end{array}$ & 92 & 0 & 92 & 100.0 & .803 & 4 \\
\hline
\end{tabular}

\subsubsection{Non-Technical Factors}

The Cronbach alpha values for non-technical factors constructs are as following: software tool is .712, vendor (.738), opinion (.734), and overall factors (.824) which is greater than 0.7 thresholds, therefore, the non-technical factors for software tool construct are consistent given sample size $(\mathrm{N})$ of 92 . Table 4.13 below depicts the constructs and matching Cronbach alpha values given the specified sample size.

Table 4.13. Non-Technical Factors Cronbach Alpha

\begin{tabular}{|l|c|c|c|c|c|c|}
\hline Construct/s & $\begin{array}{c}\text { Valid } \\
\text { Cases (N) }\end{array}$ & $\begin{array}{l}\text { Excluded } \\
\text { Cases (N) }\end{array}$ & $\begin{array}{c}\text { Total } \\
\text { Cases (N) }\end{array}$ & $\begin{array}{l}\text { Percentage } \\
(\%)\end{array}$ & $\begin{array}{l}\text { Cronbach's } \\
\text { Alpha }\end{array}$ & $\begin{array}{l}\text { N of } \\
\text { Items }\end{array}$ \\
\hline $\begin{array}{l}\text { Software Tool } \\
\text { Construct }\end{array}$ & 92 & 0 & 92 & 100.0 & .712 & 4 \\
\hline $\begin{array}{l}\text { Vendor } \\
\text { Construct }\end{array}$ & 92 & 0 & 92 & 100.0 & .738 & 6 \\
\hline $\begin{array}{l}\text { Opinion } \\
\text { Construct }\end{array}$ & 92 & 0 & 92 & 100.0 & .734 & 4 \\
\hline $\begin{array}{l}\text { Overall } \\
\text { Technical } \\
\text { Factors }\end{array}$ & 92 & 0 & 92 & 100.0 & .824 & 4 \\
\hline
\end{tabular}

\subsection{Factor Analysis}

Table 4.14 below depicts the KMO measure and Bartlett's test results, which are used to judge the adequacy of the sample size for the study and to test whether the correlation matrix is suitable for factor analysis. The KMO value is 0.76 which is greater than the accepted minimum threshold value of 0.50 according to Baah et al. (2015) and the Bartlett's test p-value is 0.000 which suggests the study sample size is adequate and that some of the variables are intercorrelated, therefore the collected data is suitable for factor analysis to be conducted. 
Table 4.14: KMO and Bartlett's Test

\begin{tabular}{|c|c|c|}
\hline \multicolumn{2}{|c|}{$\begin{array}{l}\text { Kaiser-Meyer-Olkin Measure of Sampling } \\
\text { Adequacy. }\end{array}$} & .761 \\
\hline \multirow{3}{*}{$\begin{array}{l}\text { Bartlett's Test of } \\
\text { Sphericity }\end{array}$} & Approx. Chi-Square & 979.419 \\
\hline & Df & 378 \\
\hline & Sig. & .000 \\
\hline
\end{tabular}

The initial and final value of extraction communalities is shown in Table 4.15 below. The variables are given an initial variance which is the total communality of 1 (one), as indicated in Table 4.15. The final extraction communalities of each variable denote the variance accounted for by the specific factor solution for the variable. A total of 23 variables remained in the final factor solution out of 28 variables after suppressing all the scores less than 0.57 which is a significant value. The other five variables were removed from the analysis because the recorded communalities are less than 0.57 or they were cross-loading hence appeared in more than one factor. The final communalities shown in Table 4.15 are at least 0.57 which symbolizes at least $57 \%$ of the initial communality of each variable accounted for in the final solution (Baah et al., 2015). Therefore, the factor solution is deemed satisfactory as more than half of the variance is shared with factors. 
Table 4.15: Communalities

\begin{tabular}{|l|r|r} 
& Initial & Extraction \\
\hline TechConsSoftToolQ1 & 1.000 & .684 \\
\hline TechConsSoftToolQ2 & 1.000 & .686 \\
\hline TechConsSoftToolQ3 & 1.000 & .742 \\
\hline TechConsSoftToolQ4 & 1.000 & .578 \\
\hline TechConsSoftToolQ5 & 1.000 & .671 \\
\hline TechConsVendorQ1 & 1.000 & .611 \\
\hline TechConsVendorQ3 & 1.000 & .661 \\
\hline TechCons VendorQ4 & 1.000 & .614 \\
\hline TechConsVendorQ5 & 1.000 & .676 \\
\hline TechConsOpinionQ1 & 1.000 & .620 \\
\hline TechConsOpinionQ2 & 1.000 & .606 \\
\hline TechConsOpinionQ4 & 1.000 & .716 \\
\hline NonTechConsSoftToolQ2 & 1.000 & .697 \\
\hline NonTechConsSoftToolQ3 & 1.000 & .642 \\
\hline NonTechConsSoftToolQ4 & 1.000 & .654 \\
\hline NonTechConsVendorQ1 & 1.000 & .596 \\
\hline NonTechConsVendorQ2 & 1.000 & .615 \\
\hline NonTechConsVendorQ3 & 1.000 & .645 \\
\hline NonTechConsVendorQ4 & 1.000 & .630 \\
\hline NonTechConsVendorQ5 & 1.000 & .641 \\
\hline NonTechConsOpinionQ1 & 1.000 & .629 \\
\hline NonTechConsOpinionQ3 & 1.000 & .650 \\
\hline NonTechConsOpinionQ4 & 1.000 & .582 \\
\hline
\end{tabular}

To determine the number of factors to retain a three criteria approach was used to interpret the factors: 1) Eigenvalue-greater-one rule, 2) Percentage of variance explained, and 3) The scree plot (Joseph F Hair et al., 2006). A total number of seven components have eigenvalues greater than one, therefore seven factors can be retained for the interpretation with the eigenvalues great than one. The scree plot in Figure 4.5 below suggests extracting eight factors as the plot begins to straighten out after the 8th component. The first seven components explain $61.3 \%$ of the variance in the data which is more than the suggested $60 \%$ threshold according to Joseph $\mathrm{F}$ Hair et al. (2006), while the first eight components account for $64.9 \%$ of the variance in the data. The seven factors retained for interpretation are shown in Table 4.16 below. 
Table 4.16: Total Variance Explained

\begin{tabular}{|c|c|c|c|c|c|c|c|c|c|}
\hline \multirow[b]{2}{*}{ Component } & \multicolumn{3}{|c|}{ Initial Eigenvalues } & \multicolumn{3}{|c|}{ Extraction Sums of Squared Loadings } & \multicolumn{3}{|c|}{ Rotation Sums of Squared Loadings } \\
\hline & Total & $\begin{array}{l}\% \quad \text { of } \\
\text { Variance }\end{array}$ & $\begin{array}{l}\text { Cumulative } \\
\%\end{array}$ & Total & $\begin{array}{l}\% \text { of } \\
\text { Variance }\end{array}$ & $\begin{array}{l}\text { Cumulative } \\
\%\end{array}$ & Total & $\begin{array}{l}\% \quad \text { of } \\
\text { Variance }\end{array}$ & $\begin{array}{l}\text { Cumulative } \\
\%\end{array}$ \\
\hline 1 & 6.881 & 24.575 & 24.575 & 6.881 & 24.575 & 24.575 & 2.797 & 9.989 & 9.989 \\
\hline 2 & 2.279 & 8.138 & 32.713 & 2.279 & 8.138 & 32.713 & 2.770 & 9.893 & 19.882 \\
\hline 3 & 2.131 & 7.609 & 40.322 & 2.131 & 7.609 & 40.322 & 2.587 & 9.240 & 29.122 \\
\hline 4 & 1.790 & 6.394 & 46.716 & 1.790 & 6.394 & 46.716 & 2.439 & 8.711 & 37.834 \\
\hline 5 & 1.501 & 5.360 & 52.076 & 1.501 & 5.360 & 52.076 & 2.285 & 8.162 & 45.996 \\
\hline 6 & 1.358 & 4.849 & 56.926 & 1.358 & 4.849 & 56.926 & 2.242 & 8.006 & 54.002 \\
\hline 7 & 1.236 & 4.413 & 61.339 & 1.236 & 4.413 & 61.339 & 2.055 & 7.338 & 61.339 \\
\hline 8 & 1.019 & 3.638 & 64.977 & & & & & & \\
\hline
\end{tabular}

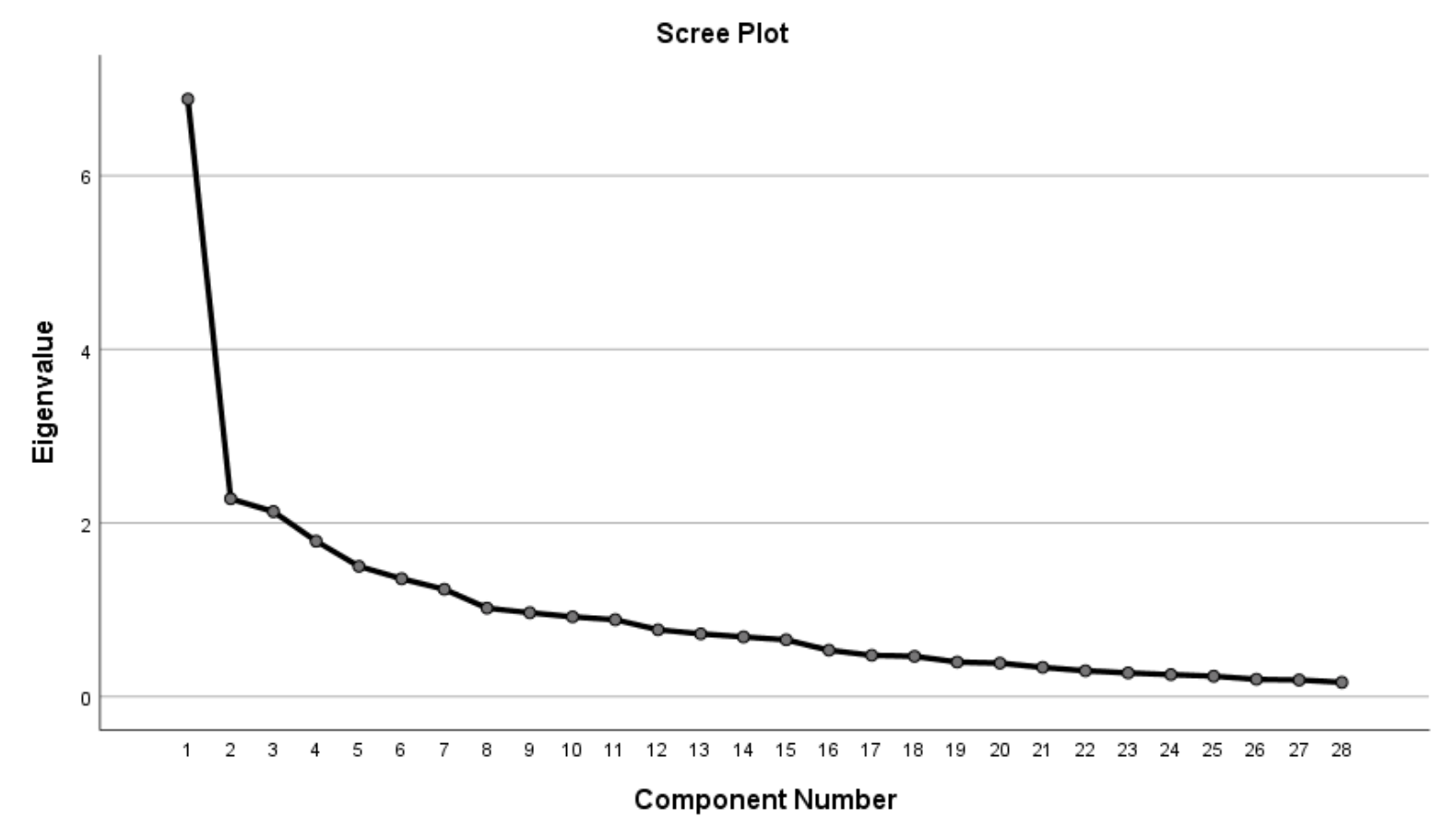

Figure 4.5: Plot of eigenvalues against factor number.

Table 4.17 below on page 65 shows factors extracted and respective loadings of various variables on the factors after the initial factor solution had been rotated using the Varimax method so that each variable load high on only one factor. The method also ensures that the factors are uncorrelated (Baah et al., 2015). The loadings represent the extent of correlation between a variable and a factor. For interpretation of loadings for factors, the higher the 
absolute value of loading of the variable on a factor, the more influential the variable is on the factor. Based on the literature and knowledge, a loading of 0.50 is regarded as significant for a sample size of 92 (Joseph F Hair et al., 2006). However, a higher value of 0.57 was used to ensure that only variables of practical and high significance are included and loaded in the final factor solution. All the loadings which were below 0.57 were omitted and suppressed. The remaining components depicted in Table 4.17 below on page 65 are presumed to be the underlying dimensions informing the significant factors when selecting the BI tools for the South African financial services provider. The factors were named as follows:

Factor 1: Opinions and views related to software tool

Factor 2: Software marketing and promotion

Factor 3: Ease of use and technical support

Factor 4: Vendor Ethos

Factor 5: Longevity and Costing

Factor 6: Underlying code of software tool

Factor 7: Compatibility 
Table 4.17: Rotated Component Matrix

\begin{tabular}{|c|c|c|c|c|c|c|c|}
\hline Component & 1 & 2 & 3 & 4 & 5 & 6 & 7 \\
\hline Subordinates & .757 & & & & & & \\
\hline $\begin{array}{l}\text { Improvement in customer } \\
\text { service }\end{array}$ & .674 & & & & & & \\
\hline $\begin{array}{l}\text { Outside personnel } \\
\text { acquaintances }\end{array}$ & .673 & & & & & & \\
\hline End-users & .630 & & & & & & \\
\hline $\begin{array}{l}\text { Computer/IS trade } \\
\text { magazine, software } \\
\text { product leaflets }\end{array}$ & & .826 & & & & & \\
\hline $\begin{array}{l}\text { Potential vendors/sales } \\
\text { representatives }\end{array}$ & & .767 & & & & & \\
\hline In house "Experts" & & .579 & & & & & \\
\hline Quality of product & & & .714 & & & & \\
\hline $\begin{array}{l}\text { Availability of technical } \\
\text { support }\end{array}$ & & & .670 & & & & \\
\hline Functionality & & & .626 & & & & \\
\hline Technical skills & & & .597 & & & & \\
\hline Ethics and Integrity & & & & .760 & & & \\
\hline Business Skills & & & & .618 & & & \\
\hline Popularity & & & & & .756 & & \\
\hline Lifespan & & & & & .711 & & \\
\hline $\begin{array}{l}\text { Version currently in the } \\
\text { market }\end{array}$ & & & & & .602 & & \\
\hline Price & & & & & .593 & & \\
\hline $\begin{array}{l}\text { Availability of source } \\
\text { code }\end{array}$ & & & & & & .765 & \\
\hline $\begin{array}{l}\text { Availability of an } \\
\text { Integrated } \\
\text { hardware/software } \\
\text { package }\end{array}$ & & & & & & .702 & \\
\hline Ease of use/User-friendly & & & & & & & .814 \\
\hline $\begin{array}{l}\text { Compatibility with } \\
\text { existing } \\
\text { hardware/software }\end{array}$ & & & & & & & .651 \\
\hline
\end{tabular}

\subsection{Hypotheses Testing}

To conduct hypothesis testing the researcher used Partial Least Squares Structural Equation Modelling (PLS-SEM) methodology by employing a software application called SmartPLS 3 (Kock, 2016). SmartPLS 3 is an open-source (free) software that is downloaded over the Internet, it is used to conduct hypothesis testing, data analysis, and other capabilities (Kock, 2016). Structural equation modelling (SEM) is a multivariate data analysis method that is 
useful when examining the relationship between constructs and to test the strength of the relationship, whereas Partial Least Square (PLS) is a subclass of SEM and is designed when conducting multiple regression test given a small sample and non-normal data (Ali et al., 2018; Joe F Hair et al., 2012). There are two types of measurement scales in SEM namely reflective and formative. Formative measure occurs when the outer model indicators makeup the construct, whereas reflective measurement is when indicators in the outer model are caused by the construct (Joe F Hair et al., 2012).

\section{Hypothesis testing with $P$ values and confidence intervals}

Hypothesis testing in the context of PLS-SEM is usually conducted through the calculation of a $P$-value for each path coefficient or T ratio test. $P$-value test, conduct a test of the hypothesis that $\beta>0$ at the 0.05 significance level (i.e., 1-95\%), we calculate the one-tailed (most powerful test) P-value associated with the path coefficient (Kock, 2015). This quantity could be interpreted as the probability that $\beta$ belongs to a distribution with a mean of zero and a standard deviation of $\sigma$. It can be calculated as the area under the curve considering the total area to be 1 (Joe F Hair et al., 2012; Kock, 2016). If $\mathrm{P} \leq 0.05$ the hypothesis is accepted, otherwise it is rejected. The $\mathbf{T}$ ratio test can be seen as a variation of $\mathrm{P}$-value test, where the $\mathrm{T}$ ratio (commonly known as $\mathrm{T}$ value, $\mathrm{T}$ statistic, and $\mathrm{t}$-statistic) calculated as $\beta / \sigma$ is used instead of the corresponding P-value for comparison against a threshold such as 1.64 or 1.96 (Kock, 2016). The significance value is when $T$ value $>=1.96$ statistical, therefore the hypothesis is accepted, otherwise it is rejected.

For this research hypothesis testing, the researcher used the results of the factor analysis conducted in the previous section (factor analysis, Table 4.17 above on page 65 ) as the initial model depicted in Figure 4.6 below since it showed to group significant factors and their significance needs to be tested. Figure 4.6 shows the initial model of the research as depicted in the proposed conceptual model (Figure 2.10) above on page 29. The initial model shows the relationship between the outer model and the inner model, as well as the independent variables linking to the dependent variable. This model contains seven latent variables: Software tool technical factors (T_ST), Vendor technical factors $\left(T_{-}\right.$V), Opinion technical factors (T_O), Software tool non-technical factors (NT_ST), vendor non-technical factors (NT_V), Opinion non-technical factors (NT_O), and lastly critical factors (CF). Software tool technical factors (T_ST) measures critical technical factors in relation to software tool when selecting BI 
software tool to employ, vendor technical factors $\left(T_{-} V\right)$ measures critical technical factors in relation to vendor when selecting BI software tool to employ, and Opinion technical factors (T_O) measures critical technical factors in relation to opinion and views when selecting BI software tool to employ. On the other hand, Software tool non-technical factors (NT_ST), vendor non-technical factors (NT_V), and Opinion non-technical factors (NT_O) all measure critical non-technical factors for each variable when selecting BI software tools. Critical factors (CF) are the dependent variable that are used to select the software tool to employ. Moreover, measures the overall perceptions of BI professionals towards BI tools selection and it is the endogenous (or dependent) latent variable in the model. The main objective of the model is to investigate the relationship between constructs and their significance towards the studied phenomenon (critical factors).

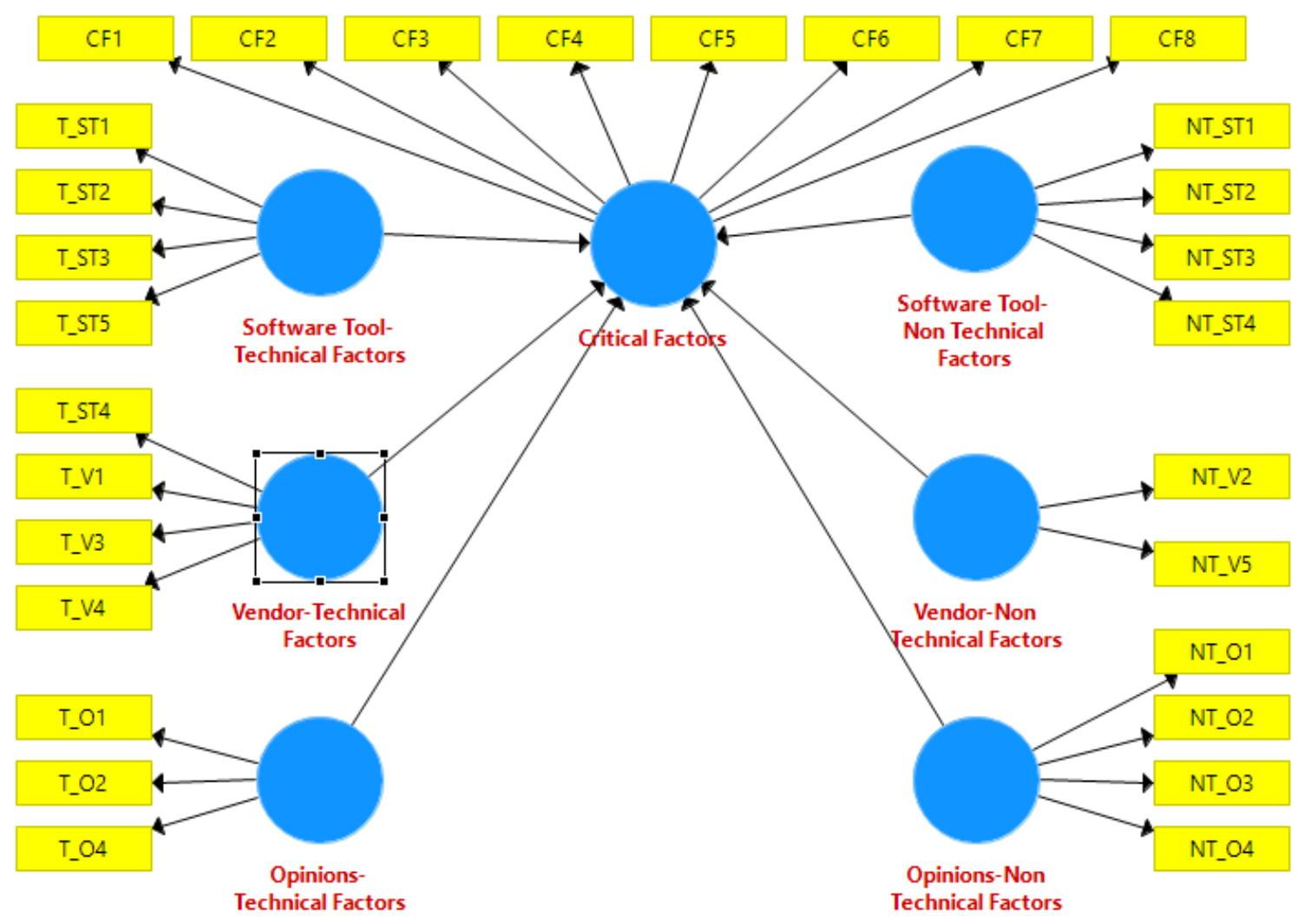

Figure 4.6: Initial Research Model.

After running a consistent PLS algorithm on the initial research model above (Figure 4.6) which is used to test the correlations of the constructs to produce consistent results with the conceptual model employed in the study (Bhattacherjee, 2012). All the indicators which had the outer loadings of less than 0.4 were removed from the initial model in Figure 4.6 since they 
proved to be insignificant for the PLS algorithm test (Kock, 2016). The final model used is depicted in Figure 4.7 below with the explained $\mathrm{R}$ squared of 0.565 which is approximately $57 \%$. The R squared value (Figure 4.8) implies that above $56 \%$ of independent variables used in the study explain the dependent variable and this value is deemed as a good R-squared value since it is higher than the minimum of $0.333(33.3 \%)$ for information systems (IS) research (Moore et al., 2015).

\section{Indicators Omitted}

- Software Tool Technical Factors= T_ST2, T_ST5

- $\quad$ Vendor Technical Factors =T_ST4

- Opinions Technical Factors =T_O2

- Software Tool Non-Technical Factors =NT_ST1

- Opinions Tool Non-Technical Factors = NT_O1

- Critical Factors $=\mathrm{CF} 1, \mathrm{CF} 2, \mathrm{CF} 4$

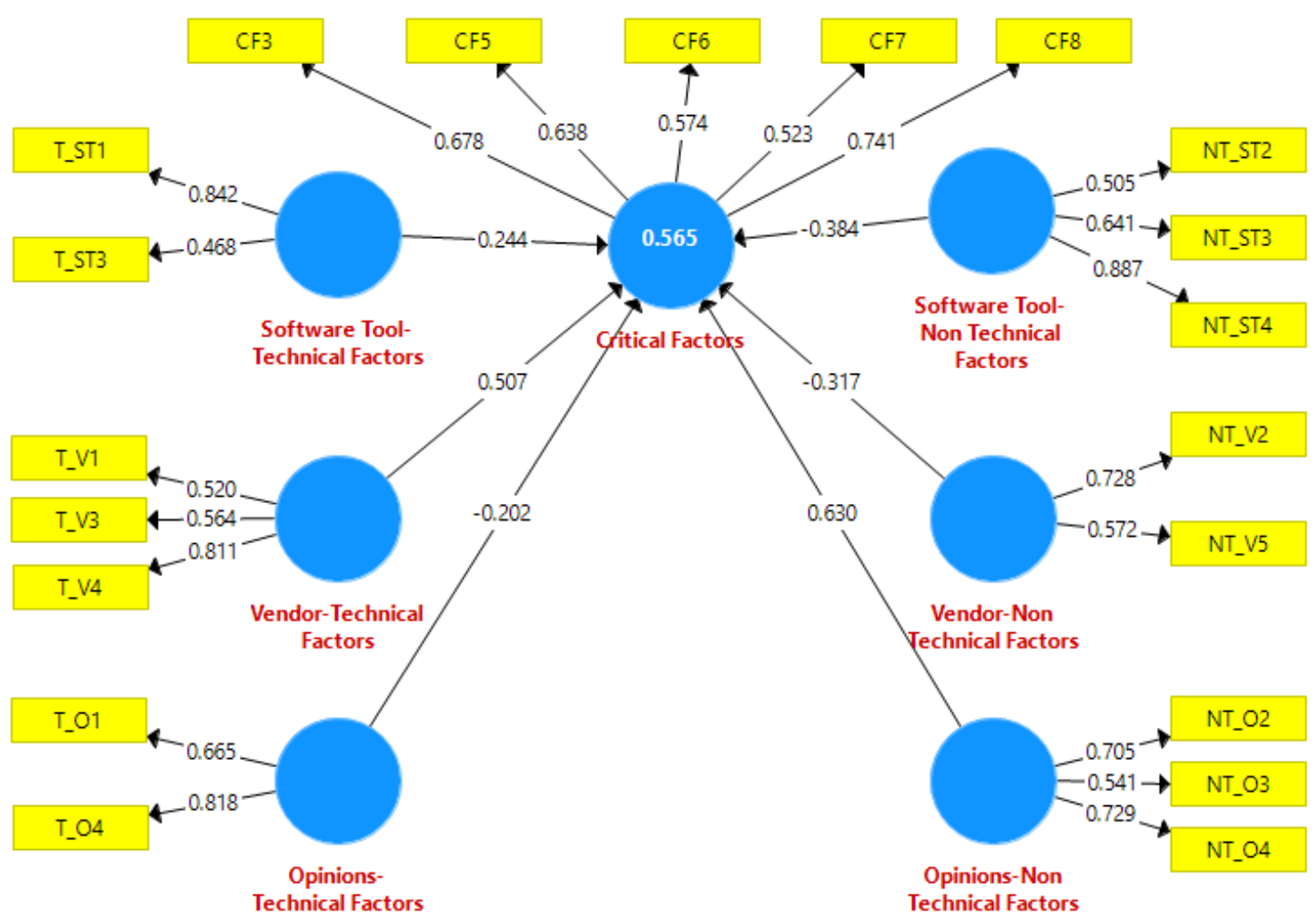

Figure 4.7: The final Research Model. 


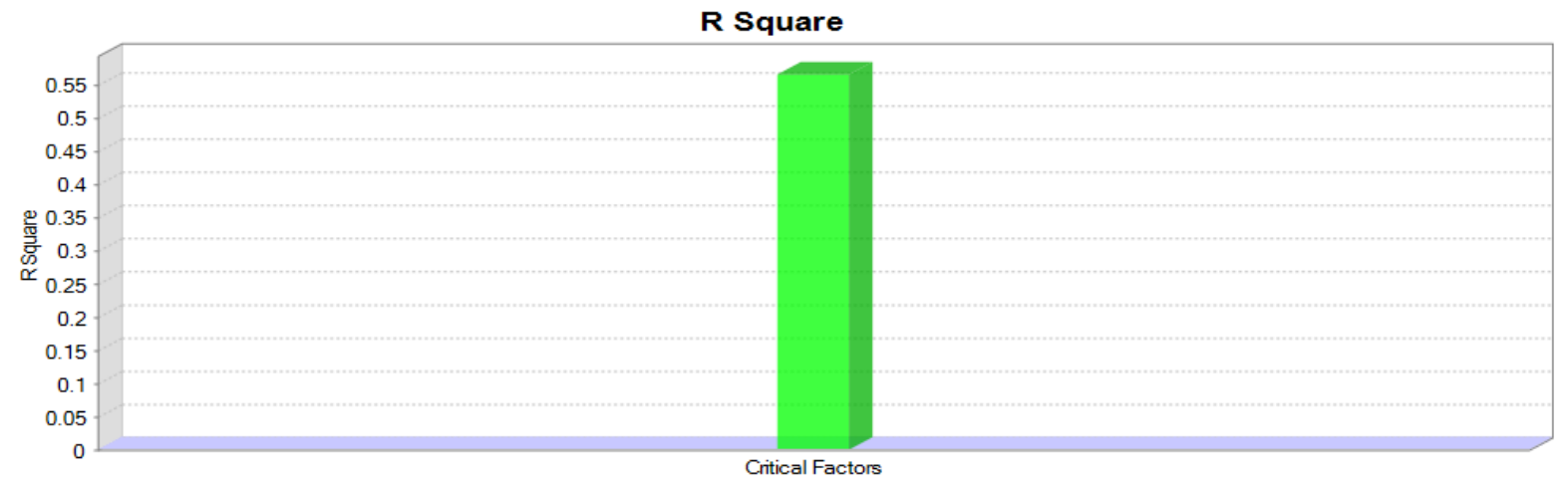

Figure 4.8: Explained R-squared Value.

\section{Hypotheses Findings}

Depicted below is the research results model of analysis with T ratio values (Figure 4.9) which shows significance and relationship between variables and Table 4.18 with results from the Bootstrap PLS Analysis. Both these methods will be used to either accept or reject the stated hypothesis.

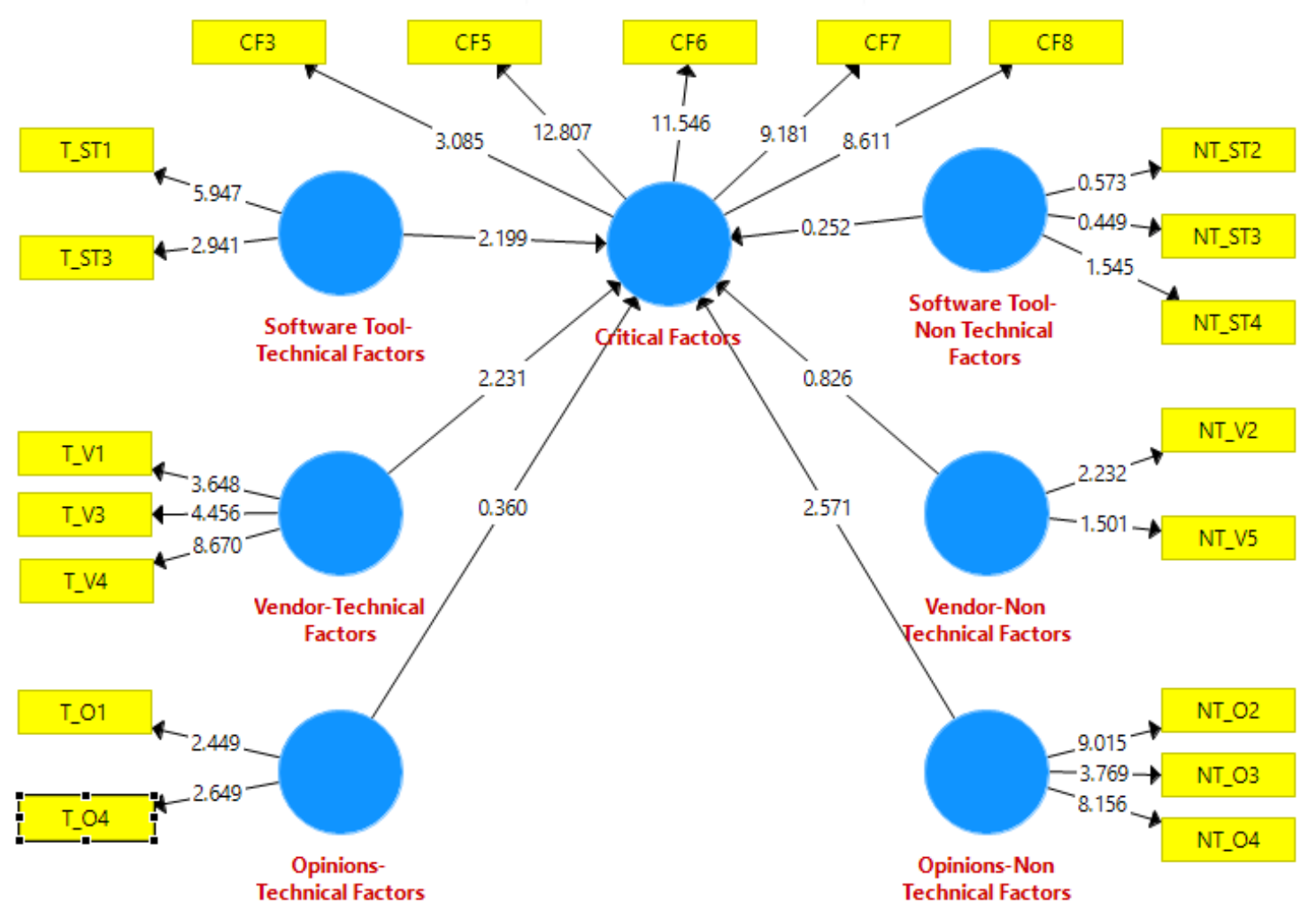

Figure 4.9: Diagram of model analysis with $\mathrm{T}$ ratio values. 
Table 4.18: Total results from the Bootstrap PLS Analysis.

\begin{tabular}{|l|r|r|r|r|} 
& Original Sample (O) & Sample Mean (M) & Standard Deviation (STDEV) & TStatistics (|O/STDEV) \\
\hline Opinions-Non Technical Factors -> Critical Factors & 0.295 & 0.294 & 0.115 & 2.571 \\
\hline Opinions-Technical Factors -> Critical Factors & -0.037 & -0.034 & 0.104 & 0.360 \\
\hline Software Tool-Non Technical Factors -> Critical Factors & -0.038 & -0.143 & 0.149 & 0.359 \\
\hline Software Tool-Technical Factors -> Critical Factors & 0.233 & 0.226 & 0.106 & 0.252 \\
\hline Vendor-Non Technical Factors -> Critical Factors & -0.109 & -0.057 & 0.132 & 2.199 \\
\hline Vendor-Technical Factors -> Critical Factors & 0.244 & 0.276 & 0.109 & 0.826 \\
\hline
\end{tabular}

Based on the above Bootstrap PLS Analysis (Table 4.18), the summary of hypotheses results is shown in table 4.19 below and hypotheses results are discussed broadly.

Table 4.19: Hypotheses Summary Results

\begin{tabular}{|c|c|}
\hline Hypotheses & Hypotheses Test Results \\
\hline H1 & Accepted \\
\hline H2 & Accepted \\
\hline H3 & Rejected \\
\hline H4 & Rejected \\
\hline H5 & Rejected \\
\hline H6 & Accepted \\
\hline
\end{tabular}

\section{Hypothesis 1 - Software Tool Technical Factors}

H1: "Software tool technical factors influence the selection of BI tools"

H0: "Software tool technical factors do not influence the selection of BI tools"

The results illustrated in Table 4.18 stipulate that there is a significant relationship between software tool technical factors and critical factors that drive the selection of BI tools $(\mathrm{t}$ value $=2.199$, $\mathrm{p}$ value $=0.014$ ), thus findings show that the $\mathrm{t}$-value is above 1.96 threshold and P-Value way less than 0.05 . Therefore, the null hypothesis for software tool technical factors is rejected and the $\mathrm{H} 1$ hypothesis accepted at 95\% level of significance. Previous literature results of related studies in packaged software selection conducted by Jadhav et al. (2011) investigating "factors to consider when selecting big data tools" reported that technical factors are critical and significant concerning software selection hence these findings are in line with that study. Another study conducted by Rahman (2018) which focused on "Data Warehousing and Business Intelligence with Big Data" confirm that software tool technical factors are critical during the software selection process. 


\section{Hypothesis 2 - Vendor Technical Factors}

H2: "Vendor technical factors influence the selection of BI tools"

H0: "Vendor technical factors do not influence the selection of BI tools"

The results illustrated in Table 4.18 stipulate that there is a significant relationship between vendor technical factors and critical factors that drive the selection of BI tools ( $\mathrm{t}$-value $=2.231$, $\mathrm{p}$ value $=0.013$ ) thus the findings show the $\mathrm{t}$-value is above 1.96 and $\mathrm{P}$-Value $<0.05$. Therefore, the null hypothesis for vendor technical factors is rejected and the $\mathrm{H} 2$ hypothesis accepted at 95\% level of significance. The findings for this research are consistent with prior studies, such as that of Bhargava et al. (2013) who conducted a study focused on the "Selection Criteria for Data Mining Software", the results showed that vendor technical factors are critical during the software selection process. In a nutshell, a vendor is required and expected to possess a high level of technical expertise and problem-solving skill. The literature suggests that implementation of BI solutions is complex and in-house experts and decision-makers may lack technical knowledge therefore rely on the vendor to provide technical support.

\section{Hypothesis 3 - Opinion Technical Factors}

H3: "Opinion technical factors influence the selection of BI tools"

H0: "Opinion technical factors do not influence the selection of BI tools"

The results illustrated in Table 4.18 stipulate that there is no significant relationship between opinion technical factors and critical factors that drive the selection of BI tools ( $\mathrm{t}$-value $=0.360$, $\mathrm{p}$ value $=0.359$ ), the findings show the $\mathrm{t}$-value is way below 1.96 and P-Value $>0.05$. Therefore, the null hypothesis for opinion technical factors is accepted and $\mathrm{H} 3$ rejected at $95 \%$ level of significance. The findings for this research is not consistent with prior studies, such as that of Chau (1995) who conducted a study focused on "factors used in the selection of packaged software in small businesses: views of owners and managers", their results indicated that opinion technical factors play a vital role during the software selection. Another study conducted by Villamarín \& Diaz Pinzon (2017) looking at key success factors for BI solution implementation stress that opinions and other non-technical factors play an important role during the selection of software. In the case of RSA FSPs organisations, this construct proved to be insignificant. 


\section{Hypothesis 4 - Software Tool Non-Technical Factors}

H4: "Software tool non-technical factors influence the selection of BI tools"

H0: "software tool non-technical factors do not influence the selection of BI tools"

The results illustrated in Table 4.18 stipulate that there is no significant relationship between software tool non-technical factors and critical factors that drive the selection of BI tools ( $t$ value $=0.252$, $\mathrm{p}$ value $=0.401$, the findings show that $\mathrm{t}$-value is below 1.96 and $\mathrm{P}-$ Value $>0.05$. Therefore, the null hypothesis for software tool non-technical factors is accepted and H4 rejected at $95 \%$ level of significance. The findings for this research are not consistent with prior studies, such as that of Liberatore \& Pollack-Johnson (2003) who conducted a study about factors influencing the selection and usage of project management software. This study suggested that non-technical software tools are significant during the selection of software to employ. Another study by Jadhav \& Sonar (2011) focused on the "framework for evaluation and selection of the software packages: A hybrid knowledge-based system approach" stress that software tool non-technical factors are vital. In the context of RSA FSPs organisations, this construct proved to be not significant.

\section{Hypothesis 5 - Vendor Non-Technical Factors}

H5: "Vendor non-technical factors influence the selection of BI tools"

H0: "Vendor non-technical factors do not influence the selection of BI tools"

The results illustrated in Table 4.18 stipulate that there is no significant relationship between vendor non-technical factors and critical factors that drive the selection of BI tools ( $t$ value $=0.826$, $\mathrm{p}$ value $=0.205$ ), the findings show that $\mathrm{t}$-value is below 1.96 and $\mathrm{P}-$ Value $>0.05$. Therefore, the null hypothesis for vendor non-technical factors is accepted and H5 rejected at 95\% level of significance. The findings for this research is not consistent with prior studies, such as that of Bhargava et al. (2013) who conducted a study in the "Selection Criteria for Data Mining Software" which showed that vendor non-technical factors are critical during the software selection process and in another study conducted in the mid-1990s by Chau (1995) evaluating important factors relating to the non-technical factors of the vendor by organisation owners and managers. In their study, reputation, business references, business skills, and past business with the vendor was rated more highly as significant. In the context of RSA FSPs organisations, this construct proved to be not significant. 


\section{Hypothesis 6 - Opinion Non-Technical Factors}

H6: "Opinion non-technical factors influence the selection of BI tools"

H0: "Opinion non-technical factors do not influence the selection of BI tools"

The results illustrated in Table 4.18 stipulate that there is a significant relationship between opinion non-technical factors and critical factors that drive the selection of BI tools ( $\mathrm{t}$ value $=2.571, \mathrm{p}$ value $=0.005$ ), the findings show $\mathrm{t}$-value is higher than 1.96 and $\mathrm{P}-$ Value $<0.05$. Therefore, the null hypothesis for opinion non-technical factors is rejected and H6 accepted at 95\% level of significance. The findings for this research are consistent with prior studies, such as that of Jadhav \& Sonar (2011) focused on the framework for evaluation and selection of the software packages: A hybrid knowledge- based system approach and (Eybers \& Giannakopoulos, 2015) study, Identifying critical success factors for BI systems. Both these studies concluded that opinions and views play a vital role during the process of software selection. What the professionals and decision- makers think of the tool or hear from peers may influence the choice of tool to employ. Opinion non-technical factors are significant in the context of RSA FSPs organisations.

\subsection{Summary of Chapter}

This section focused on data analysis to test significant constructs against proposed BI conceptual model. SPSS and SmartPLS3 was employed for the analysis. Proposed hypothesis were tested in this section and based on the study findings, the results have shown that software tool technical factors, vendor technical factors, and opinion non- technical factors proved to be significant and have influence on the selection of BI tools. Most notable is that a combination of technical and non-technical factors are vital to be considered. 


\section{CHAPTER FIVE- DISCUSSION AND SUMMARY OF FINDINGS}

\subsection{Introduction}

This chapter presents the discussion of the findings, the interpretation of the results, and summary of important elements of the study. Based on the findings of the results from hypotheses testing in section Four, results showed that three measure hypotheses are supported from the list of six posed hypotheses as critical and determinant factors influencing the selection of BI tools in the RSA setting for financial services organisations.

\subsection{Discussion of the Findings}

The findings of the study revealed that a subset and combination of technical and non-technical domain factors divided into a software tool, vendor, and opinion influence the selection of BI tools. These findings concur with the studies conducted by Farshidi et al. (2018), Hanine et al. (2016), and Jadhav \& Sonar (2011) who states in their studies that prominent technical and non-technical domain factors influence the selection of BI tools. Respondents ranked software tool technical factors as significant, critical, and influential. This led to the conclusion that when it comes to BI tools to employ, functionality, and ease of use plays a vital role. The respondents strongly agreed that functionality of software tool is important $(\mathrm{M}=4.48 ; \mathrm{SD}=0.58)$ and ease of use $(M=4.37 ; S D=0.65)$. Bhargava et al. (2013) in their study investigating the "selection criteria for data mining tool" found that software functionality and ease of use are vital, thus this is in line with the findings of the current study. Furthermore, Chau (1995) in their study investigating factors influencing the selection of packaged software in SMMEs found that ease of use/user-friendliness of the software package was viewed significant. This finding is not surprising since organisations would invest in a technology software that performs at an optimal level, error-free, and user-friendly to improve productivity and business operations without having to invest much time learning how to use the procured technology to address difficulties and complexities of the software tool. In the case of RSA FSPs, respondents rated this factor as significant since some users are generally not regarded as "sophisticated", secondly, in some organisations technical support might be generally inadequate.

Another important distinction noted is that organisations keep a close eye on how efficient the software tool to employ integrate and fit with already existing systems. The latter finding is supported by the study conducted by Farrokhi \& Pokoradi (2013) who found that efficiency, usablility, and maintanability are some of the salient factors/ characteristics software tool must 
suffice to be considered suitable and capable to deliver intended competences. Reinventing a wheel in the field of BI is a waste of time and resources, rather it is important to acquire technology platform that will work with existing solutions and support smooth and easy migration. It not surprising that in the case of RSA FSPs the issue of software tool compatibility with existing systems in rated high since it regarded as the strategic and compatibility issue as tactical/operational.

Respondents also stressed the significance of the underlying source code of the software tool; in most cases source code availability helps during debugging particularly when errors are encountered. It enables the control to fix and improve code as needed which is the benefit some organisations could be eager to explore to improve business operations and to keep up with business maturity. It is common for well-established organisations to perform maintenance and upgrades as to deal with business changing needs Chau (1995), therefore, it was expected that the respondents in RSA FSPs will rate this factor higher since the study focused on wellestablished and JSE listed organisations. Finally, it is not by chance that respondents deem software technical factors significant since they agree to the following statement: Software tools technical factors drive $\mathrm{BI}$ tool selection $(\mathrm{M}=3.96 ; \mathrm{SD}=1.015)$. The overall findings of the current study are in line with previous work conducted by Bhargava et al. (2013),Kara \& Cheikhrouhou (2014), and Mali \& Bojewar (2015) that revealed technical factors in relation to software tool are critical during the selection of software tool.

The findings surrounding vendor technical factors as being critical, means that organisations are cautious of jumping and rushing into contractual discussions and striking a deal with the potential vendor who is not capable to deliver and provide necessary technical support when the need arise. It is ubiquitous that some organisations end up purchasing the software in a vacuum and fail to reap the benefits it is intended for (Villamarín \& Diaz Pinzon, 2017). According to the respondents, the chosen vendor must show a high level of technical expertise $(\mathrm{M}=3.99 ; \mathrm{SD}=0.871)$, available for technical support $(\mathrm{M}=4.18 ; \mathrm{SD}=1.005)$, and a proven track record of good quality product $(\mathrm{M}=4.38 ; \mathrm{SD}=0.739)$. The latter findings are supported by few studies conducted around the subject like that of Jadhav \& Sonar (2011) and Bhargava et al. (2013) that revealed the importance of vendor competency and availability for technical support. Most notable is that having used the product produced by the same vendor is critical hence issues surrounding product quality, trust, proven technical expertise, and technical support do not become a concern and issue. In the case of RSA FSPs, it is noted that 
respondents value the technical ability of the vendor since the BI field is still growing and maturing. Furthermore, the skills shortage might be viewed as a challenge hence organisations reliance on the vendor technical support.

Additionally, the vendor being capable to provide additional material and documentation relating to tutorial documents for upskilling and self-learning is importing as it will help inhouse talent and human resources for upskilling purposes and subsequently save organisations tones of financial resources for formal training. Likewise, a guide that contains information relating to troubleshooting is important and the availability of user manuals very significant. In the case of RSA FSPs, the researcher conclude that the respondents rated the latter factors higher as to bridge the skills shortage gap that might exist in organisations. The overall findings around the vendor technical factors concur with literature that rate the vendor construct and linked technical factors critical during the selection of software (Chau, 1995; Chhina, 2016; Jadhav \& Sonar, 2009).

Opinion non-technical factors being a determinant in the selection of BI tools means that organisations focus on both functional and non-functional requirements of the software tool to employ; based on this, the researcher conclude that technical and non-technical factors need to be considered equally. The latter finding is supported by Bhargava et al. (2013) study findings that revealed a combination of technical and non-technical factors are interrelated and need to be considered and given attention equally. Most evidently is that organisations need to take into consideration the views of end-users/in-house experts $(\mathrm{M}=3.75 ; \mathrm{SD}=1.034)$ and those of other organisation employees regarding the software to employ. End-users are the individuals who use the procured and purchased software tool on daily basis and based on this study their opinion, views, and advice is important. In another study by Chau (1995) found that in-house expert opinions are rated high. In the case RSA FSPs study findings, this infers that organisations put higher weigh on the opinions given by internal sources, including in-house experts and end users.

Taking into consideration the views of in-house experts will help and bridge the gap which might exist on final decision-makers particularly the one that says "decision-makers may lack essential technical experience and technical knowledge due to long years without practicing" (Jadhav \& Sonar, 2009). Another benefit of including end-users in the software selection discourse helps to discover the readiness of inhouse resources who will use the selected 
technology tool and to audit the skillset they have. It is important to accommodate all the views (bottom-up approach) in the final decision-making process and to consults as to avoid purchasing the software in a vacuum (Villamarín \& Diaz Pinzon, 2017). In relation to the opinion non-technical factors, positive sentiments surrounding improvements in customer services proved to be vital, therefore most organisations prefer conducting business with a vendor whose client-centric, possessing a high level of ethical standards \& good business ethos, and value clients. The overall findings surrounding opinion construct and related factors concur with previous research conducted around the subject of software selection like the studies of Chau (1995); Jadhav \& Sonar (2011); Richards et al. (2019); and Villamarín \& Diaz Pinzon (2017) that emphasize the significance of considering opinion non-technical factors as the determinant for software tools selection.

The software tool non-technical factors relating to price, popularity, lifespan, and version currently in the market has been highlighted in some studies as significant and influential in the selection of tools (Büyüközkan et al., 2018; Jadhav \& Sonar, 2009). It is not surprising in this study as well that price $(\mathrm{M}=4.49 ; \mathrm{SD}=0.687)$ and software lifespan $(\mathrm{M}=4.12 ; \mathrm{SD}=0.724)$ were rated high by respondents. In some studies, like that of Chau (1995) has shown contrasting views in relation to software tool price factor that it is not always significant. Software tool non-technical factors as an overall construct proved otherwise, findings from the BI professionals in the RSA setting stipulates that software tool non-technical factors are insignificant. In a nutshell, the respondents do not rate these factors influential during the selection process of BI tools and thus, this means that the respondents were more concerned with how efficient, effective, and functional the software tool is capable to complete all the intended tasks. This explains that a huge number of respondents did not care about how much the software tool cost, only if the software does the functions it is purported to do, in contrary this contradict the findings by Jadhav \& Sonar (2011) who claim that cost and benefits relating to the software tool are vital and significant. Respondents agreed to the statements and sentiments surrounding version of the software $(M=3.80 ; S D=0.842)$, and popularity $(M=3.97$; $\mathrm{SD}=0.818$ ). Nevertheless, the latter findings still apply that as much as some of the individual characteristics/factors are significant, the overall construct was found to be insignificant, therefore the findings mean that the ease of use and functionality are more critical in the RSA FSPs. 
Vendor non-technical factors were also not rated to be significant by respondents even though certain studies in packaged software, big data tools selection, and ERP revealed that vendor non-technical factors are significant and influential (Jadhav \& Sonar, 2011). The findings in the RSA setting are that the organisations are satisfied and pleased with the vendor as much as the level of technical ability and expertise is possessed. One can conclude that vendor nontechnical factors come secondary if are considered to an extent. Though a huge number of respondents did not rate vendor non-technical factors as having influence in determining the choice of a software tool to employ as an organisation, they agree with the following statements/factors as important to give attention: reputation $(\mathrm{M}=4.41 ; \mathrm{SD}=0.649)$, business skills $(\mathrm{M}=4.11 ; \mathrm{SD}=0.763)$, references $(\mathrm{M}=4.11 ; \mathrm{SD}=0.805)$, past business experience $(\mathrm{M}=4.14 ; \mathrm{SD}=0.921)$, ethics and integrity $(\mathrm{M}=4.25 ; \mathrm{SD}=0.779)$, and professionalism $(\mathrm{M}=4.17 ; \mathrm{SD}=0.735)$.

Opinion technical factors proved to be insignificant in the study and this means the overall sentiments and advice offered by consultants, potential vendors/sales representatives, and computer/IS trade magazine, and software product leaflets have little to none influence on the software tool during the selection process of BI tools. Therefore, the findings are that external individuals may be biased and lack impartiality when providing advice and this may even speak to the issue of trust and integrity as far as external individuals are concerned. This finding contradicts previous work done by Chau (1995); Jadhav \& Sonar (2011) who claim that opinion technical factors are critical. Noteworthy is that a huge number of respondents shared the same sentiments that inhouse "Experts" views and advice ( $\mathrm{M}=3.72 ; \mathrm{SD}=1.103)$ is crucial, this finding means that organisations trust their own people and are certain their views are important and to go by. Respondents had no view when it comes to the following factors: external consultants $(\mathrm{M}=3.43 ; \mathrm{SD}=1.082)$, potential vendors/sales representatives and computer/IS trade magazine $(M=3.15 ; S D=1.048)$, software product leaflets $(M=2.77 ; S D=0853)$. Chau (1995) in their study found that even though computer/IS trade magazines or software tool leaflets are considered useful to an extent, to some degrees were rated to be least important by organisations owners. This finding is supported by the following statement which disagree that opinion technical factors are significant: Opinion technical factors drive BI tool selection $(\mathrm{M}=3.42 ; \mathrm{SD}=1.019)$. 
Out of the 92 respondents who participated in the study, 35 (38.04\%) replied to an open ended question regarding software tool technical factors, the question seeks additional factors deemed crucial and important not appearing from the list gathered from the literature, $11(31.42 \%)$ respondents out of 35 who participated on the question named software licensing as an additional critical factor. Software licensing refers to the legal document governing cost, use, terms and conditions, and redistribution of the software ( $\mathrm{Li}$ et al., 2017). When it comes to licensing, it is common that organisations find themselves at loggerheads with the software tool vendors in reaching the common ground and agreement, this is due to the exorbitant cost of such tools and the minimal number of licenses issued. The number of licenses issued by product vendors is usually limited hence organisations need to be aware of the number prior to striking a deal and signing of contracts.

Another factor relates to vendor technical factors and is called proof of concept (POC). The researcher noted that $15.23 \%$ (14) respondents named POC as critical and crucial. Proof of concept is defined as an evidence base demonstration to show that the software tool is feasible and functional prior to being filed (Kendig, 2015). This finding means that a vendor must demonstrate a level of capability and technical expertise to deliver a product that does the tasks effective and efficient. Demonstrating and verifying certain concepts and processes to be achieved during the development stage is important hence demos and prototypes are vital to be considered.

Lastly, vendor geographical location emerged as the vendor non-technical factor of which $16.30 \%$ (15) of respondents deem this factor crucial and critical. Respondents viewed the location of the vendor important especially when it comes to accessibility and how convenient and possible, they can visit a vendor. In most organisations, it common that during the initial stages of new technology purchase and adoption, end-users will spend time attending workshops, learning, and upskilling sessions at the vendor's work premises, therefore, access to the vendor as a factor needs a priority. It is also a good practice to know where the client you are doing business with is based in case working relationship collapse. 


\subsection{Summary of findings}

The purpose of this study was to discover and explore factors that influence the selection of BI tools to implement sound and successful BI systems/solutions meeting organisation needs and objectives. The study was guided by the following objectives: to identify critical factors to consider when selecting suitable BI tools of which when it is further broken down into smaller objectives it gives the following sub-objectives: to discover critical technical factors for BI tools selection, and to discover critical non-technical factors for BI tools selection.

The findings revealed that software tool technical factors, vendor technical factors, and opinion non-technical factors are critical and major important factors to be considered by financial organisations in the South African setting when selecting the choice of BI tools to employ. The surveyed BI professionals strongly agreed with the following statements concerning the factors they deemed critical: functionality of the software tool, ease of use/user-friendly, compatibility with existing hardware/software, availability of an integrated hardware/software package and lastly, availability of source code, and agreed with the following statements: quality of the product, availability of technical support, technical skills, availability of user manual for important information, tutorial for learning and troubleshooting guide, experience in using a product developed by the same vendor, and improvement in customer service. Most notable is that even though opinion non-technical factors are deemed critical when choosing the choice of BI tool to employ, respondents had no opinion when it comes to the following statements as having influence: subordinates and outside personnel acquaintances views.

\subsection{Chapter Summary}

Some studies in packaged software, ERP, big data, and project management fields have tried to understand the problem of software selection by discovering influential factors driving the selection, therefore it was imperative to test these factors in the BI space and most importantly to discover new critical factors deemed important. Study results frequently confirm that a combination of technical and non-technical factors concerning a software tool, vendor, and opinion is critical and a determinant. It is not surprising that based on this study software tool technical factors, vendor technical factors, and opinion non-technical factors were found to be critical and significant. Additional factors that relate to software licensing, vendor proof of concept (POC), and vendor geographical location emerged as additional influencing factors. 


\section{CHAPTER SIX- CONCLUSION AND RECOMMENDATIONS}

\subsection{Conclusion}

Studies have tried to understand the problem of BI tools selection by focusing on the selection methodology, selection criteria, evaluation criteria, and slightly on factors driving the selection of BI tools. Researchers have in different studies found that functionality, ease of use, userfriendly, technical support, technical skills, subordinates' opinion, and end-user's opinion factors (to name a few) have great significance while using existing theories as basis for empirical research results.

This study focused at discovering critical factors driving the selection of BI tools in RSA FSPs. The study answered the research question "What are the critical factors to consider when selecting BI tools in RSA FSPs?" of which, broken down into smaller sub-questions results in the following questions:" What are the technical factors that influence the selection of BI tools in RSA FSPs?" and "What are the non-technical factors that influence the selection of BI tools in RSA FSPs?". The findings of the analysis section concluded that three constructs were deemed as the main constructs that impact the selection of BI tools. As stipulated in chapter two, the research model used in this study was a proposed BI conceptual model. The conceptual model incorporated three major constructs namely: software tool, vendor, and opinion organized into technical and non-technical domain factors. The results of this study indicated that software tool technical factors, vendor technical factors, and opinion non-technical factors are the combination of significant factors that influence the selection of BI tools.

The research objectives of this paper were to " Identify the critical factors to consider when selecting suitable BI tools in RSA FSPs". The results of the study indicated that most BI professionals working in South African financial services providers deem functionality, ease of use/user-friendliness, compatibility with existing hardware/software, availability of an integrated hardware/software package, availability of source code, technical skills, availability of technical support, quality of product, experience in using product developed by same vendor, availability of user manual for important information, tutorial for learning and troubleshooting guide, end-users, and improvement in customer service are highly significant. Three other constructs namely: opinion technical factors, software tool non-technical factors, and vendor non-technical factors proved to be insignificant, but the individual factors which relate to price, 
lifespan, ethics \& integrity, professionalism, business skills, and external consultants opinion proved to be crucial hence organisations need to give attention to an extent.

The study contributes to both academia and industry, in discovering the critical factors driving the selection of BI tools, researchers and practitioners conducting research in the selection of software will benefit from this research work. It is hoped that new research work will arise and subsequently might benefit the BI research community. Since the research study aimed and focused at finding solutions to the issue of software selection experienced by industries during the selection of BI tools, organisations embarking on the selection of appropriate and suitable BI tools might immensely benefit since they will use discovered critical factors and constructs as the checklist and the basis for selection. It is hoped that these research findings might assist organisations to limit the rate at which they take uninformed decisions and reliance on human intuition during the BI tools selection process. The high failure rate of BI solutions and abandoned projects will be significantly curbed and minimized that are a result of inappropriate selection of BI tools.

\subsection{Limitations of the study}

Most of the data was collected using the emailed and online distributed questionnaire aimed and focused on one industry (financial services) in a specific geographic location (South Africa). Whether these results can be extended to other industries, the researcher views it as a matter of speculation. South Africa is a developing country and not known to be the hub of technology therefore in other geographic locations the issue of factors influencing the selection of BI tools might be viewed differently owing to a different background, economic position, and culture. Another limitation of the study is the return rate of emailed surveys and reluctance of participants to participate in the research study. To overcome the issue of online surveys and return rate, the researcher sent an email reminder to individuals known to the researcher, and for physically delivered questionnaires the researcher collected them.

Furthermore, BI is a new and emerging profession in South Africa; therefore, very few BI professionals were found and willing to participate in the study. Another limitation was the number of financial services institutions listed in the JSE top 100, the total of 24 financial institutions were gathered based on the market cap which is too little. To ensure unbiasedness in the results, the researcher surveyed at least one individual from each organisation (24 
organisations in the JSE top 100 list). The other limitations were related to time allocated to complete the research on time which limited the scope of the research project.

\subsection{Recommendations and Future Work}

The study recommendations are that a case study is necessary where the discovered significant factors may be tested to determine the extent to which they drive the success or failure of BI systems implementation. The discovered factors need to be tested across business units and organisations types classification (small medium enterprise and established) to determine their generic applicability. Based on the proposed conceptual model, it is suggested that further research is required to thoroughly test the framework for the purpose of adoption in the body knowledge of BI fraternity. It is recommended that additional factors that were gathered from participants namely: software licensing, vendor proof of concept (POC), and vendor geographical locations are tested for significance in the BI field prior to being adopted as critical factors to be considered during the software tool selection process.

Since the study was focused in the RSA setting, it is recommended that the factors identified as critical are tested in developed countries using an extensively large sample in the financial services organisations to accurately generalize the results for both developed and developing countries (comparative study). It also recommended that the very same factors must be tested against BI cloud tools as to gather insight of the generalization of these factors across BI field.

This study set out to determine and describe the critical factors that affect the selection of BI tools in RSA FSPs using the formulated BI conceptual model. Most of the previous work on the selection of technology software was carried out in developed countries. This study determined the factors relevant to BI tools selection from the perspective of a developing country (RSA). This survey based empirical study examined factors driving the selection of BI tools from $92 \mathrm{BI}$ professionals employed by RSA FSPs listed on the JSE based on the market capitalization. It found that software tool technical factors, vendor technical factors, and opinion non-technical factors are important determinants of BI tools selection in RSA FSPs. Whereas software tool non-technical factors, vendor non-technical factors, and opinion technical factors were found to be statistically insignificant in determining BI tools selection decisions in RSA FSPs. By leveraging on existing BI literature and examining BI selection 
theories in the IS context, this research has added to the body of knowledge on the factors that influence BI tools selection in FSPs. 


\section{REFERENCES}

Ahmed, A. (2008). Ontological, Epistemological and Methodological Assumptions: Qualitative versus Quantitative. In Online Submission.ERIC.Retrieved from https://www.researchgate.net/publication/267736833

Ali, F., Rasoolimanesh, S. M., Sarstedt, M., Ringle, C. M., \& Ryu, K. (2018). An assessment of the use of partial least squares structural equation modeling (PLS-SEM) in hospitality research. International Journal of Contemporary Hospitality Management, 30(1), 514-538. https://doi.org/10.1108/IJCHM-10-2016-0568

Alireza, S., \& Seyedeh, A. P. (2015). Comparing fuzzy AHP and fuzzy TOPSIS for evaluation of business intelligence vendors. Decision Science Letters, 4(2), 137-164. https://doi.org/10.5267/j.ds1.2015.1.002

Amuhaya, B. (2013). Factors Influencing The Choice of Technology For Development of Instructional Materials For Distance education: A Case of The School of Continuing and Distance Education [Masters dissertation, University of Nairobi]. Retrieved from http://erepository.uonbi.ac.ke:8080/handle/11295/56398

Ansari, R., Soltanzadeh, J., \& Tavassoli, A. (2016). Technology selection between technology management and decision making: a case study from the Iranian automotive industry. International Journal of Automotive Technology and Management, 16(4), 365-388.

Avgerou, C. (2008). Information systems in developing countries: A critical research review. Journal of Information Technology, 23(3), 133-146. https://doi.org/10.1057/palgrave.jit.2000136

Baah, E. M., Johnson, J. K., \& Twenefour, F. B. (2015). A Statistical Model of Organizational Performance using Factor Analysis--A case of a Bank in Ghana. International Journal of Mathematics and Statistics Studies, 3(1), 38-46.

Bach, M. P., Čeljo, A., \& Zoroja, J. (2016). Technology acceptance model for business intelligence systems: Preliminary research. Procedia Computer Science, 100, 995-1001.

Baglione, L. A. (2018). Writing a research paper in political science: A practical guide to inquiry, structure, and methods. Cq Press.

Bhargava, N., Aziz, A., \& Arya, R. (2013). Selection Criteria for Data Mining Software: A Study. International Journal of Computer Science Issues, 10(3), 308-312.

Bhattacherjee, A. (2012). Social science research: Principles, methods, and practices. Global text project.

Bogdana, P. I., Felicia, A., \& Delia, B. (2009). The role of business intelligence in business performance management. Annals of Faculty of Economics, 4(1), 1025-1029.

Borut, P., Tiago, O., \& Aleš, P. (2018). Understanding the determinants of business intelligence system adoption stages: An empirical study of SMEs. Industrial Management \& Data Systems, 118(1), 236-261. https://doi.org/10.1108/IMDS-05-2017-0170

Browner, W. S., Newman, T. B., \& Hulley, S. B. (2007). Estimating sample size and power: applications and examples. Designing Clinical Research, 3, 367. 
Büyüközkan, G., Göçer, F., \& Feyzioğlu, O. (2018). Cloud computing technology selection based on interval-valued intuitionistic fuzzy MCDM methods. Soft Computing, 22(15), 5091-5114. https://doi.org/10.1007/s00500-018-3317-4

Canito, J., Ramos, P., Moro, S., \& Rita, P. (2018). Unfolding the relations between companies and technologies under the Big Data umbrella. Computers in Industry, 99, 1-8. https://doi.org/https://doi.org/10.1016/j.compind.2018.03.018

Chau, P. Y. K. (1995). Factors used in the selection of packaged software in small businesses: views of owners and managers. Information \& Management, 29(2), 71-78. https://doi.org/10.1016/0378-7206(95)00016-P

Chen, H., Chiang, R. H. L., \& Storey, V. C. (2012). Business Intelligence and Analytics: From Big Data to Big Impact. MIS Quarterly, 36(4), 1165-1188. https://doi.org/10.2307/41703503

Chhina, R. (2016). Recommendation of Business Intelligence Tool [Masters dissertation,North Dakota State University].Retrieved from https://library.ndsu.edu/ir/handle/10365/25586

Chugh, R., \& Grandhi, S. (2013). Why Business Intelligence?: Significance of Business Intelligence Tools and Integrating BI Governance with Corporate Governance. International Journal of EEntrepreneurship and Innovation (IJEEI), 4(2), 1-14. https://www.igiglobal.com/article/whybusinessintelligence/89282

Collins, D. (2003). Pretesting survey instruments: an overview of cognitive methods. Quality of Life Research, 12(3), 229-238.

Curry, E. (2016). The big data value chain: definitions, concepts, and theoretical approaches. In New horizons for a data-driven economy, 29-37. Springer, Cham. https://doi.org/10.1007/978-3$\underline{319-21569-3 \quad 3}$

Damsgaard, J., \& Karlsbjerg, J. (2010). Seven principles for selecting software packages. Communications of the ACM, 53(8), 63-71. https://dl.acm.org/magazine/cacm

Dawson, L., \& Van Belle, J.-P. (2013). Critical success factors for business intelligence in the South African financial services sector. SA Journal of Information Management, 15(1), 1-12. https://doi.org/10.4102/sajim.v15i1.545

Edirisingha, P. (2012). Interpretivism and positivism (Ontological and epistemological perspectives). Research Paradigms and Approaches.

Efe, B. (2016). An integrated fuzzy multi criteria group decision making approach for ERP system selection. Applied Soft Computing Journal, 38, 106-117.

https://doi.org/10.1016/j.asoc.2015.09.037

Eybers, S., \& Giannakopoulos, A. (2015). Identifying critical success factors for business intelligence systems. Proceedings of the European Conference on IS Management and Evaluation, ECIME, 77-84.Bristol,England.

Eybers, S., Hattingh, M. J., \& Kuoe, L. (2019). Investigating Factors that Influence the Adoption of BI Systems by End Users in the Mining Industry in Southern Africa. Conference on E-Business, $e$-Services and e-Society, 113-124. Springer, Cham. Retrieved from https://doi.org/10.1007/978-3-030-29374-1_10

Farrokhi, V., \& Pokoradi, L. (2013). Organizational and technical factors for implementing business intelligence. Fascicle of Management and Technological Engineering, 1(1), 75-78. https://doi.org/10.15660/auofmte.2013-1.2785 
Farshidi, S., Jansen, S., de Jong, R., \& Brinkkemper, S. (2018). A decision support system for software technology selection. Journal of Decision Systems, 27(sup1), 98-110. https://doi.org/10.1080/12460125.2018.1464821

Feast, L., \& Melles, G. (2010). Epistemological positions in design research: A brief review of the literature. 2nd International Conference on Design Education, University of New South Wales, Sydney, Australia.Retrieved from http://folksonomy.co/?permalink=3125

Ferland, C., \& Flachbarth, J. (2018). IR and Vendors: Selecting the Right Product. New Directions for Institutional Research, 2018(178), 27-37. http://10.0.3.234/ir.20265

Fischer, M., Heim, D., Hösselbarth, M., Winkelmann, A., \& Kurosu, M. (2017). Assessing Organization-System Fit in ERP Selection Procedures - A Literature Review. Springer International Publishing, 10271, 134-149. https://doi.org/10.1007/978-3-319-58071-5_11

Flannelly, L. T., Flannelly, K. J., \& Jankowski, K. R. B. (2014). Independent, Dependent, and Other Variables in Healthcare and Chaplaincy Research. Journal of Health Care Chaplaincy, 20(4), 161-170. https://doi.org/10.1080/08854726.2014.959374

Gartner Magic Quadrant for Data Intergration Tools, (2019). Retrieved from https://www.gartner.com/doc/reprints?id=1-10CI16P3\&ct=190801\&st=sb

Ghauri, P., Grønhaug, K., \& Strange, R. (2020). Research methods in business studies. Cambridge University Press.

Gillon, K., Aral, S., Lin, C.-Y., Mithas, S., \& Zozulia, M. (2014). Business analytics: radical shift or incremental change? Communications of the Association for Information Systems, 34(1), 13. https://aisel.aisnet.org/cais/vol34/iss1/13/

Grandhi, S., \& Wibowo, S. (2018). A Multi-Criteria Group Decision Making Method for Selecting Big Data Visualization Tools. Journal of Telecommunication, Electronic and Computer Engineering (JTEC), 10(1-8), 67-72.

https://journal.utem.edu.my/index.php/jtec/article/view/3737

Hair, Joe F., Sarstedt, M., Ringle, C. M., \& Mena, J. A. (2012). An assessment of the use of partial least squares structural equation modeling in marketing research. Journal of the Academy of Marketing Science, 40(3), 414-433.

Hair, Joseph. F., Black, W. C., Babin, B. J., Anderson, R. E., Tatham, R. L., \& others. (2006). Multivariate data analysis (Vol. 6). Upper Saddle River, NJ: Pearson Prentice Hall.

Hancock, P. G. (2011). Informal learning at work: the art of learning by doing [Doctorate, Melbourne Graduate School of Education, The University of Melbourne]. Retrieved from https://minervaaccess.unimelb.edu.au/handle/11343/36289

Hanine, M., Boutkhoum, O., Agouti, T., \& Tikniouine, A. (2017). A new integrated methodology using modified Delphi-fuzzy AHP-PROMETHEE for Geospatial Business Intelligence selection. Information Systems and E-Business Management, 15(4), 897-925. https://link.springer.com/article/10.1007/s10257-016-0334-7

Hanine, M., Boutkhoum, O., Tikniouine, A., \& Agouti, T. (2016). Application of an integrated multicriteria decision making AHP-TOPSIS methodology for ETL software selection. SpringerPlus, 5(1), 263. https://doi.org/10.1186/s40064-016-1888-Z

Hanson, C. (2012). Indigenous Research Methodologies. International Journal of Critical Indigenous Studies, 5(1), 93-95.

Harnisch, S. (2014). Enterprise-level packaged software acquisition: A structured literature review through the lens of IT governance. ECIS 2014 Proceedings - 22nd European Conference on Information Systems, 0-17.Retrieved from https://ideas.repec.org/p/dar/wpaper/65170.html 
Hart, C. (2018). Doing a literature review: Releasing the research imagination.Sage.

Hartley, K., \& Seymour, L. F. (2011). Towards a Framework for the Adoption of Business Intelligence in Public Sector Organisations: The Case of South Africa. Proceedings of the South African Institute of Computer Scientists and Information Technologists Conference on Knowledge, Innovation and Leadership in a Diverse, Multidisciplinary Environment, 116-122. Retrieved from https://doi.org/10.1145/2072221.2072235

Hughes, D. L., Rana, N. P., \& Simintiras, A. C. (2017). The changing landscape of IS project failure: an examination of the key factors. Journal of Enterprise Information Management, 30(1), 142165. https://doi.org/10.1108/JEIM-01-2016-0029

Hussein, G., Grida, M., \& Zaied, A. N. (2020). Critical Success Factors Framework for implementing and adapting BIS on Organizational Performance. International Journal of Business Information Systems, 1, 1. https://doi.org/10.1504/IJBIS.2020.10023785

IcsiK, Öy., Jones, M. C., \& Sidorova, A. (2013). Business intelligence success: The roles of BI capabilities and decision environments. Information \& Management, 50(1), 13-23.

Jadhav, A. S., \& Sonar, R. M. (2009). Evaluating and selecting software packages: A review. Information and Software Technology, 51(3), 555-563. https://doi.org/10.1016/j.infsof.2008.09.003

Jadhav, A. S., \& Sonar, R. M. (2011). Framework for evaluation and selection of the software packages: A hybrid knowledge based system approach. Journal of Systems and Software, 84(8), 1394-1407. https://doi.org/10.1016/j.jss.2011.03.034

JSE. (2019). Top 100 JSE Listed Firms By Market Capitalisation.Retrieved from https://www.sashares.co.za/top-100-jse-companies/

Kara, S. S., \& Cheikhrouhou, N. (2014). A multi criteria group decision making approach for collaborative software selection problem. Journal of Intelligent and Fuzzy Systems, 26(1), 37-47. https://doi.org/10.3233/IFS-120713।

Kendig, C. (2015). What is Proof of Concept Research and how does it Generate Epistemic and Ethical Categories for Future Scientific Practice? Science and Engineering Ethics, 22, 735-753. https://doi.org/10.1007/s11948-015-9654-0

Kilinç, H., \& Firat, M. (2017). Opinions of expert academicians on online data collection and voluntary participation in social sciences research. Educational Sciences: Theory \& Practice, 17(5), 1467-1486. https://doi.org/10.12738/estp.2017.5.0261

Kock, N. (2015). One-tailed or two-tailed P values in PLS-SEM? International Journal of ECollaboration (IJeC), 11(2), 1-7.

Kock, N. (2016). Hypothesis testing with confidence intervals and P values in PLS-SEM. International Journal of E-Collaboration (IJeC), 12(3), 1-6.

Kok, J. A. (2006). Business intelligence and the telecommunications industry: Can business intelligence lead to higher profits? South African Journal of Information Management, 8(3), 1.

Krejcie, R. V, \& Morgan, D. W. (1970). Determining sample size for research activities. Educational and Psychological Measurement, 30(3), 607-610.

Lake, P., \& Crowther, P. (2013). Data, an organisational asset. In Concise Guide to Databases. Springer, London.

Lautenbach, P., Johnston, K., \& Adeniran-Ogundipe, T. (2017). Factors influencing business intelligence and analytics usage extent in South African organisations. South African Journal of Business Management, 48(3), 23-33. 
Lederman, N. G., \& Lederman, J. S. (2015). The Status of Preservice Science Teacher Education: A Global Perspective. Journal of science teacher education, 26(1), 1-6. https://doi.org/10.1007/s10972-015-9422-7

Lehmann, D., Fekete, D., \& Vossen, G. (2016). Technology selection for big data and analytical applications (ERCIS Working Paper, No. 27). http://hdl.handle.net/10419/156084

Li, S., Cheng, H. K., Duan, Y., \& Yang, Y.-C. (2017). A study of enterprise software licensing models. Journal of Management Information Systems, 34(1), 177-205.

Liberatore, M. J., \& Pollack-Johnson, B. (2003). Factors influencing the usage and selection of project management software. IEEE Transactions on Engineering Management, 50(2), 164-172. https://doi.org/10.1109/TEM.2003.810821

Ma, D., Chang, C.-C., \& Hung, S.-W. (2013). The selection of technology for late-starters: A case study of the energy-smart photovoltaic industry. Economic Modelling, 35, 10-20.

Magaireah, A. I., Sulaiman, H., \& Ali, N. (2017). Theoretical framework of critical success factors (CSFs) for Business Intelligence (BI) System. ICIT 2017 - 8th International Conference on Information Technology, Proceedings, 455-463. Amman. Retrieved from https://doi.org/10.1109/ICITECH.2017.8080042

Mali, N., \& Bojewar, S. (2015). A Survey of ETL Tools. International Journal of Computer

Techniques, 2(5), 20-27. http://www.ijctjournal.org/

Malinin, L. (2016). Technology selection based on main parameters of value and fuzzy logic. International Journal of Business Innovation and Research, 11(3), 431-443. https://doi.org/10.1504/IJBIR.2016.078876

Moody, W., Kinderman, P., \& Sinha, P. (2010). An exploratory study. Journal of Fashion Marketing and Management: An International Journal, 4(3), 2-3. https://doi.org/10.1080/0097840X.1978.9934988

Moore, D. S., Notz, W. I., \& Fligner, M. A. (2015). The basic practice of statistics. Macmillan Higher Education.

Moreno Saavedra, M. S., \& Bach, C. (2017). Factors to Determine Business Intelligence Implementation in Organizations. European Journal of Engineering Research and Science, 2(12), 1. https://doi.org/10.24018/ejers.2017.2.12.527

Mudzana, T., \& Maharaj, M. (2015). Measuring the success of business-intelligence systems in South Africa: An empirical investigation applying the DeLone and McLean Model. SA Journal of Information Management, 17(1), 1-7. https://doi.org/10.4102/sajim.v17i1.646

Negash, S., \& Gray, P. (2008). Business intelligence. In Handbook on decision support systems 2, 175-193. Springer Berlin, Heidelberg.

Osanloo, A., \& Grant, C. (2016). Understanding, selecting, and integrating a theoretical framework in dissertation research: Creating the blueprint for your "house." Administrative Issues Journal: Connecting Education, Practice, and Research, 4(2), 7.

Oztaysi, B. (2015). A group decision making approach using interval type-2 fuzzy ahp for enterprise information systems project selection. Journal of Multiple-Valued Logic and Soft Computing, 24(5-6), 475-500.

Palanisamy, R., Verville, J., Bernadas, C., \& Taskin, N. (2010). An empirical study on the influences on the acquisition of enterprise software decisions: A practitioner's perspective. Journal of Enterprise Information Management, 23(5), 610-639. https://doi.org/10.1108/17410391011083065 
Pellissier, R., \& Kruger, J.-P. (2011). Understanding the use of strategic intelligence as a strategic management tool in the long-term insurance industry in South Africa. SA Journal of Information Management, 13(1), 1-13. https://doi.org/10.4102/sajim.v13i1.426

Pham, Q., Mai, T. and Misra, S. (2016) .Critical success factors for implementing business intelligence system: empirical study in Vietnam, in Gervasi, O. et al. (Ed.): International Conference on Computational Science and Its Applications, Springer International Publishing, 567-584. Beijing, China. Retrieved from https://doi.org/10.1007/978-3-319-42092-9_43

Ponelis, S. R. (2012). An exploratory study of business intelligence in knowledge-based growth small, medium and micro-enterprises in South Africa. [PhD dissertation, University of Pretoria].Retrieved from https://doi.org/10.13140/2.1.1439.1360

Pretorius, H. W., Mawela, T., Strydom, I., Villiers, C. de, \& Johnson, R. D. (2015). Continuing the discourse of women in information technology: a South African perspective. Gender, Technology and Development, 19(3), 346-369.

Qualtrics, L. L. C. (2014). Online survey software tools and solutions: Qualtrics. Retrieved from https://www.qualtrics.com/uk/

Rahman, N. (2018). DATA WAREHOUSING AND BUSINESS INTELLIGENCE WITH BIG DATA. In E-H. Ng, B. Nepal, E. Schott, and H. Keathley (Eds.). Proceedings of the International Annual Conference of the American Society for Engineering Management., 16.Hunsville. Retrieved from https://search.proquest.com/openview/95bf52ff82aa63a77969946626f4cd2a/1 ?pqorigsite $=$ gscholar $\& \mathrm{cbl}=2037614$

Rezaie, K., Ansarinejad, A., Haeri, A., Nazari-Shirkouhi, A., \& Nazari-Shirkouhi, S. (2011). Evaluating the business intelligence systems performance criteria using group fuzzy AHP approach. 2011 UkSim 13th International Conference on Computer Modelling and Simulation, 360-364. https://doi.org/10.1109/UKSIM.2011.75

Richards, G., Yeoh, W., Chong, A. Y. L., \& Popovič, A. (2019). Business intelligence effectiveness and corporate performance management: an empirical analysis. Journal of Computer Information Systems, 59(2), 188-196.

Saedi, D., \& Danielsson, P. (2018). Business Intelligence: Understanding disparity in information interpretation[Masters dissertation, Karlstads Universitet].

Saunders, M., Lewis, P., \& Thornhill, A. (2016). Research methods for business students (Vol. Seventh).In Harlow: Pearson Education.

Sharda, R., Delen, D., Turban, E., Aronson, J., \& Liang, T. (2014). Business intelligence and analytics. In System for Decesion Support. Pearson Edition Limited.

Shariat, M., \& Hightower Jr, R. (2007). Conceptualizing business intelligence architecture. Marketing Management Journal, 17(2), 40-46.

Shi, Y., \& Lu, X. (2010). The Role of Business Intelligence in Business Performance Management. 2010 3rd International Conference on Information Management, Innovation Management and Industrial Engineering, 4, 184-186. Kunming. Retrieved from https://doi.org/10.1109/ICIII.2010.522

Simitsis, A., Vassiliadis, P., Dayal, U., Karagiannis, A., \& Tziovara, V. (2009). Benchmarking ETL workflows. Technology Conference on Performance Evaluation and Benchmarking, 199-220. Springer, Berlin, Heidelberg. Retrieved from https://link.springer.com/chapter/10.1007/978-3$\underline{642-10424-4 \_15}$

Soloukdar, A., \& Parpanchi, S. (2015). Comparing fuzzy AHP and fuzzy TOPSIS for evaluation of business intelligence vendors. Decision Science Letters, 4(2), 137-164. 
Stříteský, V. (2017). Outsourcing: Benefits and Costs for Businesses [ Bachelor thesis, Charles University]. Retrieved from https://dspace.cuni.cz/handle/20.500.11956/85890

Thamir, A., \& Poulis, E. (2015). Business intelligence capabilities and implementation strategies. International Journal of Global Business, 8(1), 34.

Trieu, V.-H. (2017). Getting value from Business Intelligence systems: A review and research agenda. Decision Support Systems, 93, 111-124. https://doi.org/10.1016/j.dss.2016.09.019

Tsai, W.-H., Lee, P.-L., Shen, Y.-S., \& Lin, H.-L. (2012). A comprehensive study of the relationship between enterprise resource planning selection criteria and enterprise resource planning system success. Information \& Management, 49(1), 36-46.

https://doi.org/https://doi.org/10.1016/j.im.2011.09.007

Venter, P., \& Tustin, D. (2009). The availability and use of competitive and business intelligence in South African business organisations. Southern African Business Review, 13(2).

Villamarín, J. M., \& Diaz Pinzon, B. (2017). Key success factors to business intelligence solution implementation. Journal of Intelligence Studies in Business, 7(1), 48-69. https://ojs.hh.se/index.php/JISIB

Walliman, N. (2017). Research methods: The basics. Routledge.

Wieder, B., \& Ossimitz, M.-L. (2015). The impact of Business Intelligence on the quality of decision making--a mediation model. Procedia Computer Science, 64, 1163-1171.

Wixom, B., \& Watson, H. (2010). The BI-based organization. International Journal of Business Intelligence Research (IJBIR), 1(1), 13-28.

Wyatt, L., Caufield, B., \& Pol, D. (2009). Principles for an ETL Benchmark. Technology Conference on Performance Evaluation and Benchmarking, 183-198. Springer, Berlin, Heidelberg. Retrieved from https://link.springer.com/chapter/10.1007/978-3-642-10424-4_14

Yeoh, W., \& Koronios, A. (2010). Critical Success Factors for Business Intelligence Systems. Journal of Computer Information Systems, 50(3), 23-32. https://doi.org/10.1080/08874417.2010.11645404

Zaidan, A. A., Zaidan, B. B., Hussain, M., Haiqi, A., Kiah, M. L. M., \& Abdulnabi, M. (2015). Multicriteria analysis for OS-EMR software selection problem: A comparative study. Decision Support Systems, 78, 15-27. https://doi.org/10.1016/j.dss.2015.07.002 


\section{APPENDICES}

APPEndix A: Financial Services Providers

\begin{tabular}{|l|l|l|}
\hline \multicolumn{1}{|c|}{ BANKS } & \multicolumn{1}{|c|}{ INVESTMENT } & \multicolumn{1}{c|}{ INSURANCE } \\
\hline Standard Bank Group Ltd. & Remgro Ltd. & Sanlam Ltd. \\
\hline Nedbank Group Ltd. & Investec plc & Old Mutual Ltd. \\
\hline Absa Group Ltd. & Rand Merchant Investment Holdings Ltd. & Discovery Ltd. \\
\hline Capitec Bank Holdings Ltd. & Quilter plc & Santam Ltd. \\
\hline FirstRand Ltd. & PSG Group Ltd. & Liberty Holdings Ltd. \\
\hline RMB Holdings Ltd. & Coronation Fund Managers Ltd. & MMI Holdings Ltd. \\
\hline Investec Ltd. & Brait SE & \\
\hline & PSG Konsult Ltd. & \\
\hline & Ninety-One plc & \\
\hline & Pepkor Holdings Ltd. & \\
\hline
\end{tabular}

Source: (JSE, 2019) 


\section{APPENDIX B: Letter of Introduction to Respondents}

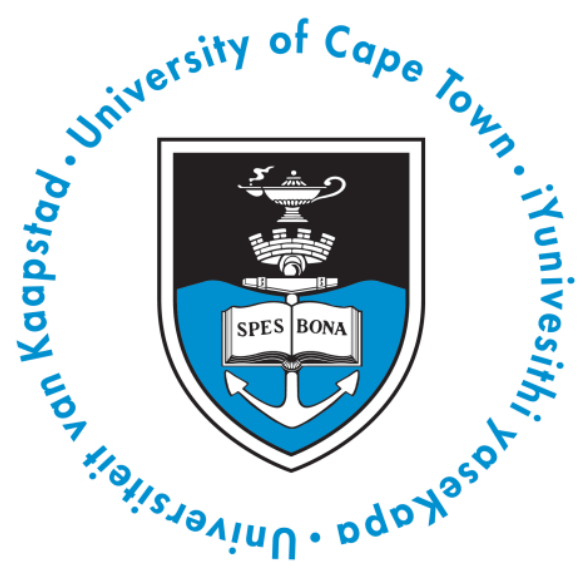

Dear Respondent,

Bonginkosi Phila Gina

Faculty of Commerce

Department of Information Systems

University of Cape Town

$3^{\text {rd }}$ Floor, Leslie Commence, Engineering Mall

Upper Campus

I am Bonginkosi Phila Gina, a master's student in the department of information systems at the University of Cape Town (UCT). I am conducting a final research project on the factors that influence choice of business intelligence $(\mathrm{BI})$ tools for the successful implementation of $\mathrm{BI}$ systems. It is the requirements of the course for the researcher to write a dissertation paper with substantiated results and findings based on the data collected around the subject being studied. Also note that the research has been approved by the Commerce Faculty Ethics in Research Committee.

Kindly and honestly respond to all the items of the questionnaire. The questionnaire is for the research purpose only and hence utmost confidentiality will be observed. Please note that taking part in this study is voluntary and you may discontinue responding to the questionnaire at any time if the need arises. Please note that there is no harm associated with the study. The questionnaire will take you approximately 15 minutes to complete, if however, you have questions please feel free to contact the researcher as per the details below:

Email addresses: GNXBON002@myuct.ac.za or bonginkosiphilagina87@gmail.com Cell: +27767910123

Thank for your co-operation.

Yours faithfully,

Bonginkosi Phila Gina 


\section{APPENDIX C: Survey of Factors Driving the Selection of Business Intelligence Tools}

\section{Section A: Demographic information}

1.Gender $\square$ Male $\square$ Female

2. Age

(Tick where appropriate)

$\square$ 18-24 years $\square 25$-34 years $\square$ 35-44 years $\square$ 45-54 years $\square$ Over 55 years

3. Education level

(Tick where appropriate)

Diploma $\square$ Bachelor's Degree $\square$ Hounors Degree $\square$ Master's Degree $\square$ PHD

Other (Specify)

4. How many years have you worked within the Information Technology Sector?

(Tick where appropriate)

$\square$ 1-5 years $\square$ 6-10 years $\square 11-15$ years $\square$ Over 16 years

5. Indicate the position that you are occupying

6. Indicate the type of financial organisation you work for e.g. Bank, Insurance etc.

7. How many individuals are employed in your organisation?

(Tick where appropriate)

$\square$ Less Than $50 \square$ 50-99 $\square$ 100-999 $\square$ 1,000-9,999 $\square$ 10,000-99,999 $\square$ 100,000 or More 


\section{Section B: Technical Factors Influencing Business Intelligence Selection}

1. Indicate the extent to which the following technical factors influence the selection of business intelligence tools in relation to the software tool

\section{1-Very little extent 2 -Little extent 3- No opinion 4- Great Extent 5 -Very Great}

\begin{tabular}{|l|l|l|l|l|l|}
\hline Software Tool & $\mathbf{1}$ & $\mathbf{2}$ & $\mathbf{3}$ & $\mathbf{4}$ & $\mathbf{5}$ \\
\hline Availability of an Integrated hardware/software package & & & & & \\
\hline Compatibility with existing hardware/software & & & & & \\
\hline Ease of use/User-friendly & & & & & \\
\hline Functionality & & & & & \\
\hline Availability of source code & & & & & \\
\hline
\end{tabular}

2.Apart from the list of technical factors provided above, which other critical technical factors in relation to software tool do you recommend.

3. Indicate the extent to which the following technical factors influence the selection of business intelligence tools in relation to the vendor

1-Very little extent 2 -Little extent 3- No opinion 4- Great Extent 5 -Very Great

\begin{tabular}{|l|l|l|l|l|l|}
\hline Vendor & $\mathbf{1}$ & $\mathbf{2}$ & $\mathbf{3}$ & $\mathbf{4}$ & $\mathbf{5}$ \\
\hline Availability of technical support & & & & & \\
\hline $\begin{array}{l}\text { Availability of User manual for important information, tutorial } \\
\text { for learning and troubleshooting guide }\end{array}$ & & & & & \\
\hline Technical skills & & & & & \\
\hline Experience in using product developed by same vendor & & & & & \\
\hline Quality of product & & & & & \\
\hline
\end{tabular}

4.Apart from the list of technical factors provided above, which other critical technical factors in relation to vendor do you recommend. 
5. Indicate the extent to which the following technical factors influence the selection of business intelligence tools in relation to the opinions

1-Very little extent 2 -Little extent 3- No opinion 4- Great Extent 5 -Very Great

\begin{tabular}{|l|l|l|l|l|l|}
\hline Opinions & $\mathbf{1}$ & $\mathbf{2}$ & $\mathbf{3}$ & $\mathbf{4}$ & $\mathbf{5}$ \\
\hline Potential vendors/sales representatives & & & & & \\
\hline In house "Experts" & & & & & \\
\hline External Consultants & & & & & \\
\hline Computer/IS trade magazine, software product leaflets & & & & & \\
\hline
\end{tabular}

6.Apart from the list of technical factors provided above, which other critical technical factors in relation to vendor do you recommend.

7. To what extent do you agree with the following statements? Respond using the following

key: SA - Strongly Agree A - Agree N - Neutral

D - Disagree SD - Strongly Disagree

\begin{tabular}{|l|l|l|l|l|l|}
\hline Statement & SA & A & N & D & SD \\
\hline $\begin{array}{l}\text { Software tools technical factors drive business intelligence tool } \\
\text { selection }\end{array}$ & & & & & \\
\hline $\begin{array}{l}\text { Vendor technical factors drive business intelligence tool } \\
\text { selection }\end{array}$ & & & & & \\
\hline $\begin{array}{l}\text { Opinions technical factors drive business intelligence tool } \\
\text { selection }\end{array}$ & & & & & \\
\hline $\begin{array}{l}\text { The Identified technical factors for selection BI tools influence } \\
\text { the success of BI systems implementation }\end{array}$ & & & & & \\
\hline
\end{tabular}




\section{Section C: Non-Technical Factors Influencing Business Intelligence Selection}

1. Indicate the extent to which the following non-technical factors influence the selection of business intelligence tools in relation to the software tool

\section{1-Very little extent 2 -Little extent 3- No opinion 4- Great Extent 5 -Very Great}

\begin{tabular}{|l|l|l|l|l|l|}
\hline Software Tool & $\mathbf{1}$ & $\mathbf{2}$ & $\mathbf{3}$ & $\mathbf{4}$ & $\mathbf{5}$ \\
\hline Price & & & & & \\
\hline Popularity & & & & & \\
\hline Lifespan & & & & & \\
\hline Version currently in the market & & & & \\
\hline
\end{tabular}

2.Apart from the list of non-technical factors provided above, which other critical technical factors in relation to software tool do you recommend.

3. Indicate the extent to which the following non-technical factors influence the selection of business intelligence tools in relation to the vendor

1-Very little extent 2 -Little extent 3- No opinion 4- Great Extent 5 -Very Great

\begin{tabular}{|l|l|l|l|l|l|}
\hline Vendor & $\mathbf{1}$ & $\mathbf{2}$ & $\mathbf{3}$ & $\mathbf{4}$ & $\mathbf{5}$ \\
\hline Reputation & & & & & \\
\hline Business Skills & & & & & \\
\hline References & & & & & \\
\hline Past business experience with vendor & & & & & \\
\hline Ethics and Integrity & & & & & \\
\hline Professionalism & & & & & \\
\hline
\end{tabular}

4.Apart from the list of non-technical factors provided above, which other critical technical factors in relation to vendor do you recommend. 
5. Indicate the extent to which the following non-technical factors influence the selection of business intelligence tools in relation to the opinions

\section{1-Very little extent 2 -Little extent 3- No opinion 4- Great Extent 5 -Very Great}

\begin{tabular}{|l|l|l|l|l|l|}
\hline Opinions & $\mathbf{1}$ & $\mathbf{2}$ & $\mathbf{3}$ & $\mathbf{4}$ & $\mathbf{5}$ \\
\hline Subordinates & & & & & \\
\hline End-users & & & & & \\
\hline Outside personnel acquaintances & & & & & \\
\hline Improvement in customer service & & & & & \\
\hline
\end{tabular}

6.Apart from the list of non-technical factors provided above, which other critical technical factors in relation to vendor do you recommend.

7. To what extent do you agree with the following statements? Respond using the following key: SA - Strongly Agree A - Agree N - Neutral

D - Disagree SD - Strongly Disagree

\begin{tabular}{|l|l|l|l|l|l|}
\hline Statement & SA & A & N & D & SD \\
\hline $\begin{array}{l}\text { Software tools non-technical factors drive business intelligence } \\
\text { tool selection }\end{array}$ & & & & & \\
\hline $\begin{array}{l}\text { Vendor non-technical factors drive business intelligence tool } \\
\text { selection }\end{array}$ & & & & & \\
\hline $\begin{array}{l}\text { Opinions non-technical factors drive business intelligence tool } \\
\text { selection }\end{array}$ & & & & & \\
\hline $\begin{array}{l}\text { The Identified non-technical factors for selection BI tools } \\
\text { influence the success of BI systems implementation }\end{array}$ & & & & & \\
\hline
\end{tabular}

Thank you for your cooperation 
APPENDIX D: Research Ethics Application Approval

\begin{tabular}{|c|c|c|}
\hline \multicolumn{2}{|c|}{ Commerce Ethics in Research } & Powered by Subritivin 0 \\
\hline \multirow[t]{3}{*}{ Project Ette: } & Ethics Application Approval & $11 / 05 / 2019$ \\
\hline & $\begin{array}{l}\text { by Bonginkosi Gina in Commerce Faculty Ethics } \\
\text { Applications } 2019\end{array}$ & id. 14383397 \\
\hline & GNDCBON002@mmuxtac.za & \\
\hline
\end{tabular}

Original submission

$11 / 05 / 2019$

\begin{tabular}{|c|c|}
\hline $\begin{array}{l}\text { UCT Student / Staff } \\
\text { Number }\end{array}$ & GNOXBND02 \\
\hline $\begin{array}{l}\text { Degree Being Studied } \\
\text { (For Students Only) }\end{array}$ & MCOM by Coursework and Dissertation in Information Systems \\
\hline $\begin{array}{l}\text { Celphone Number/ } \\
\text { UCT Extersion }\end{array}$ & 0767910123 \\
\hline UCT Email Address & GNOXBON002gmyuct.ac.za \\
\hline $\begin{array}{l}\text { Alemative Email } \\
\text { Address }\end{array}$ & bonginkosiphilagina87@gmail.com \\
\hline $\begin{array}{l}\text { 1. PRONECT } \\
\text { DETAILS }\end{array}$ & nis \\
\hline $\begin{array}{l}\text { Principal } \\
\text { Researcherls: }\end{array}$ & GNOXBON002gmyuct.ac.za \\
\hline Status of Applicant & Master Student \\
\hline \multicolumn{2}{|l|}{$\begin{array}{l}\text { Supervisor Name (For th } \\
\text { Students Only) : }\end{array}$} \\
\hline $\begin{array}{l}\text { Supervisor email } \\
\text { address }\end{array}$ & adheesh.budreeguct.ac.za \\
\hline Department: & Department of Information Systems \\
\hline $\begin{array}{l}\text { Co-researcher(s) } \\
\text { Names: }\end{array}$ & $\mathrm{n} / \mathrm{a}$ \\
\hline $\begin{array}{l}\text { Co-researcher(s) } \\
\text { Email Addresses: }\end{array}$ & $\mathrm{n} / \mathrm{a}$ \\
\hline Review Track & Normal \\
\hline
\end{tabular}


Brief description of the research project
The selection of business intelligence(Bl) tools in the financial services sector has been viewed as a serious concern and problem for managers and organisations which result in many business intelligence projects failure and abandoned. The study seeks to discover and identify critical factors which drive the selection of business intelligence tools for South African financial services providers. The population for the study are al business intelligence professionals working for South African financial services providers listed on the Johannesburg Stock Exchange (JSE). The main objective/s of the study are described below:

1.Identify critical factors to consider when selecting suitable business intelligence tools.

Sub-Objectives

1.1. Discover critical technical factors for Bil tools selection.

1.2. Discover critical non-technical factors for BI tools selection.

1.3. Develop a guide to help organizations select suitable business intelligence tools.

1.4. Minimize failure rate of Bi systems implementation.

Data colection:

Questionnaire

(please select)

File Upload

Literature_Revlew_GNXBON002.docx

Research_Design_GNXBOND02.docx

Introduction_Letter_for_Participants.docx

SURVEY_OF_FACTORS_DRMNG_THE_SELECTION_OF_BUSINESS_INTELLIGENCE_TOOLS.dOCX

Have you attached a Yes

research proposal

with research

methodology?

\section{PARTICIPANTS NIE}

2.1. Please indicate below the affiliations

Company employees

of participants from the list below :

$\begin{array}{ll}2.2 \text { Please describe } & \begin{array}{l}\text { The study will use anonymous questionnaires/surveys and no participants } \\ \text { identifiable information or records will be collected.Upon data collection, }\end{array} \\ \text { how you plan to } & \text { each respondent will be given an introduction letter which briefly describe } \\ \text { protect the } & \text { the research at hand and objectives. Moreover, the letter will speclify all the } \\ \text { participants } & \text { participants rights upon taking part in a survey. }\end{array}$


research discriminate

against participation

by individuals, or

differentiate between

participants, on the

grounds of gender,

race or ethnic group.

age range, religion,

income, handicap.

illness or any similar

classification?

\subsection{Does the}

No

research require the

participation of

socially or physically

vulnerable people

(children, aged,

disabled, etc.) or

legaly restricted

groups?

2.5 Will you be able to Yes

secure the informed

consent of all

participants in the

research? (In the

case of children, will

you be able to obtain

the consent of their

guardlans or

parents?)

2.6 Will any

No

confidential data be

collected or wilt

identifiable records of

individuals be kept?

2.7 In reporting on this No

research is there any

possibility that you will

not be able to keep

the identities of the

individuals involved

anonymous?

2.8 Are there any foreseeable risks of

physical,

psychological or

social harm to

participants that might

occur in the course of

the research? 
2.9 Does the

research include

making payments or

giving gifts to amy

participants?

2.10 Race / Ethnicity - No

Are you asking a

question about

race/ethnicity in your

questionnaire?

2.13 Gender - Are you Yes

asking a question

about gender in your

questionnaire?

2.14 If you answered Yes

Yes to 2.13 - Have

you included the

option: Prefer not to

answer" as part of

your gender question?

* If you have selected $\mathrm{n} / \mathrm{s}$

"No" in 2.14, please

explain why

3. PROMSION OF $\mathrm{n} / \mathrm{s}$

SERMCES

3.1 Does your

No

research involve the

provision of services

to communities?

* If your answer is

YES, please provide a

brief description

below:

\section{2 is the community \\ expected to make \\ decisions for, during \\ or based on the \\ research?}

*If your answer is

YES, please provide a

brief description

below. 
3.3 At the end of the

research will any

economic or social

process be terminated

or left unsupported, or

equipment or facilities

used in the research

be recovered from the

participants or

community?

"If your answer is

YES, please provide a

brief description below

3.4 Will any service

be provided at a level

No

below the generally

accepted standards?

"If your answer is

YES, please provide a

brief description

4. ORGANISATIONAL N/a

PERMISSION

4.1 If your research is The study at hand seeks to gather information from organisational

being conducted

within a specific

employees in the financial sector and the data collection will be collected outside of organisation through the use of online surveys. Wherever there

organisation, please

state how

is a need to physical collect the data from organisational employees, the

researcher intend following proper channels of contacting the human

organisational

permission has resource (HR) for that specific event for permission (which is unlikely for this study).

been/wil be obtained:

4.2 Have you Not applicable

attached the letter

from the organisation

granting permission?

(please select)

4.3 Are you making

No

use of UCT students

as respondents for

your research?

\subsection{Please \\ Not applicable}

acknowledge that

approval from the

Department of Student

Affairs wil be obtained

before commencing

research. 
acknowledge that approval from the Executive Director of Human Resources wil. be obtained.

\subsection{Was approval No} granted?

\begin{tabular}{ll}
\hline Contact Detalls & $\begin{array}{l}\text { Executive Director: Human Resources - Miriam. Hoosain@uct.ac.za } \\
\text { Executive Director: Student Affairs - Moonira.Khan@uct.ac.za }\end{array}$ \\
\hline $\begin{array}{l}\text { 5. INFORMED } \\
\text { CONSENT }\end{array}$ & $\mathrm{nla}$
\end{tabular}

5.1 What type of consent wil be obtained from study participants?

\subsection{How and where} will consent/permission be recorded?
Anonymous survey questionnaire (covering letter required and no consent form needed))

This research is making use of anonymous surveys which will include a covering letter for all the participants to read prior to participating in the study.Participation in the study is not mandatory and respondents will be informed on the cover letter to quit participation at any given point when the need arise. Most notable is that this study does not have any risks associated with it.

\section{CONFLICT OF n/a} INTEREST

6.1 is there any existing or potential conflict of interest between a research sponsor, academic supervisor, other researchers or participants?

\subsection{Will information}

No

that reveals the identity of participants

be supplied to a research sponsor, other than with the permission of the individuals? 
6.3 Does the

proposed research

potentialy conflict with

the research of amy

other individual or

group within the

University?

6.4 Are you aware of No

any other conflict of

interest that you

would like to declare?

If you have answered $n / s$

YES to any of these

questions, please

describe how you plan

to address these

issues (Questions 6.1

$-6.4)$

7. RISK TO

$n / 8$

PARTICIPANTS

\subsection{Does the}

No

proposed research

pose any physical,

psychological, social,

legal, economic, or

other risks to study

participants you can

foresee, both

immediate and long

range? (please select)

- If YES, please

$n / 8$

answer the following

questions:

7.2 Describe in detail $\mathrm{n} / \mathrm{a}$

the nature and extent

of the risk and provide

the rationale for the

necessity of such

risks

7.3 Outline any

alternative

approaches that were

or will be considered

and why alternatives

may not be feasible in

the study 
8. Data Management Plan

The data to be collected is for this study alone and will not be shared or use for other purposes. It is the researchers interest to keep the data as confidential as possible. The researcher intends storing data in a password protected storage e.g. DropBox

8.1. I am intending to No

share my data after the research on an open-platform

8.2 Data Storage during and after the study

8.3 I have discussed data storage and the opportunity to provide my data on an open platform with my supervisor or my research team

I certify that I have true

read the the

Commerce Faculty

Ethics in Research

policy

(http://www.commerce.uct.ac_za/Pages/Comfac-

Downloads)

I hereby undertake to * there is no apparent legal objection to the nature or the method of carry out my research research; and

in such a way that "the research will not compromise staff or students or the other

responsibilities of the University;

* the stated objective will be achieved, and the findings will have a high

degree of validity;

* limitations and alternative interpretations will be considered;

* the findings could be subject to peer review and publicly available; and

* I will comply with the conventions of copyright and avoid any practice

that would constitute plagiarism.

Sign off Supervisor has seen the application

Supervisor has seen true

the application

Signature

Ethics_Approval_Request.pdf

Signed by.

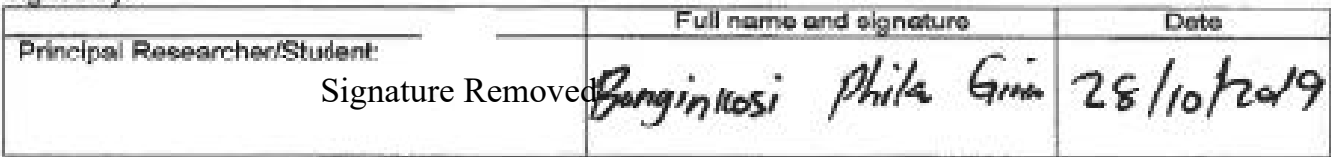

This aoplication is aoproved by:

Supervieor

Departmental Ethics Rep

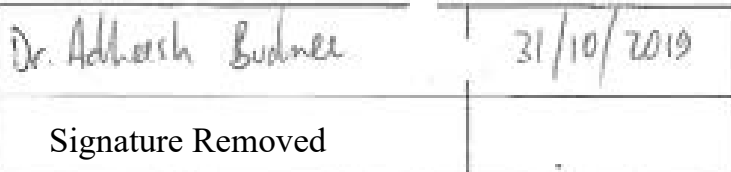




\title{
APPENDIX E: Ethics Approval Letter
}

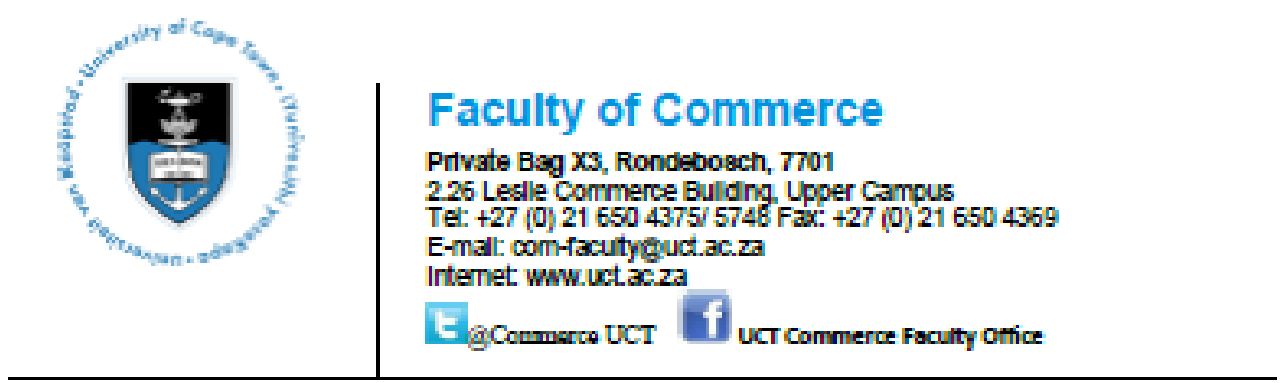

$11^{\text {th }}$ November 2019

\author{
Mr Bonginkosi Gina \\ Department of information \\ Systems \\ University of Cape Town \\ Dear Mr Gina \\ REF: REC 2019/10/059
}

\section{CRITICAL FACTORS THAT DRIVE THE SELECTION OF BUSINESS INTELLIGENCE TOOLS IN SOUTH AFRICAN FINANCIAL SERVICE PROVIDERS}

We are pleased to inform you that your ethics application has been approved. Unless otherwise specified this ethical clearance is valid for 1 year and may be renewed upon application.

Please be aware that you need to notify the Ethics Committee immediately should any aspect of your study regarding the engagement with participants as approved in this application, change. This may include aspects such as changes to the research design, questionnaires, or choice of participants.

The ongoing ethical conduct throughout the duration of the study remains the responsibility of the principal investigator.

We wish you well for your research.

Shandre Swain

Administrative Assistant

University of Cape Town

Commerce Faculty Office

Room 2.26 | Leslie Commerce Building

Office Telephone: +27 (0)21 $6502695 / 4375$

Office Fax: +27 (0)21 6504369

E-mail: sl.swain@uct.ac.za

Website: www.commerce.uct.ac.za<http//www.commerce.uct.ac.za/ 


\section{APPENDIX F: Conference Invitation}

A research paper is a protocol and manuscript that researcher(s) or author(s) submit for academic review, the research paper is reviewed by a research program committee to meet rigorous academic standards of publication (Baglione, 2018). The papers are reviewed for the following reasons: conceptual quality, relevance, innovation, and clarity of presentation. The accepted papers are published in conference proceedings and may be used by other researchers pursuing studies around the same subject. Two types of papers can be submitted for academic review namely full research paper and short research paper.

The researcher submitted a short manuscript in a prestigious international conference called International Conference on Artificial Intelligence, Big Data, Computing and Data Communication Systems (icABCD2020) which is an IEEE sponsored e-conference(due to Covid-19 pandemic was converted to an e-Conference), the paper was accepted in the conference and is to be presented in the upcoming E-conference taking place on the $6^{\text {th }}-7^{\text {th }}$ August 2020 for oral presentation and subsequently to be published on the IEEE Xplore digital library. The research topic for the paper is "A Review of Literature on Critical Factors That Drive the Selection of Business Intelligence Tools" and it forms part of the current study at hand particularly the current study chapter two (Literature Review). The focus of the research study was aimed at exploring and discovering literature addressing the issue of software selection experienced by organisations and to discover and examine major constructs and factors influencing the selection of BI tools APPENDIX F: Conference Invitation is attached below. 
2020 International Conference on Artificial Intelligence, Big

Data, Computing and Data Communication Systems (icABCD)

iCABCD

Address: PO Box 88, Siripath Post Office, Reservoir Hills, 4125 ,

KZN,

Durban, South Africa

icABCD Email: icabed.ora@gmail.com

Nebsite: ittp:/licabcd org/

(Tel) : +27847933225

IEEE Conference Number: \#49160

ISBN of Conference Proceedings: 978-1-7281-6769-5

Invitation to Participate in the 2020 International Conference on Artificial Intelligence. Big Data. Computing and Data.

Communication Systems (icABCD)

25 April 2020

Desr Bonginkosi Gins,

The organising committee of the iCABCD 2020 conference with support from the IEEE South Africa Section has the immense plessure to inform you that, after a double-blind peer review process, your paper entitled "-84 - A Review of Literoture on Critical Factors That Drive the Selection of Business Intelligence Tools" has been accepted for an online presentation at the 2020 international Conference on Artificial intelligence, Big Data, Computing and Data Communication Systems (iCABCD) which will be held ss an e-conference from Durban, KwaZulu Natal, South Africa on the $6^{\text {th }}$ and $7^{\text {th }}$ of August 2020.

All sccepted and registered papers will be submitted for potential inclusion in the IEEE Xplore Digital Library subject to the popers meeting oll IEEE stondards.

You are hereby invited to sttend the e-conference to present your paper.

If you have any queries about the conference, plesse email us on icabcd.oratomail.com.

Looking forward to seeing you at the e-conference.

Yours sincerely,

Signature Removed

Dr. Upasans Singh

Co-organising Chair

iCABCD.org 


\section{APPENDIX G: Originality Report}

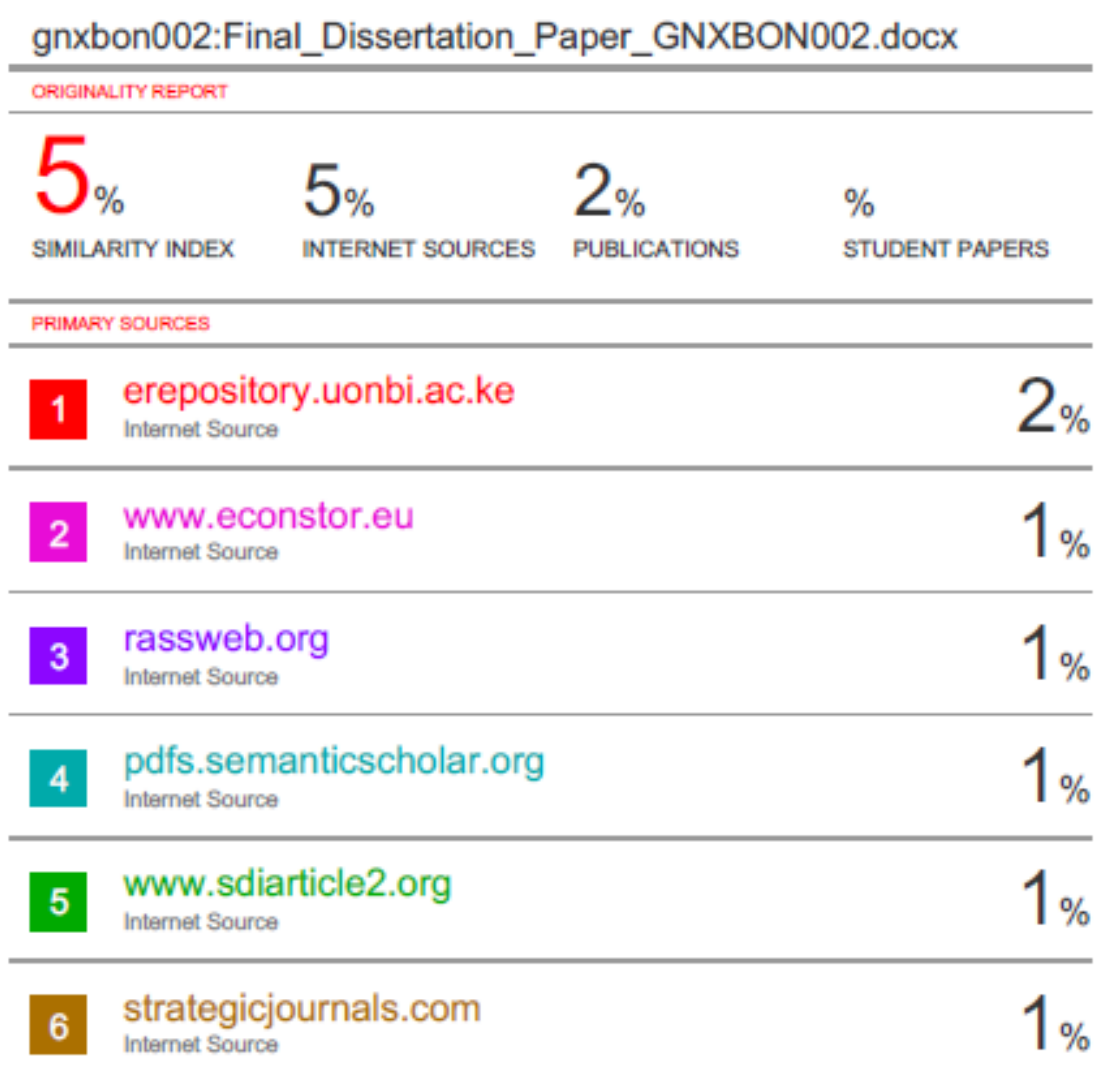

Exclude quotes

Exclude matches

$<1 \%$

Exclude bibliography

On

